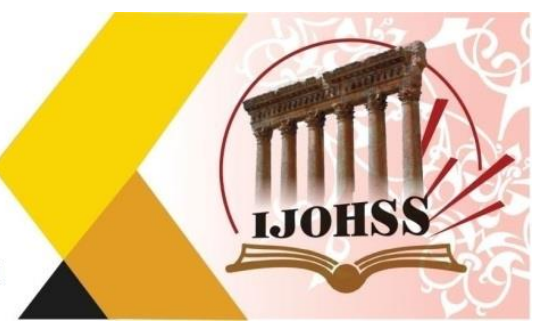

\title{
الاوبئة وتمثلاتها في النص المسرحي العراقي
}

\author{
م.م. حسنين حمزة عبد علي الزهيري \\ مديرية تربية بابل - وزارة التربية الزيل هيري

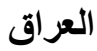 \\ البريد الاكتروني: Hsnynalzhyry87@gmail.com
}

الملخص

ان دراسة الاوبئة وتمثلاتها في النص المسرحي العراقي جاءت تبحث عن التساؤلات في كيفية نوظف الكاتب موضوع الوباء في الحبكة المسرحية ، وما رافق الثخصيات من متغيرات نفسية فكرية اجتماعية ، وتمثلاتها في هي

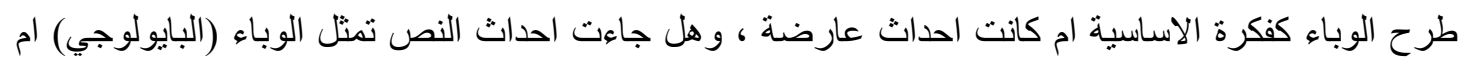

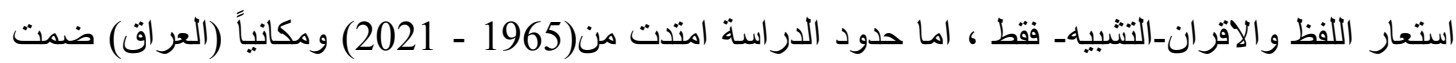
التعريف بأهم انواع الاوبئة التي تصيب الكائنات الحية ومن ثم دراسة الاوبئة في الفكر الاجتماعي وما ر افقها من متغيرات اجتماعية فكرية اقتصادية ، ركزت دراسة الاوبئة في النصوص المسرحية على الكتاب الذين تناولوا الاوبئة في نصوصهم المسرحية وكيفية توظيفها عالمياً ، فضلا عن دراسة الاوبئة في النص المسرحي العربي حيث وققت الدراسة عند مؤلفات العرب فكانت هناك تنظير ات لغوية لغونية فلسفية ادبية فضلاً عن كتاب المسرح

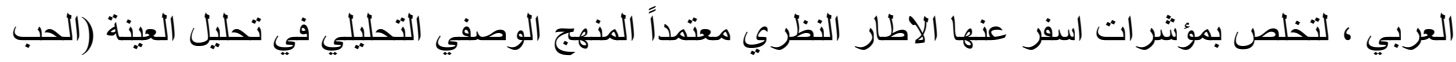
في زمن الكولير // لعبد الخالق كريم)كما جاءت نتائج البحث منها: عانت الثخصيات من الوباء الجسدي و الوباء النفسي الفكري فأن الاخير يكون أكبر تأثيراً من الاول لتكون الثخصية محاطة ومرهقة حداعة حد التخمة بالمعاناة

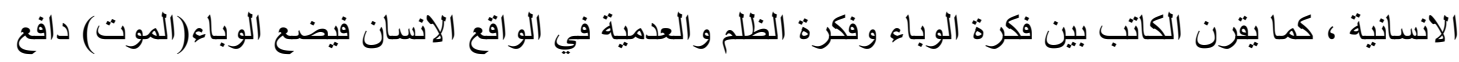
للشخصيات لارتكاب الافعال و الاحداث الكبرى ، اما الاستنتاجات منها : ان الوباء كان مؤثر بشكل فعال في بنية

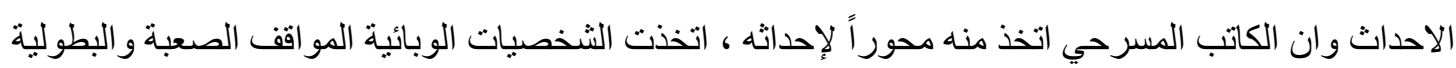

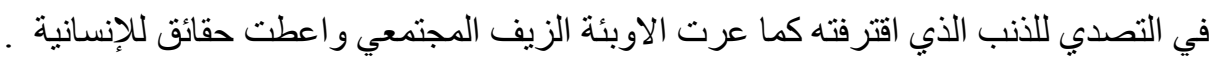




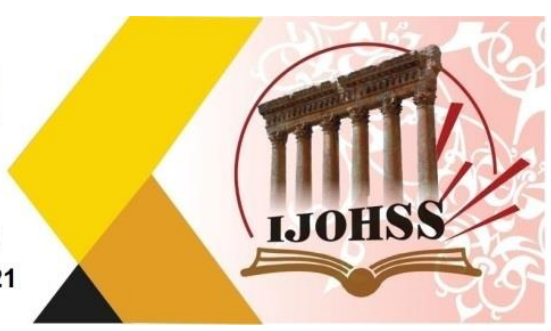

\title{
Epidemics And Their Representations in The Iraqi Theatrical Text
}

\author{
Hassanain Hamza Abd Ali \\ Babel Education Directorate-Ministry of Education \\ Iraq \\ Email: Hsnynalzhyry87@gmail.com
}

\begin{abstract}
The study of epidemics and their representations in the Iraqi theatrical text came looking for questions about how the writer employs the subject of the epidemic in the theatrical plot, and the psychological, intellectual and social variables that accompanied the characters, and their representations in presenting the epidemic as a basic idea or were they accidental events, and did the events of the text represent the epidemic (biological). ) Or borrowed the word and peers - the analogy - only. As for the limits of the study, it extended from (1965 - 2021) and spatially (Iraq) included the definition of the most important types of epidemics that affect living organisms and then the study of epidemics in social thought and the accompanying social, intellectual and economic variables, a study focused Epidemics in theatrical texts is referred to the writers who dealt with epidemics in their theatrical texts and how to employ them globally, as well as the study of epidemics in the Arab theatrical text. The analytical descriptive approach in analyzing the sample (Love in the Time of Cholera / Abdul Khaleq Karim) the results of the research came from: the characters suffered from a physical epidemic and an intellectual psychological epidemic, the latter being more influential than the first so that the character is surrounded and exhausted to the extent of saturation with human suffering. The epidemic (death) motivated the characters to commit major actions and events, as for the conclusions from them: that the epidemic was effectively influential in the structure of events and that the playwright took him as the centerpiece of the events, the epidemic characters took difficult and heroic positions in addressing the guilt they committed, as epidemics exposed the societal falsehood and gave facts for humanity.
\end{abstract}

Keywords: epidemics, plague, communicable diseases, plot, personality. 


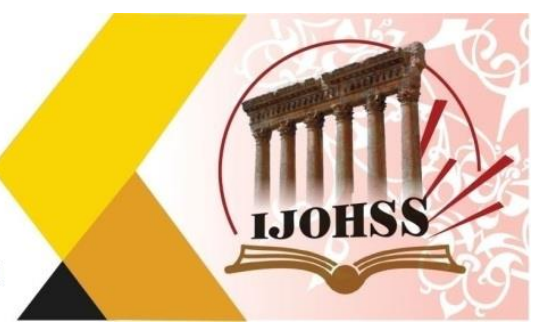

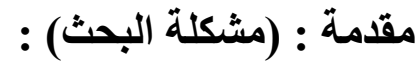

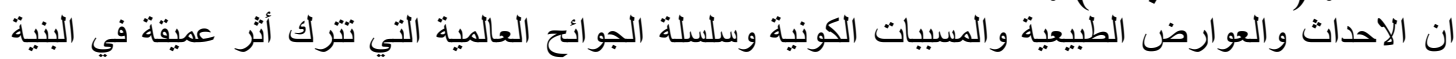

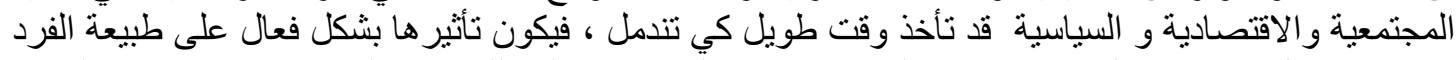

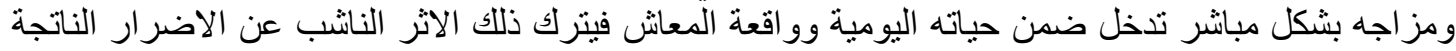

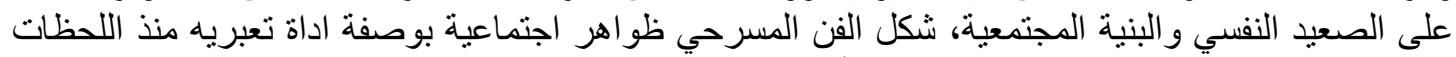

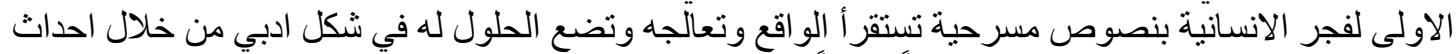

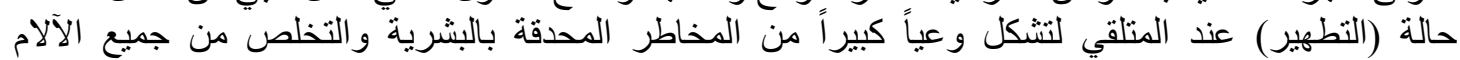

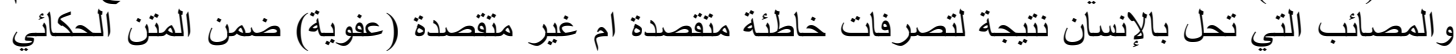

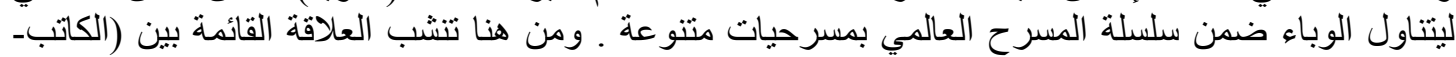

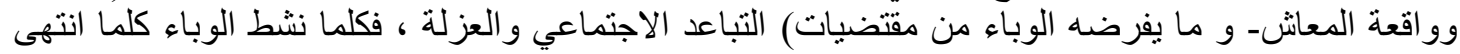

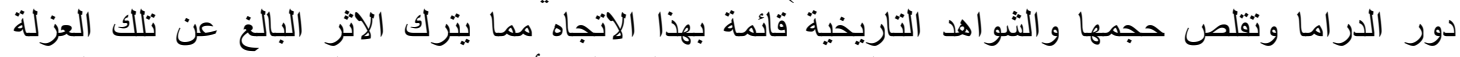

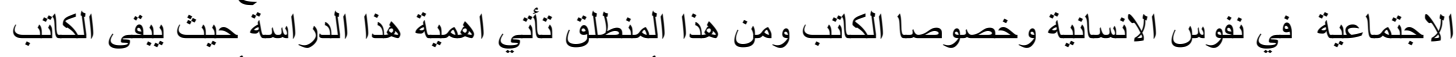

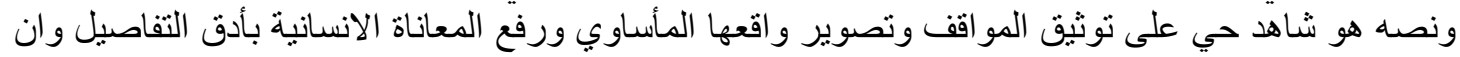

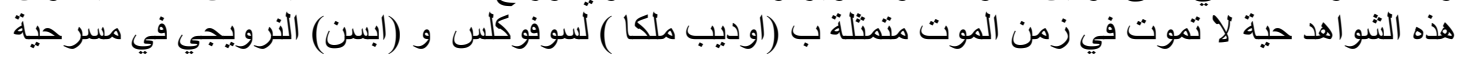

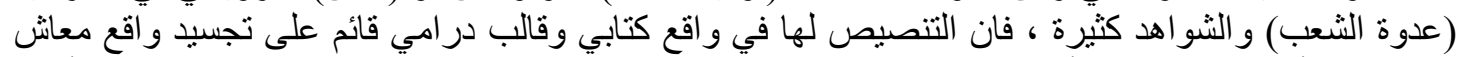

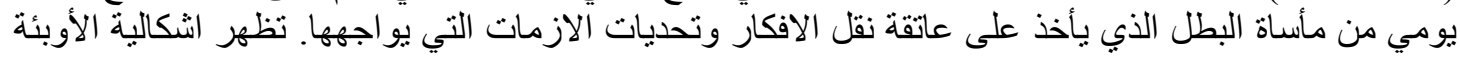

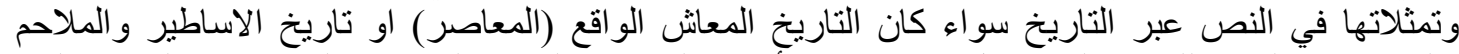

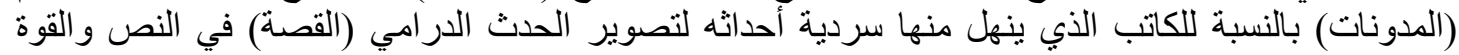

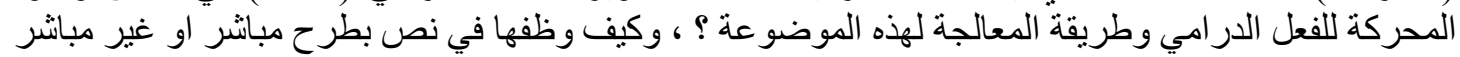

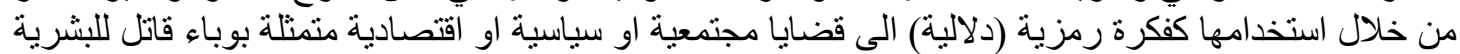

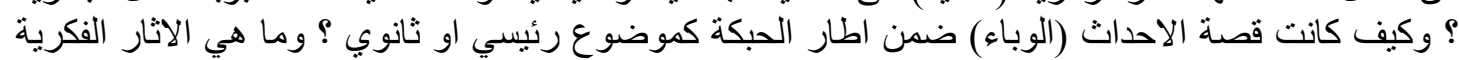

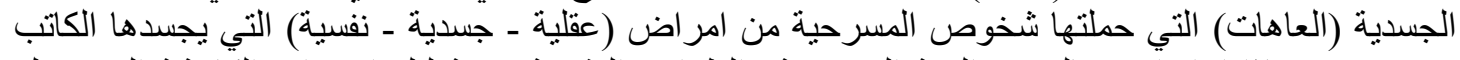

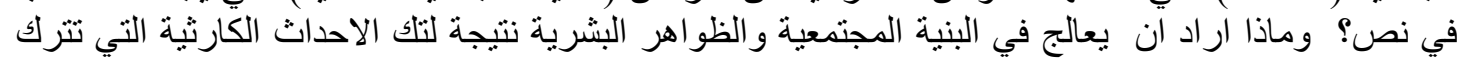

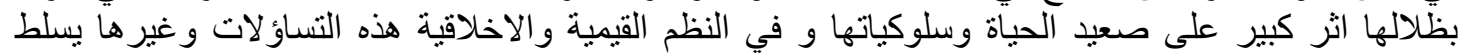

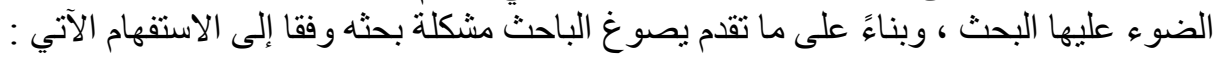

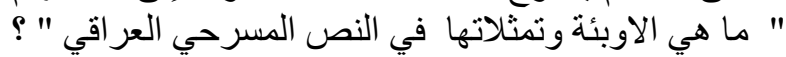

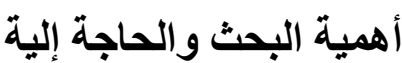

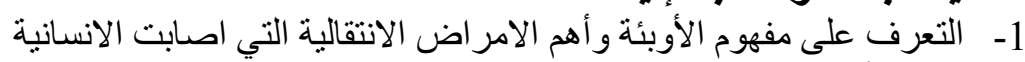

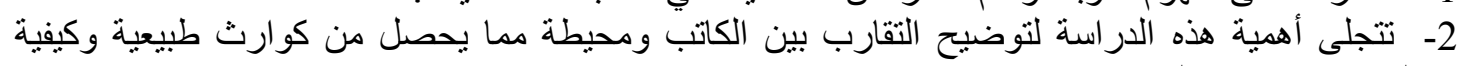

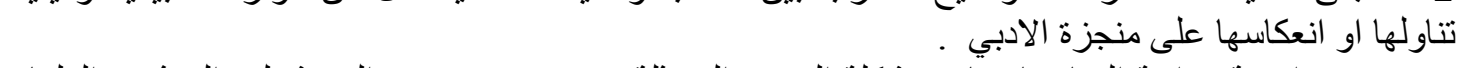

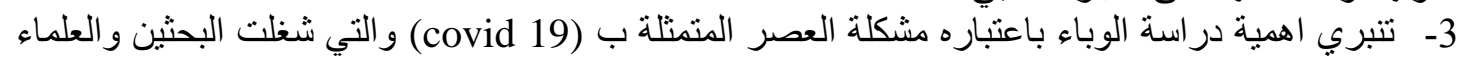

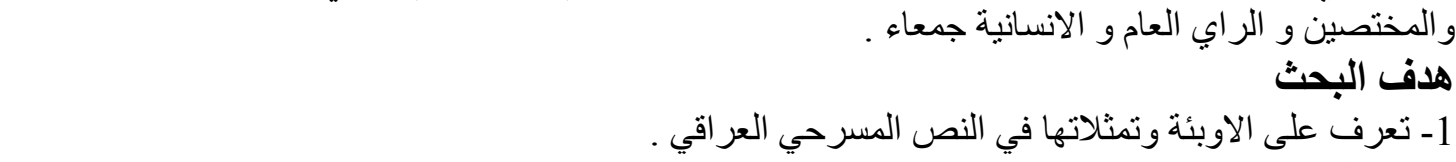

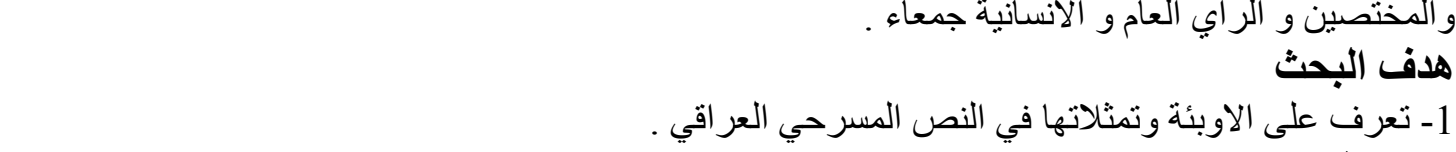

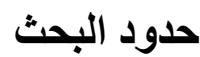
زمانيـاً :(1965 - 2021) مكانيـاً : ( العـراق ) موضـو عياً : ( دراسـة موضـوع الاوبئَة وتمثلاتهـا في النص

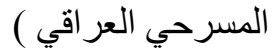

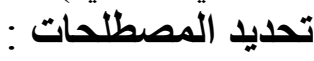

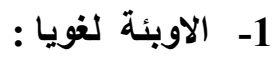

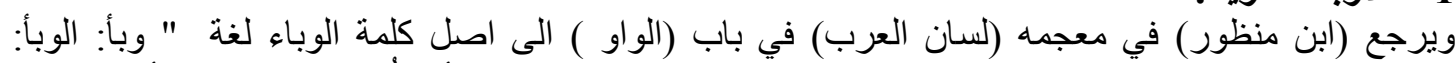

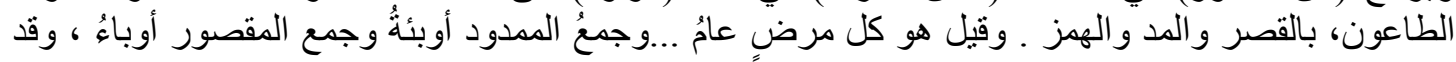




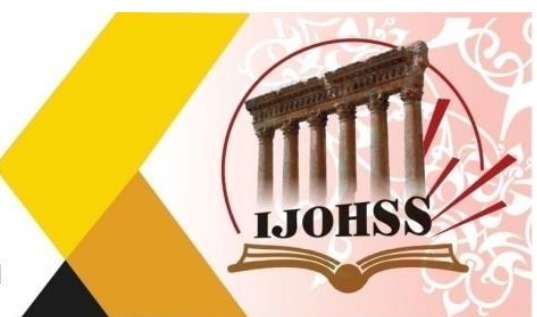

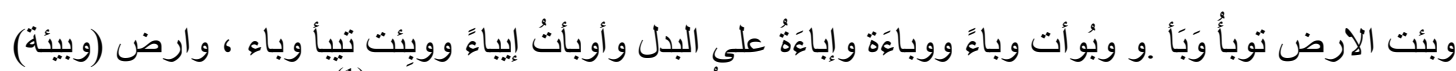

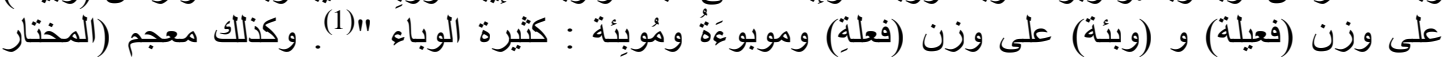

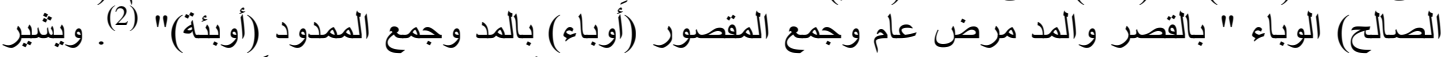

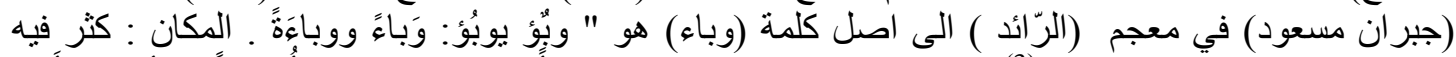

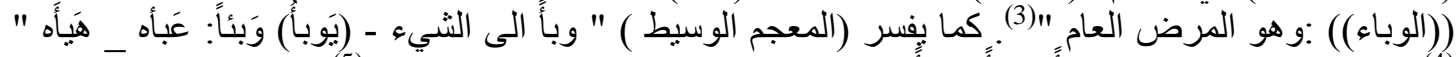

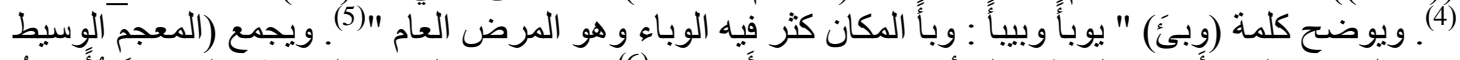

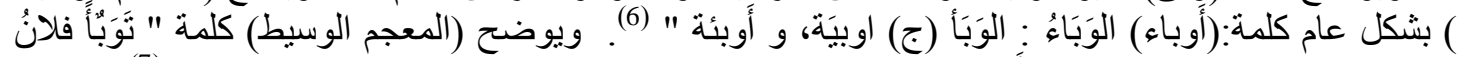

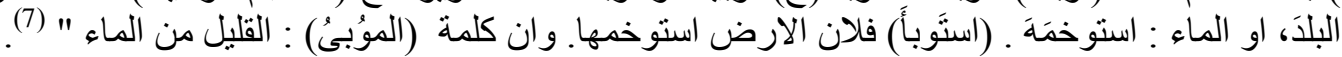

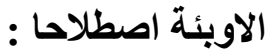

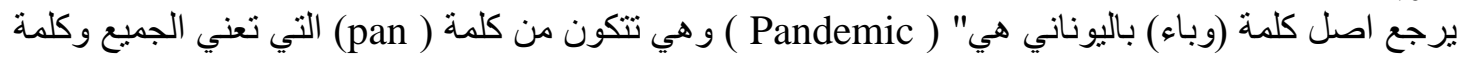

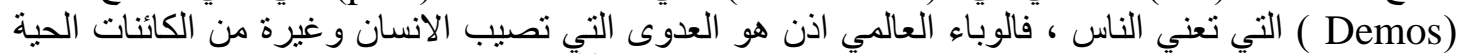

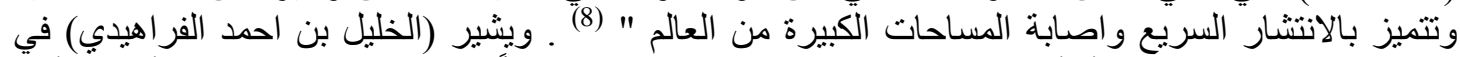

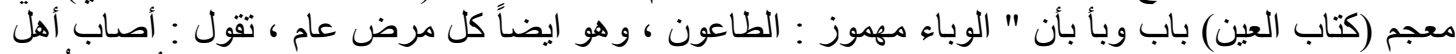

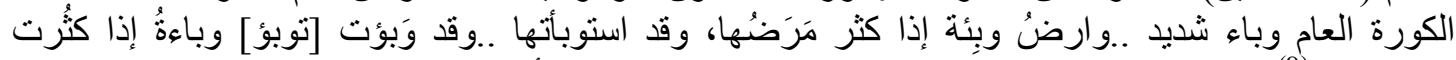

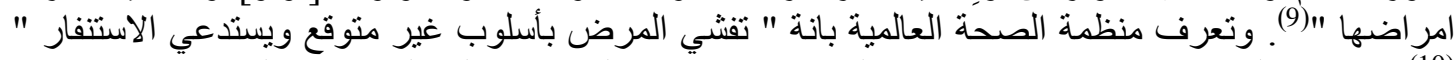

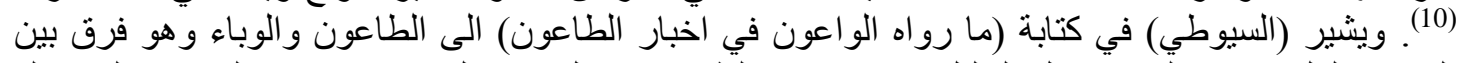

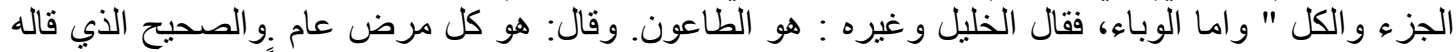

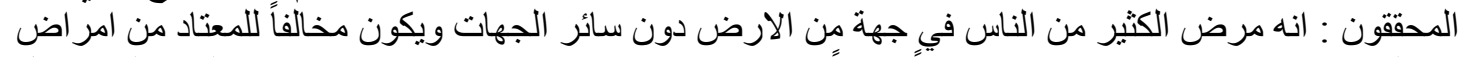

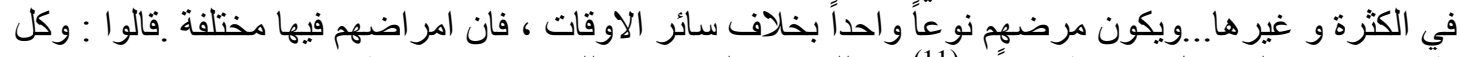

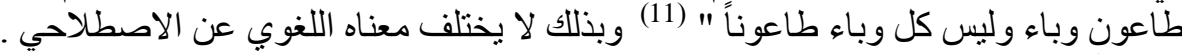

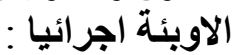

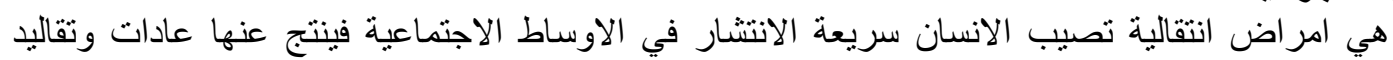

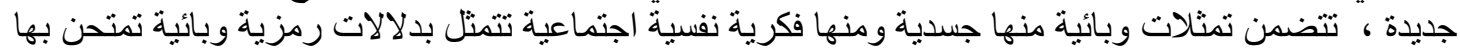

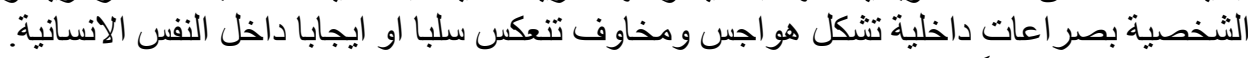

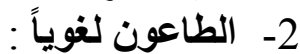

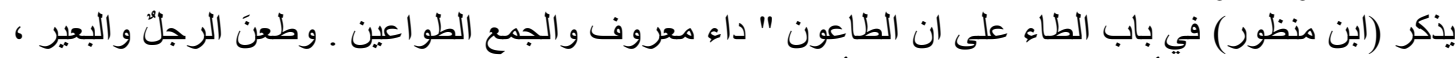

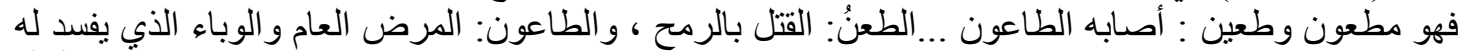

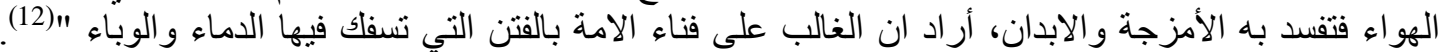

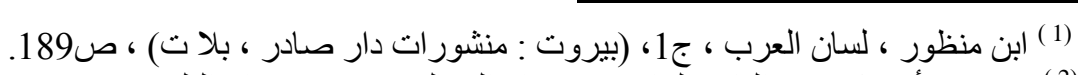

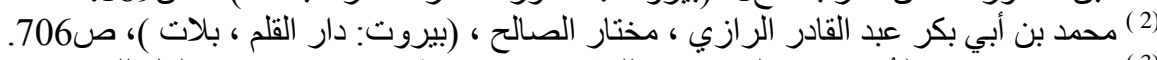

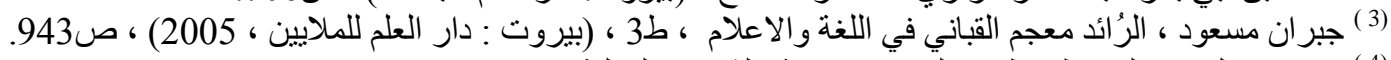

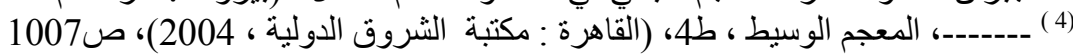

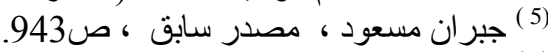

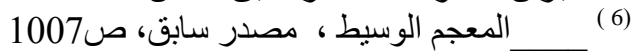

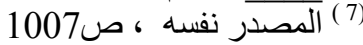

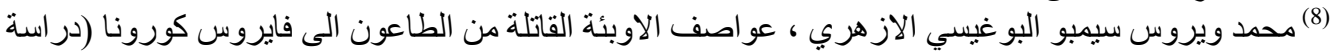

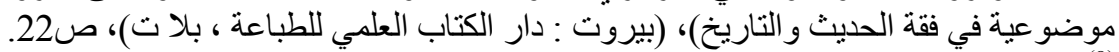

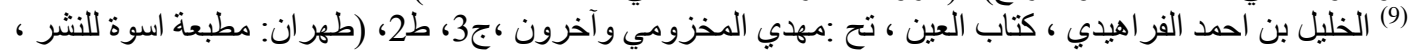

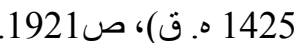

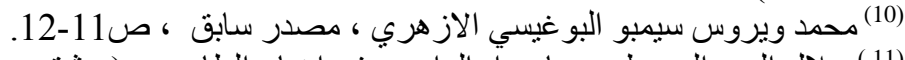

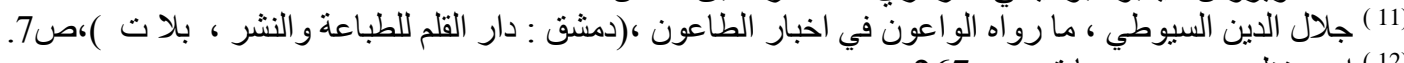

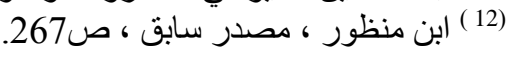




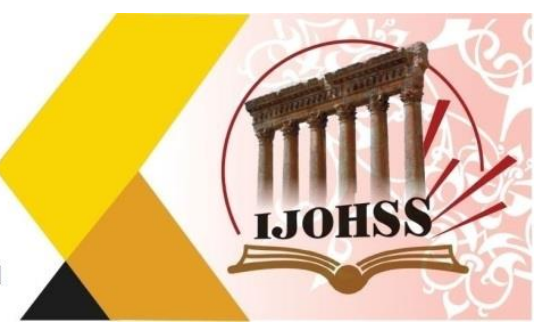

وترجع المعاجم كلمة الطاعون الى فعل "(طعن) يطعن و المطعان الرجل الكثير الطعن للعدو واما طعاناً يعنى في

اعر اض الناس ،و (الطاعون) الموت من الوباء الطعاء والجمع(الطو اعين)"(1).

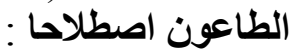

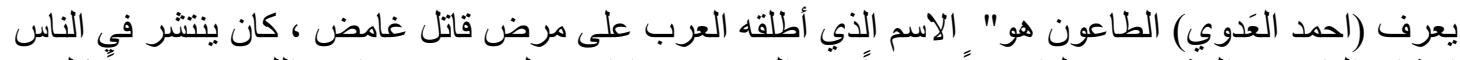

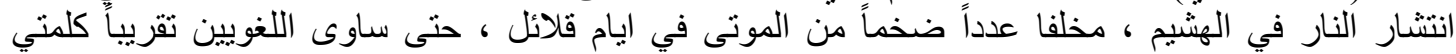

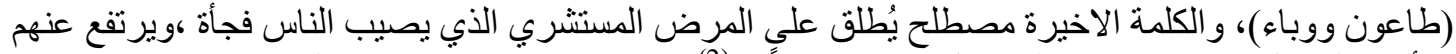

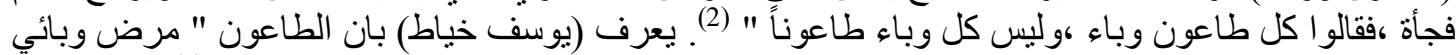

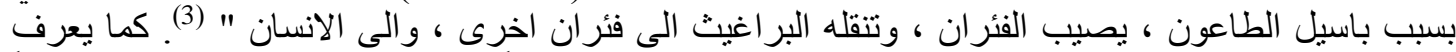

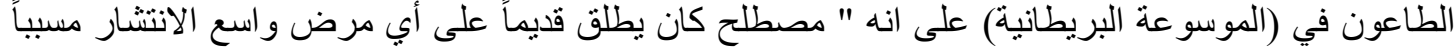

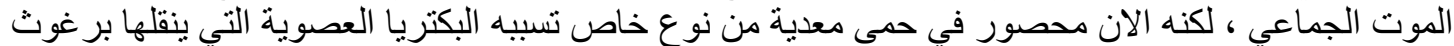

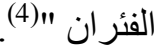

الطاعون اجرائيا : الطن

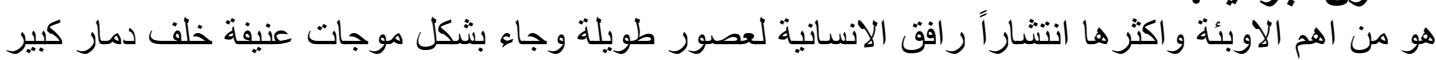

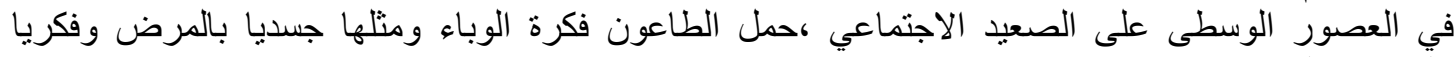

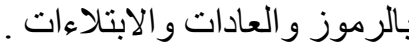

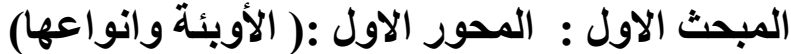

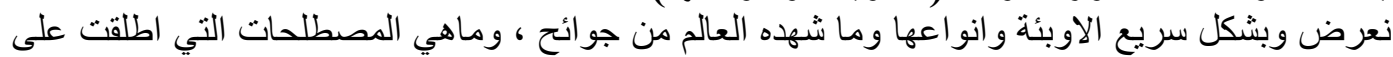

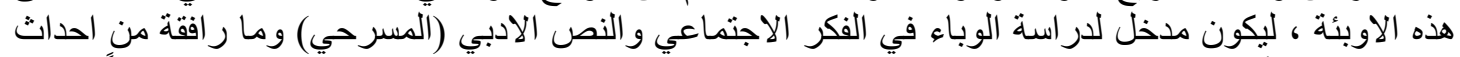

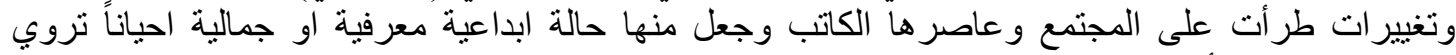

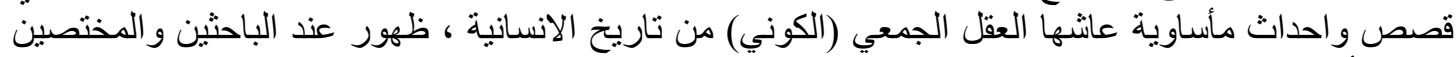

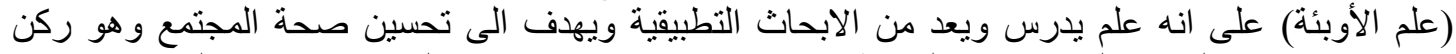

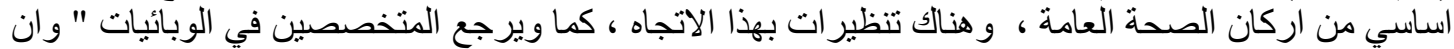

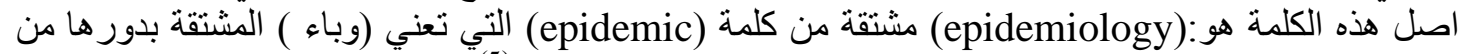

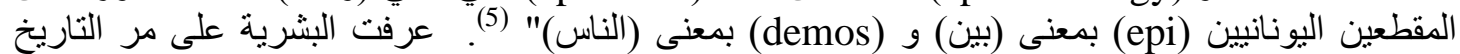

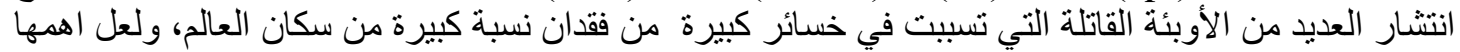

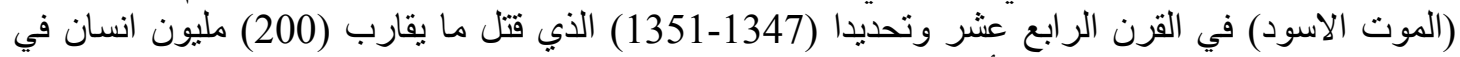

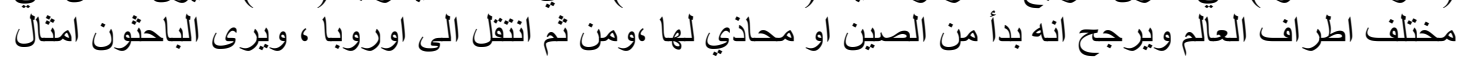

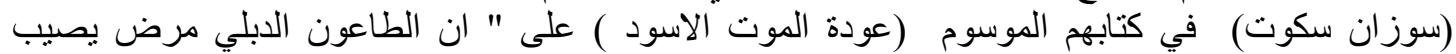

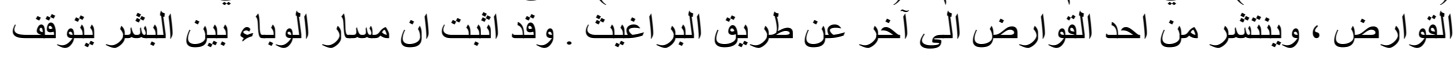

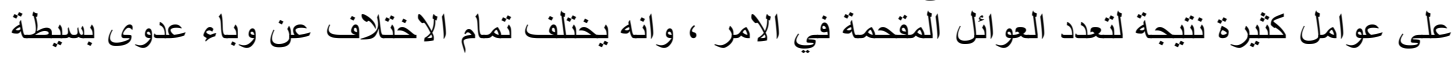

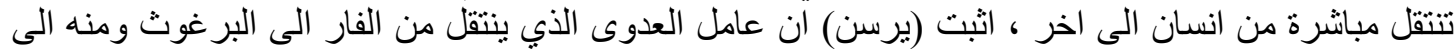

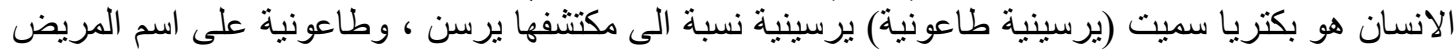

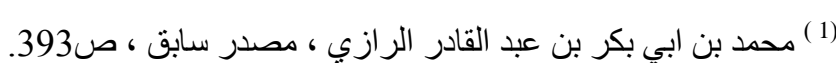

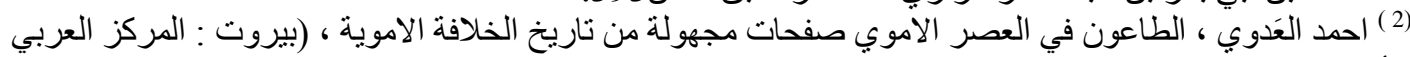

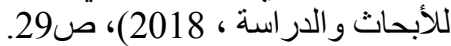

(3) الحافظ احمد بن علي بن حجر العسقلاني ، بذل الماعون في فصل الطاعون، تح :احمد عصام (الرياض: دار العاصمة

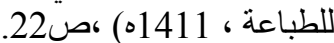

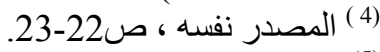
(5) رودولفو سار اتثي، علم الاوبئة مقدمة قصيرة ، تر : اسامة فاروق حسن ،مر : مصطفى محمد فؤاد ، (القاهرة : مؤسسة

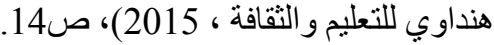




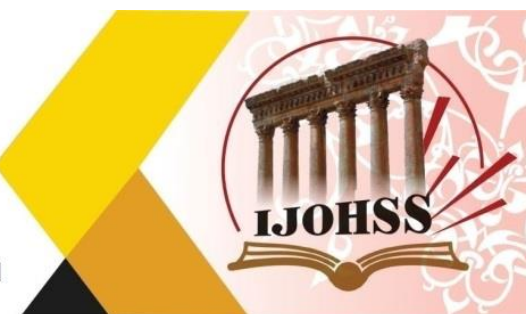

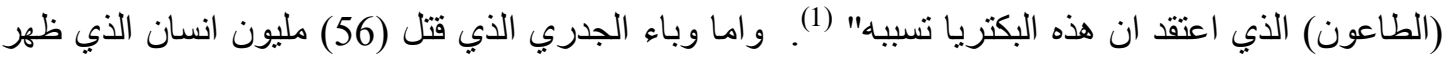

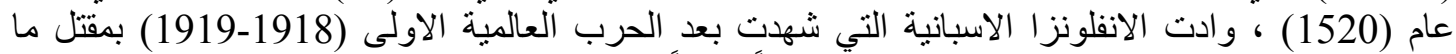

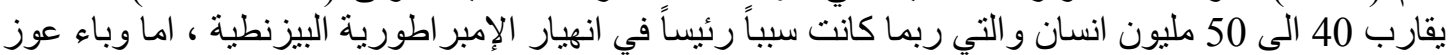

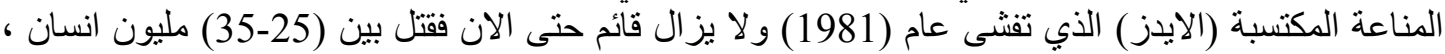

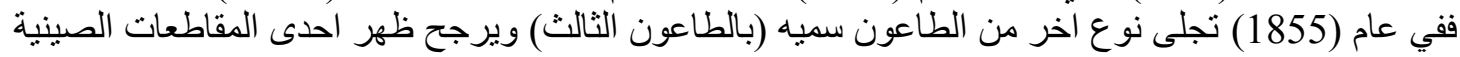

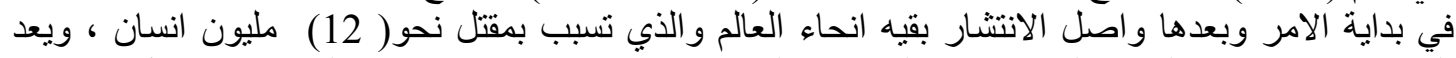

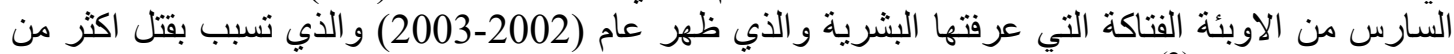

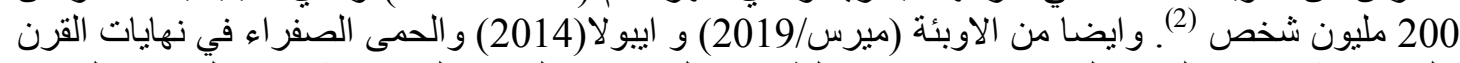

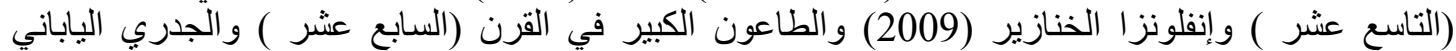

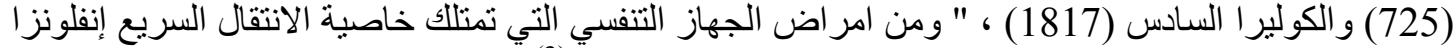

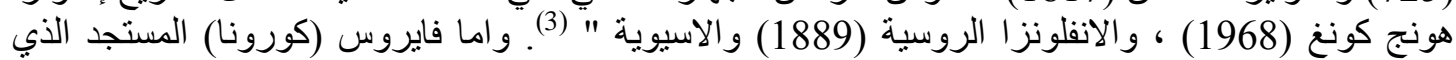

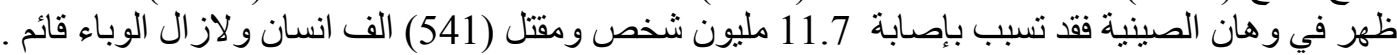

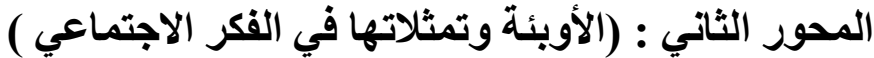

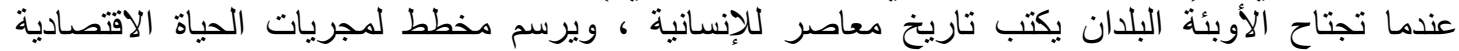

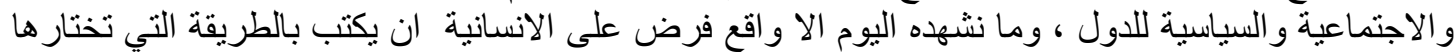

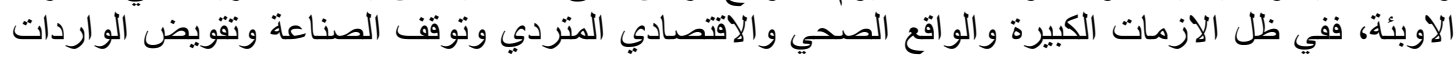

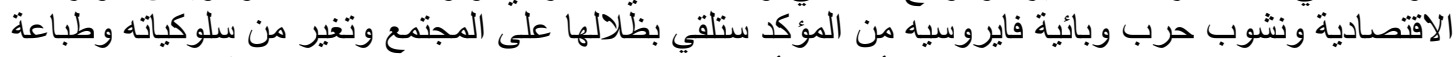

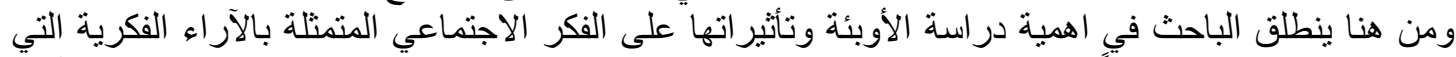

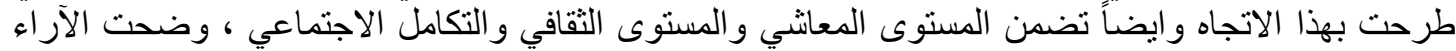

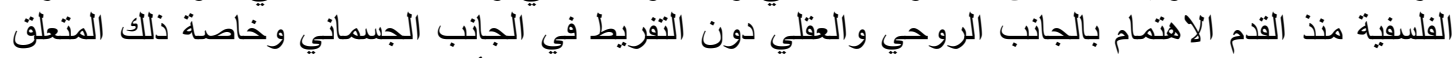

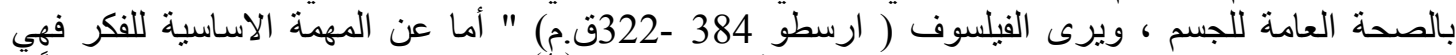

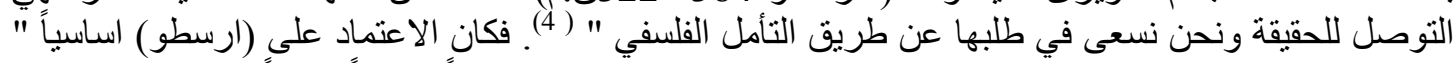

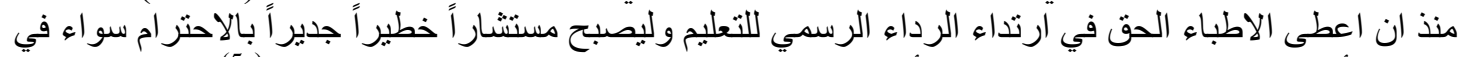

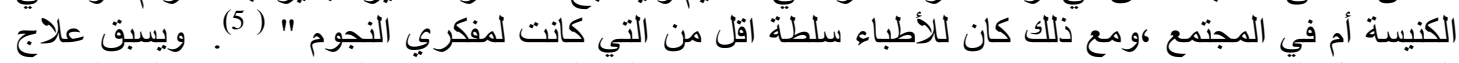

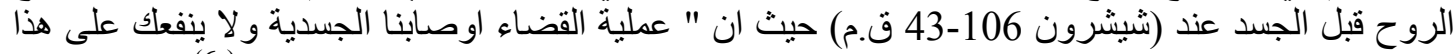

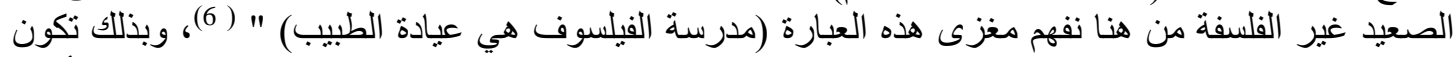

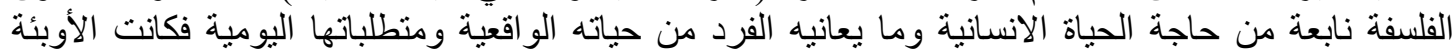

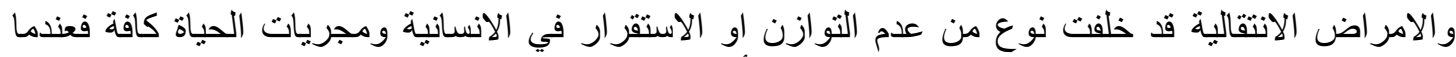

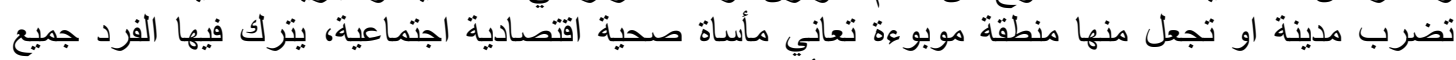

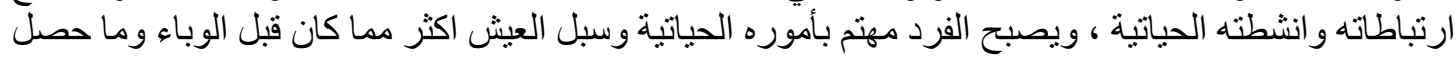

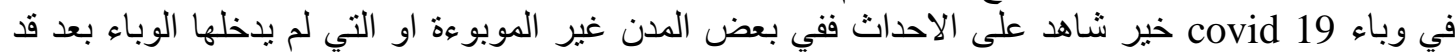

(1) سوزان سكوت وكرستوفر دنكان، عودة الموت الاسود اخطر قاتل على مر العصور ، تر : فايقة جرجس، مر : هاني

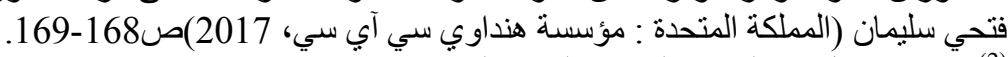
(2) ينظر : جميل ابو العباس الريان ،فلسفة علم الاوبئة جائحةً كورونا (كوفيد-19) ، (الاسكندرية : المثقف للنشر والتوزيع،

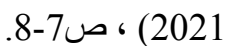

(3) روبرت س جوتفريد ، الموت الاسود جائحة طبيعية وبشرية في عالم العصور الوسطى ، تر : عبادة كحيلة ، (القاهرة :

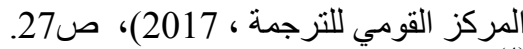

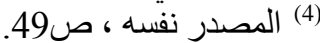

(5) شلدون و اتس ، الأوبئة و التاريخ المرض و الإمبريالية ، تر : احمد محمود عبد الجو اد ،مر : عماد صبحي، (القاهرة :

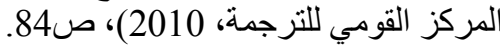
(6) جميل ابو العباس الريان ، مصدر سابق ، ص50. 


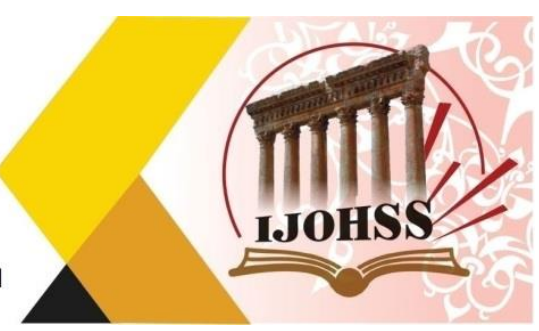

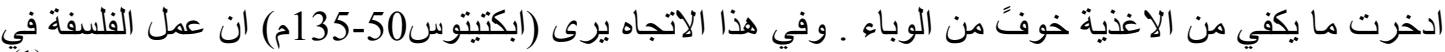

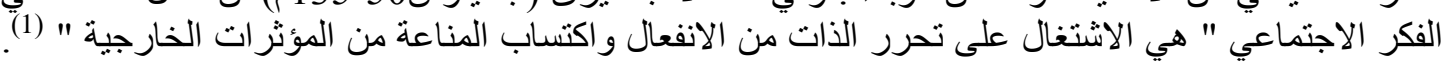

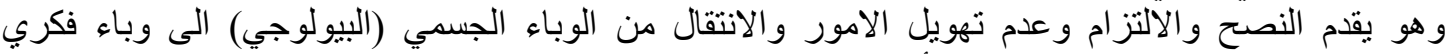

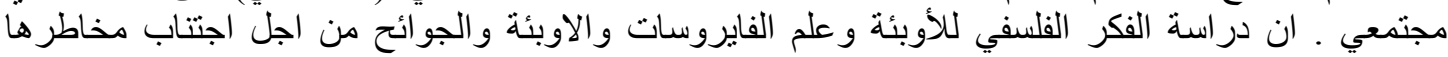

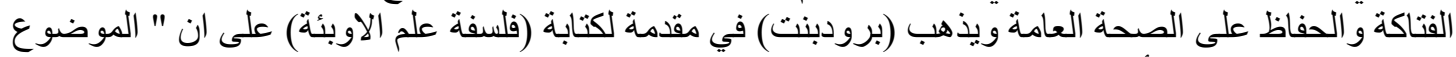

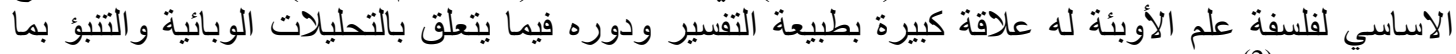

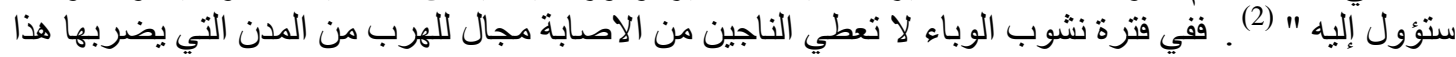

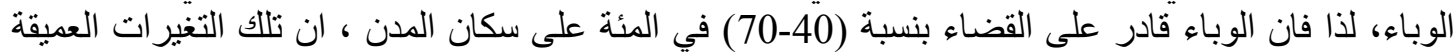

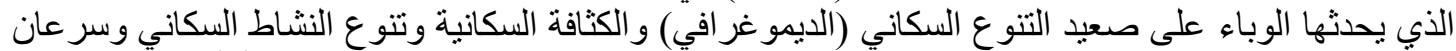

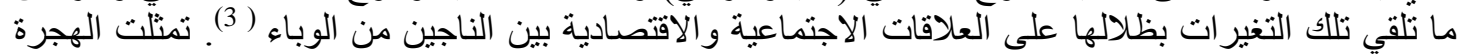

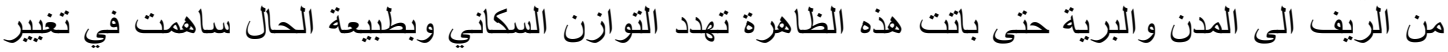

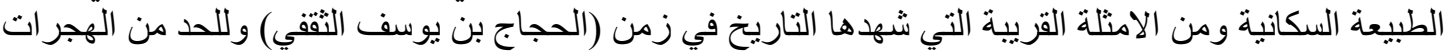

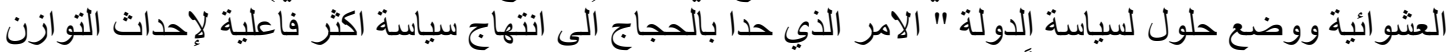

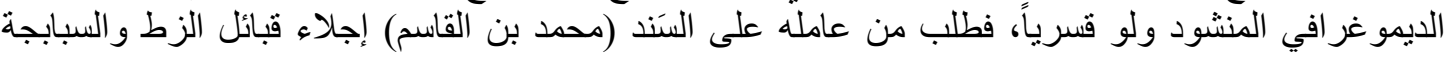

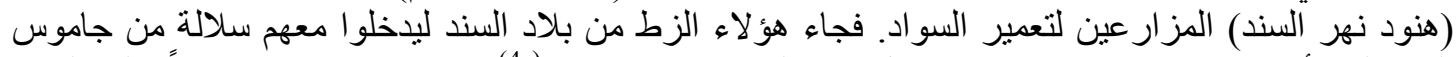

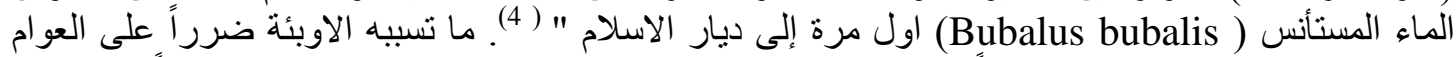

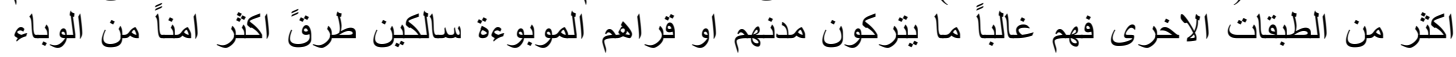

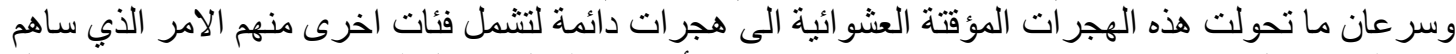

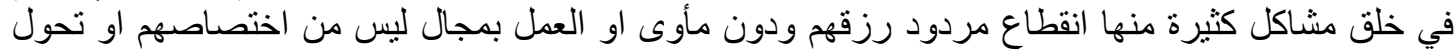

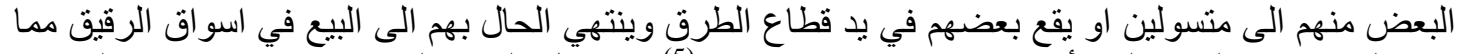

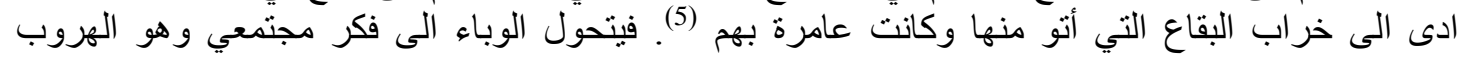

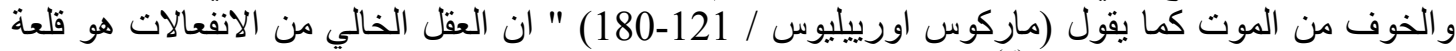

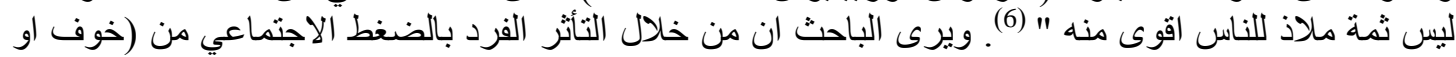

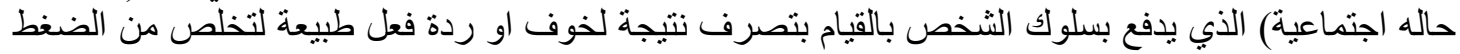

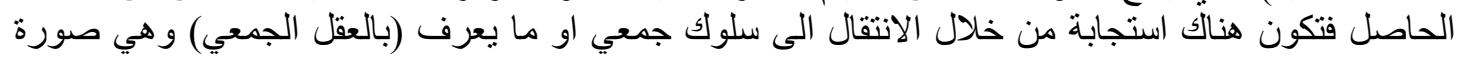

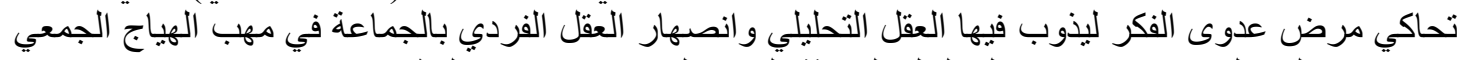

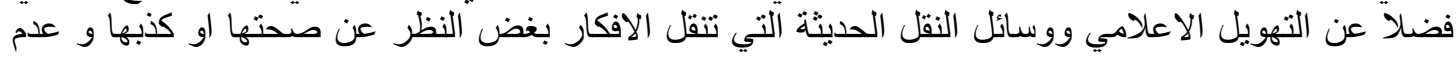

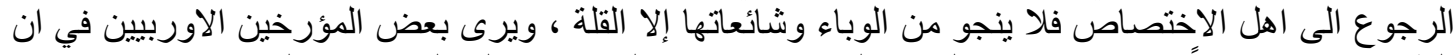

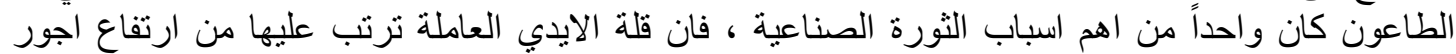

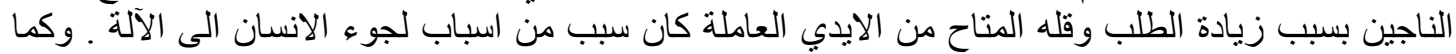

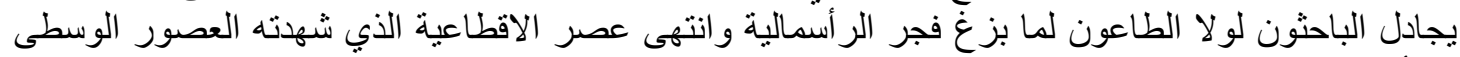

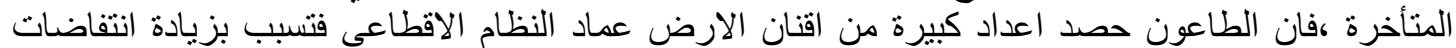

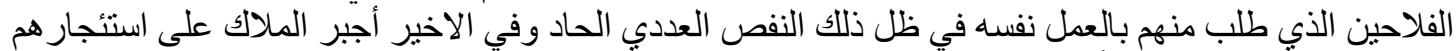

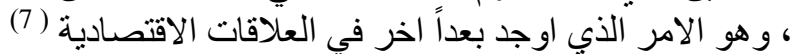

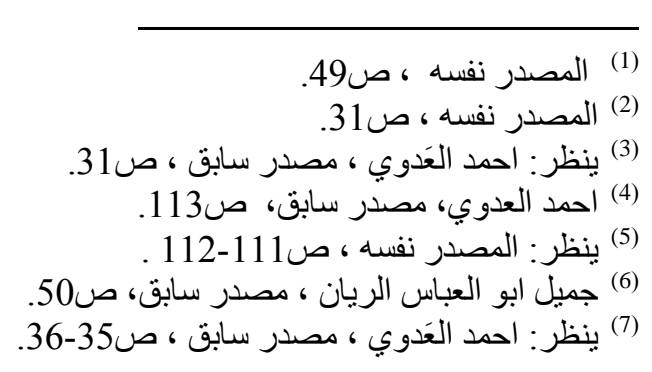




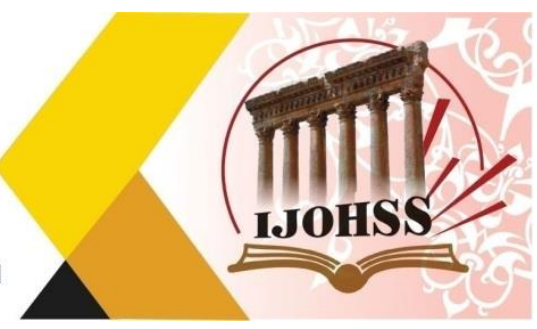

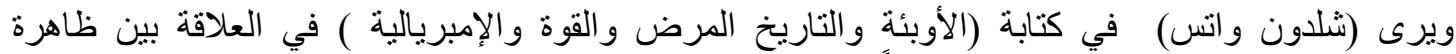

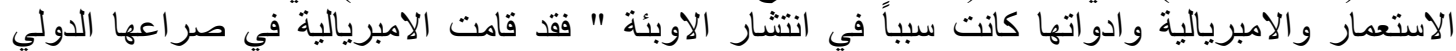

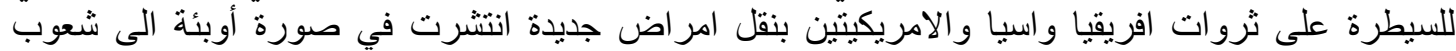

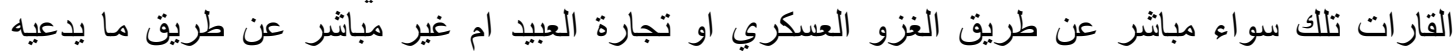

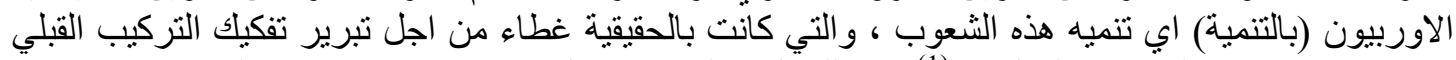

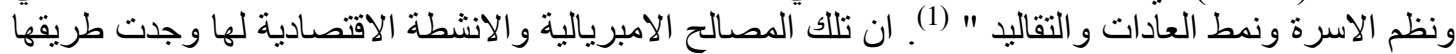

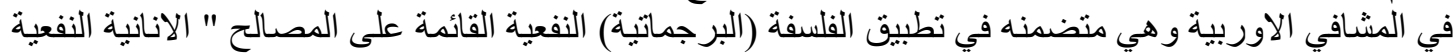

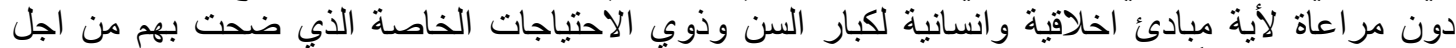

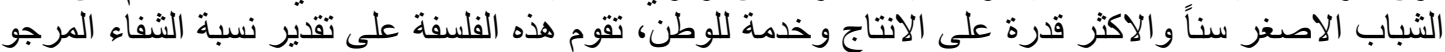

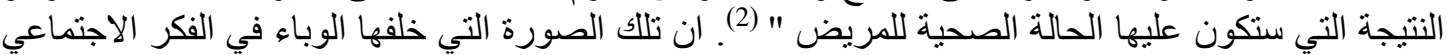

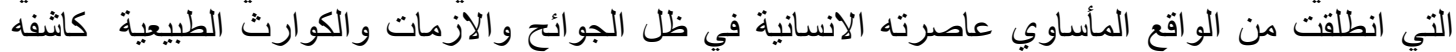

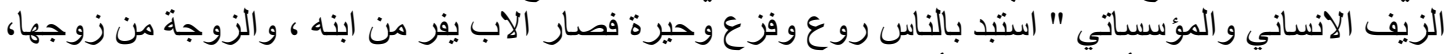

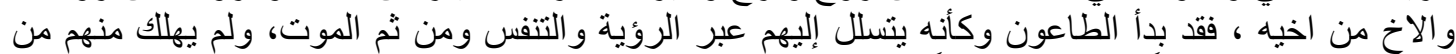

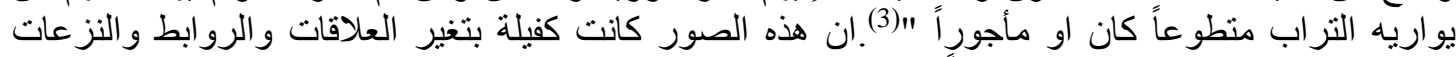

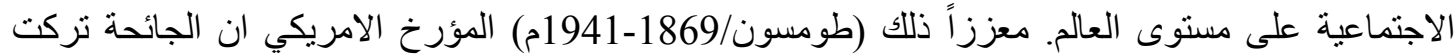

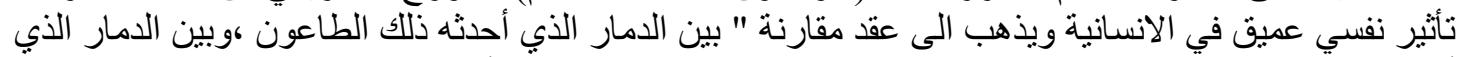

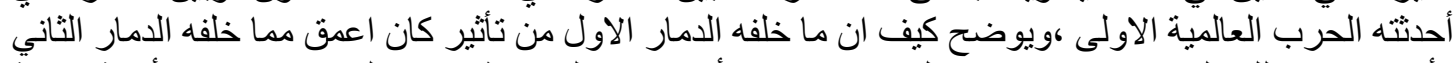

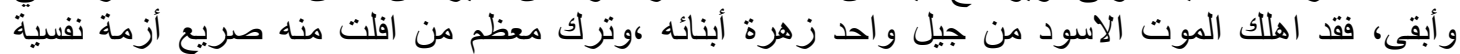

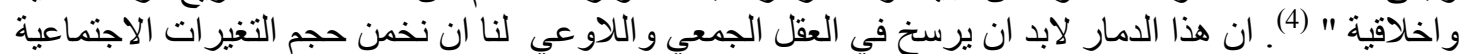

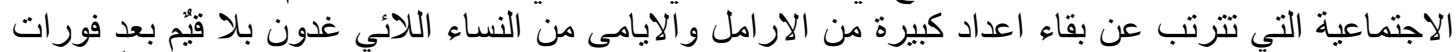

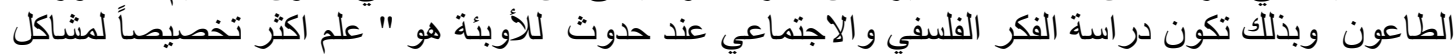

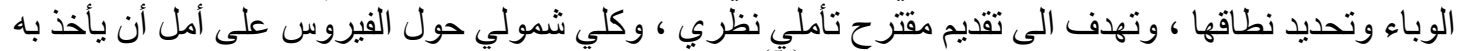

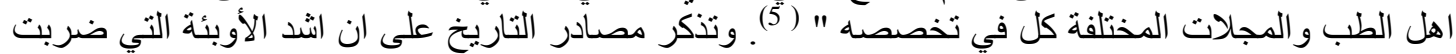

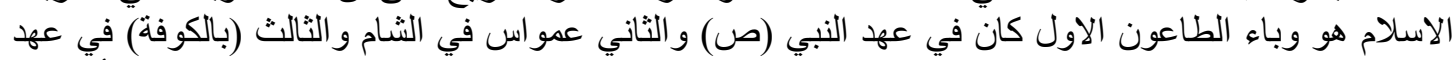

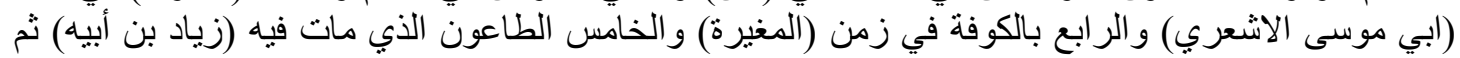

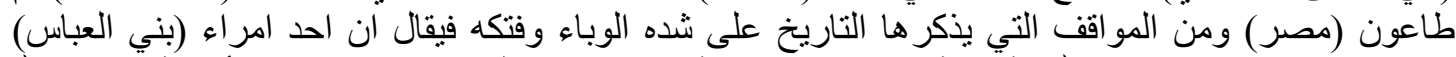

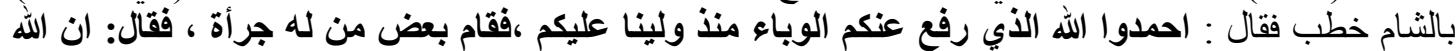

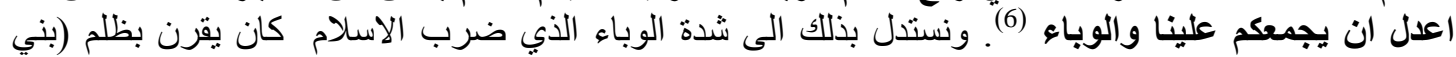

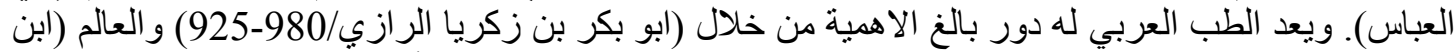

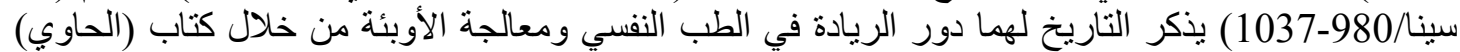

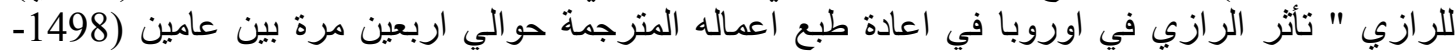

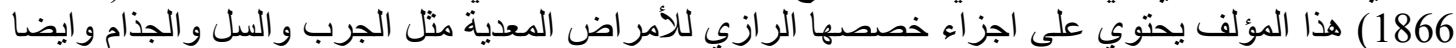
كتاب اخر منفصل عن (الحصبة و الجدري)"(7).

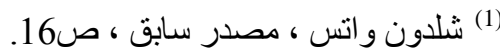

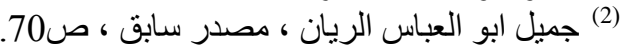

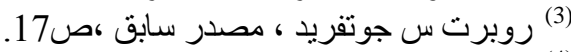

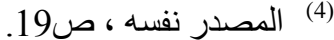

(5)

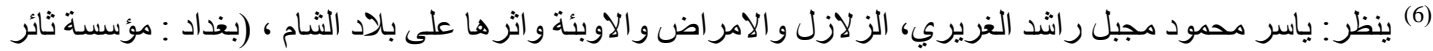

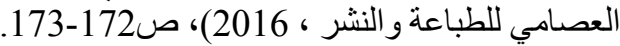

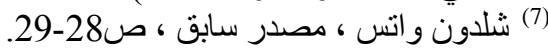




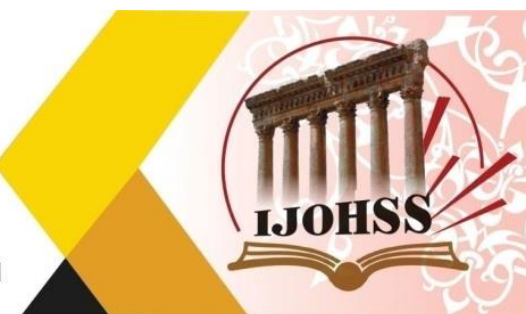

ففي معرض حديثة (ابن هيدور) يبين العلاقة بين الغلاء والوباء والجوع فيقول " لا يكون هذا الموت الإ باثٔر

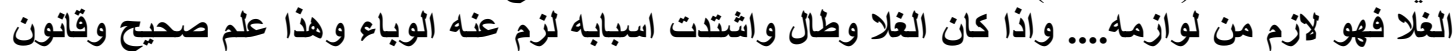

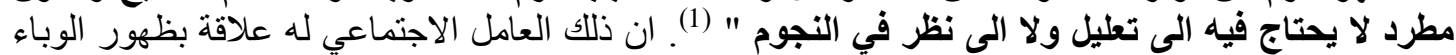

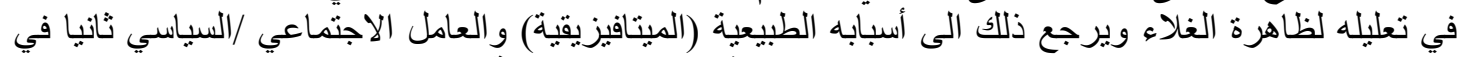

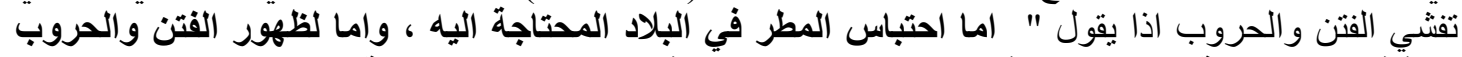

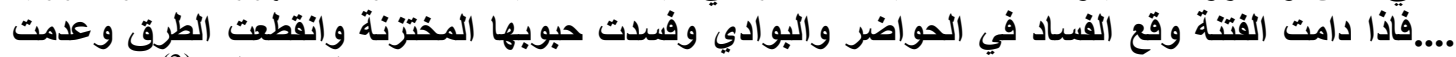

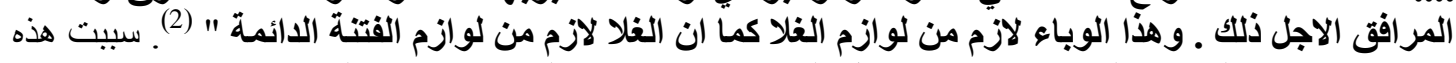

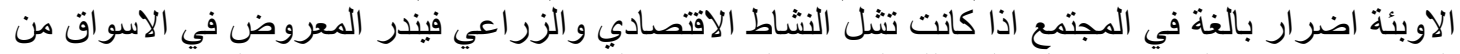

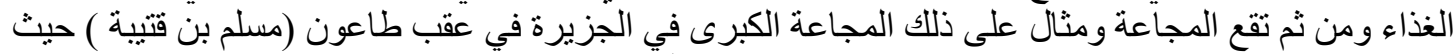

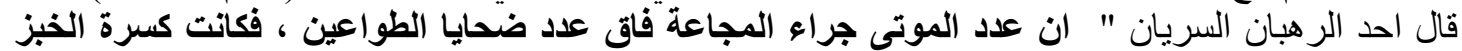

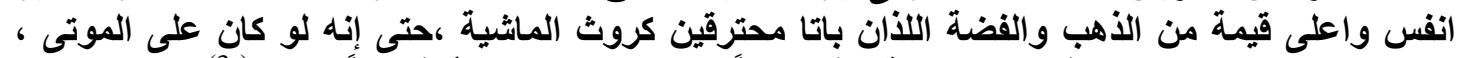

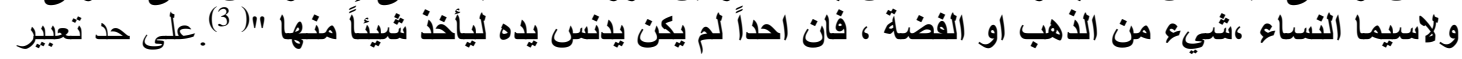

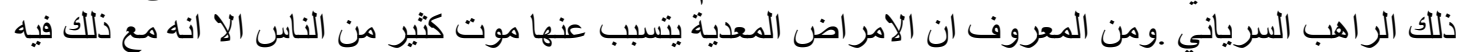

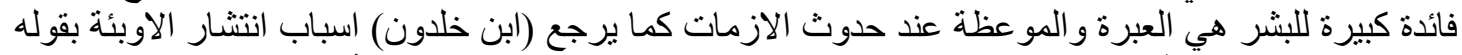

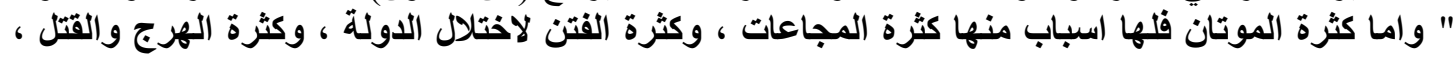

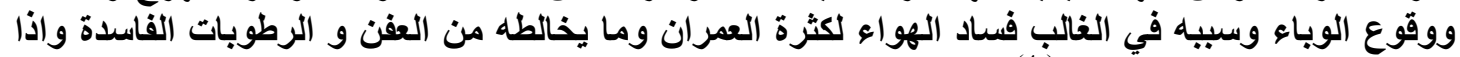

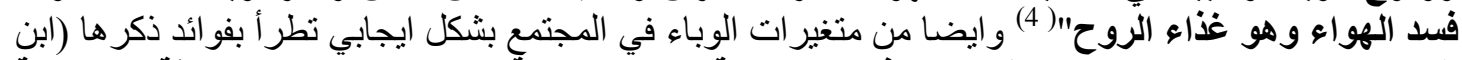

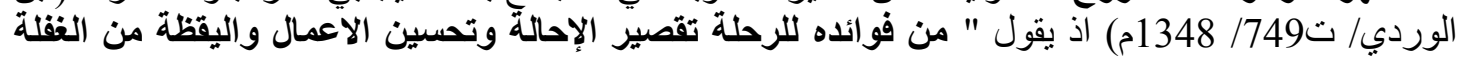

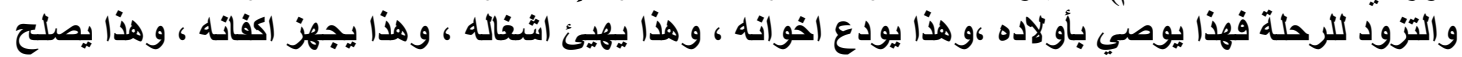

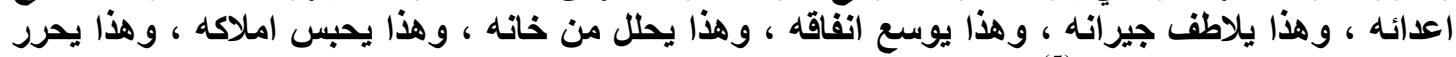

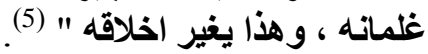

المبحث الثاني : المحور الاول (الاوبئة وتمثلاتها في النص المسرحي العالمي )

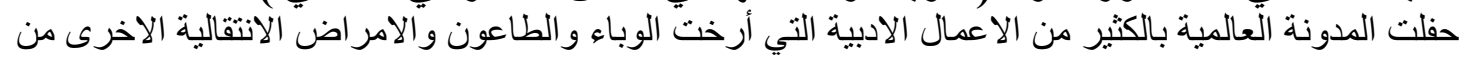

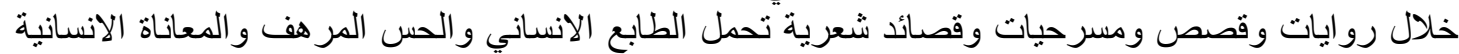

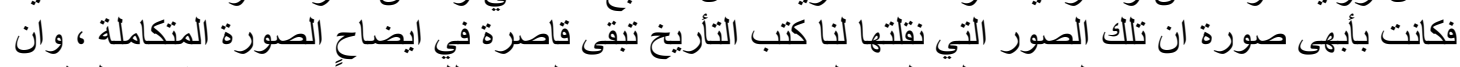

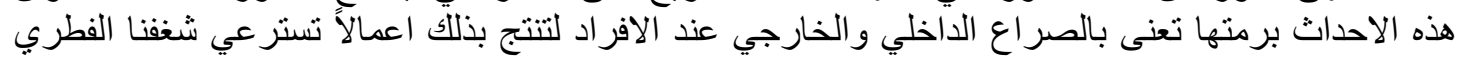

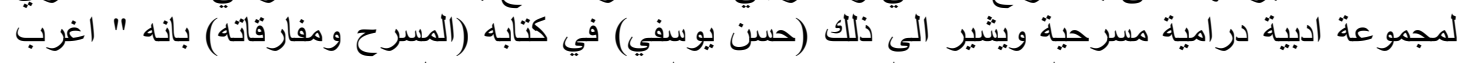

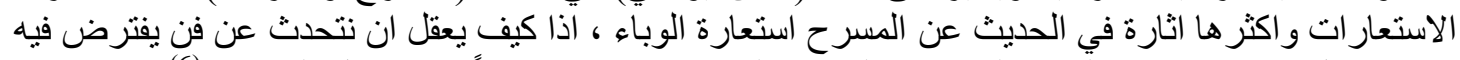

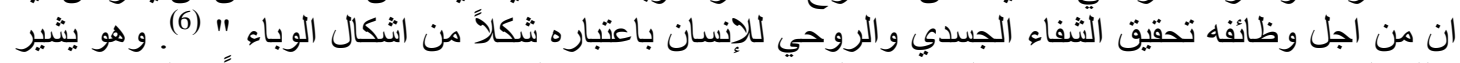

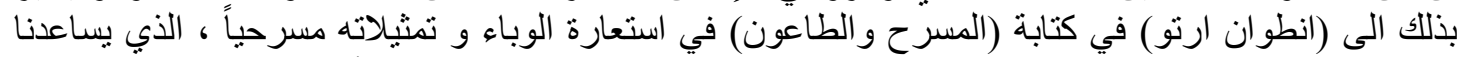

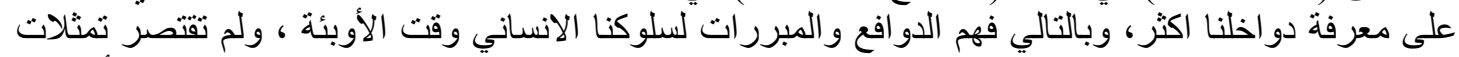

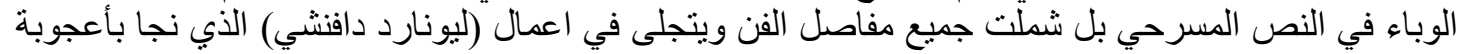
من الطاعون ، فكانت ملهمه له برسم مدينة (ميلانو ) جميلة واسعة مستقبلية .

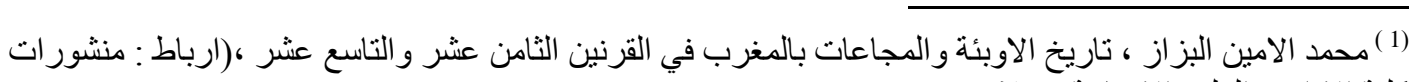

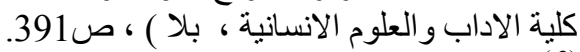

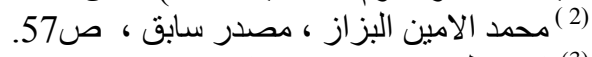

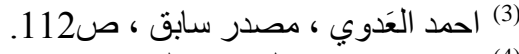

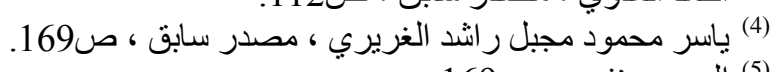

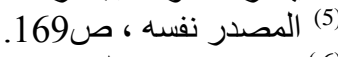

$$
\begin{aligned}
& \text { (6) حسن يوسفي ، المسر ح ومفارقاته ( ميتشيغان : مطبعة سندي للطباعة و النشر ، 1996) ، ص56. }
\end{aligned}
$$




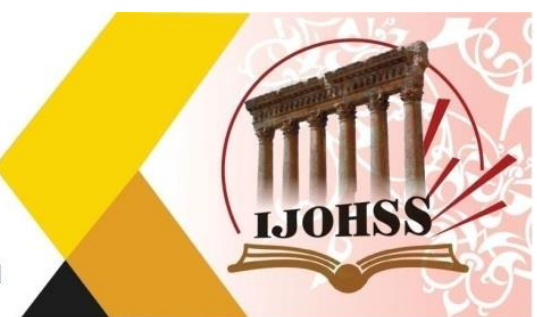

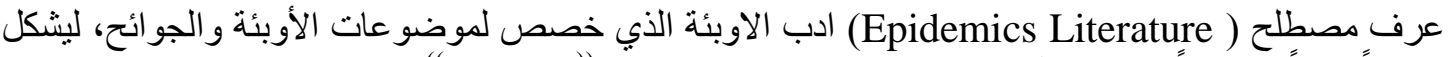

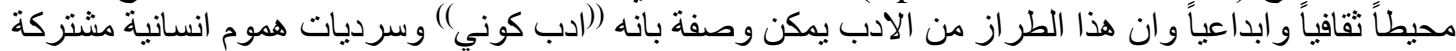

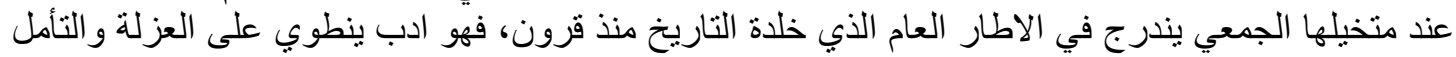

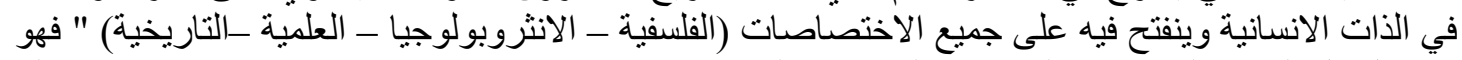

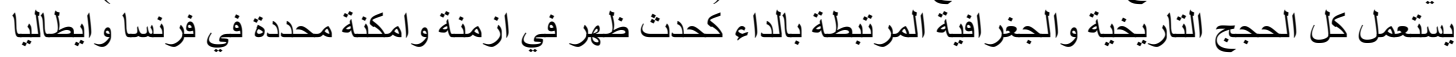

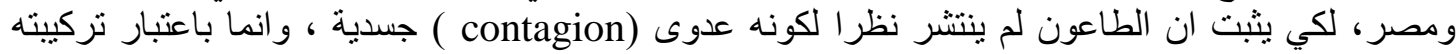

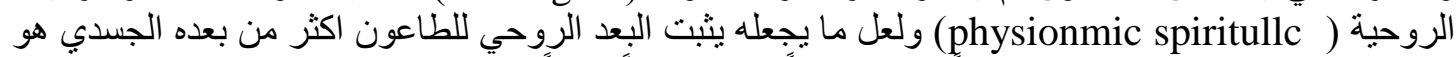

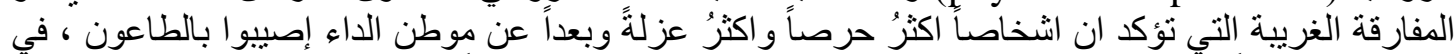

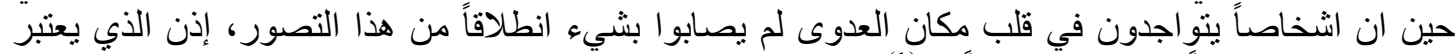

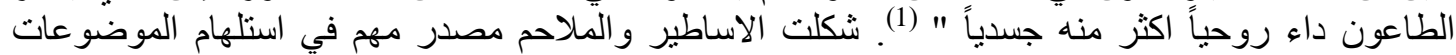

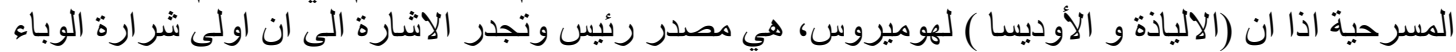

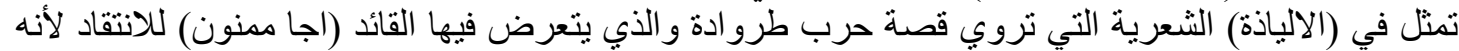

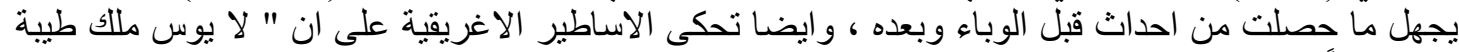

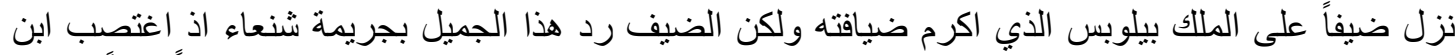

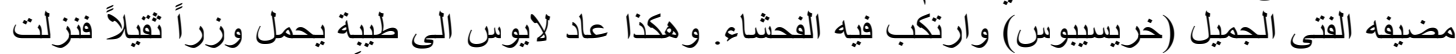

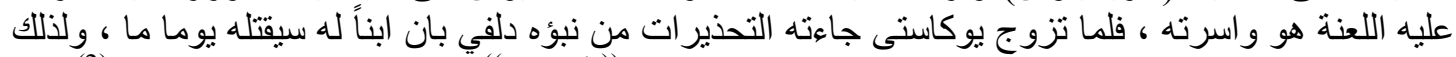

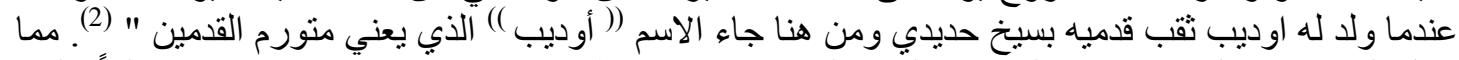

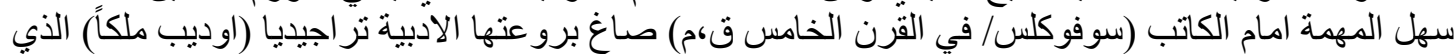

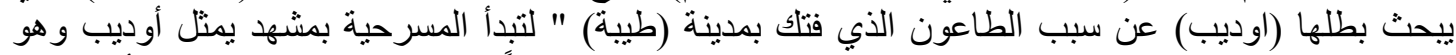

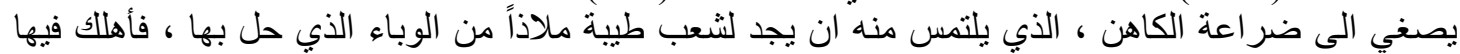

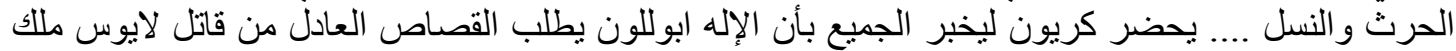

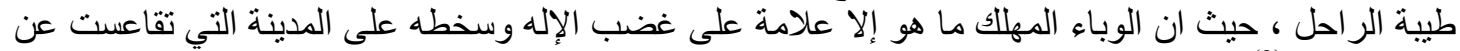

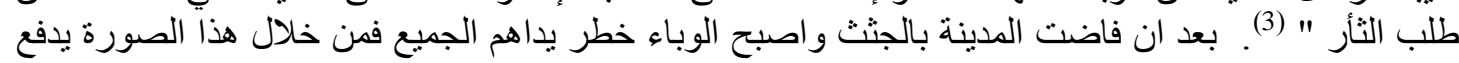

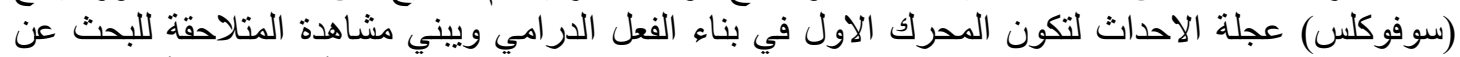

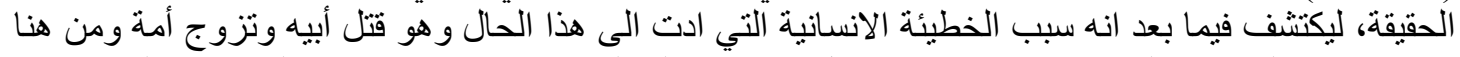

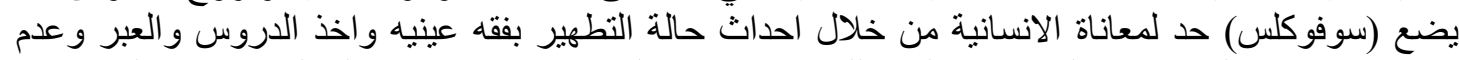

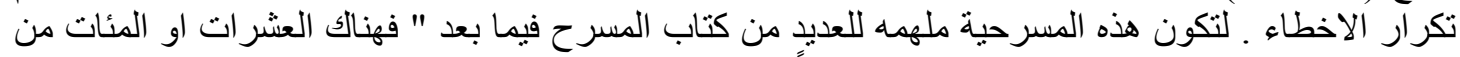

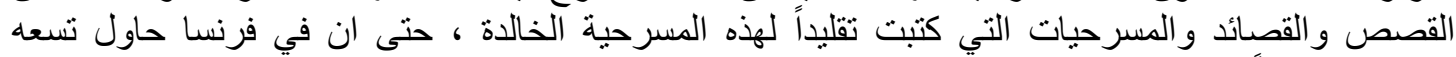

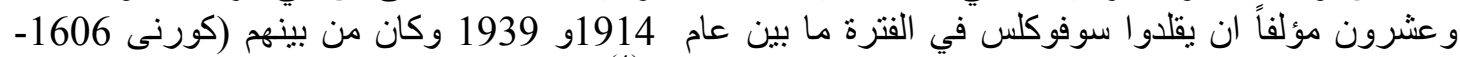

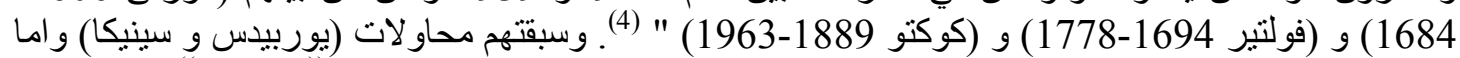

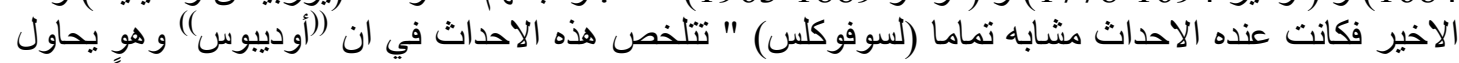

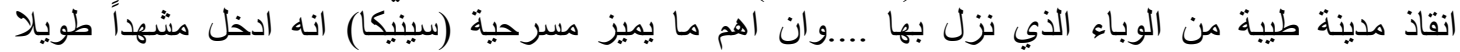

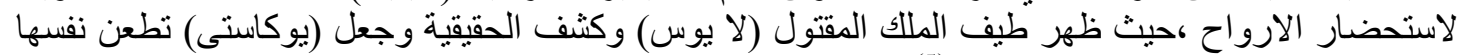

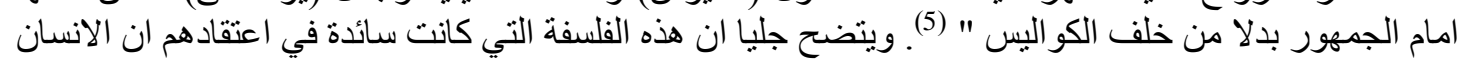

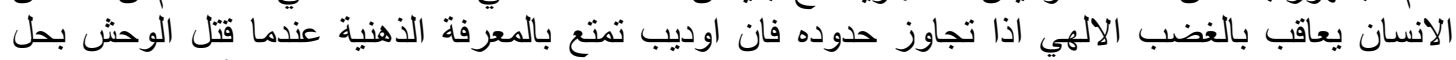

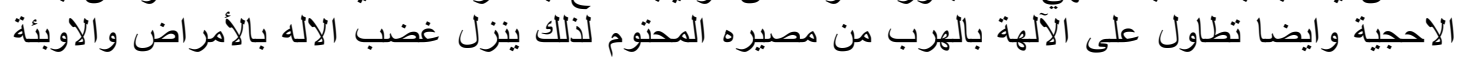

(1) (1) المصدر نفسه، ص56 (2)

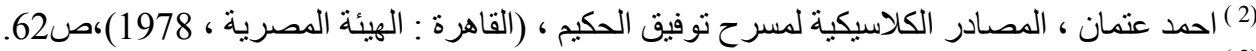

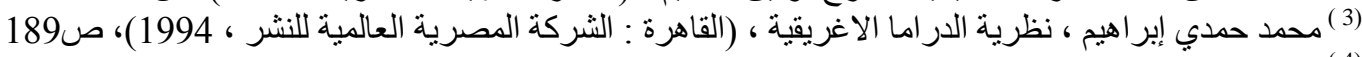

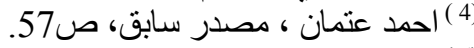
(5 ) إبر اهيم سكر ، الدمان، امدا الرومانية (القاهرة: الهيئة المصرية العامة ، 1970)،ص112. 


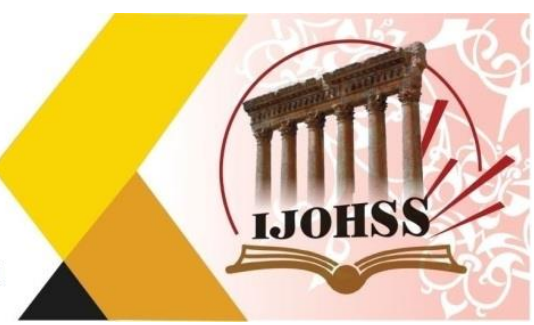

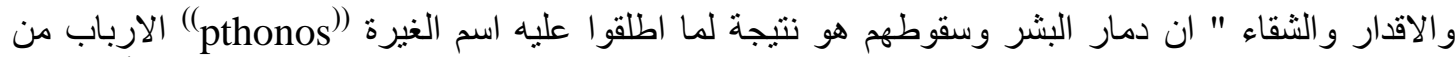

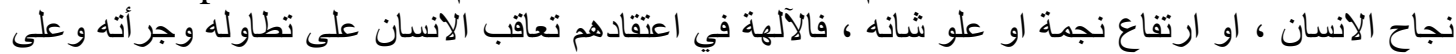

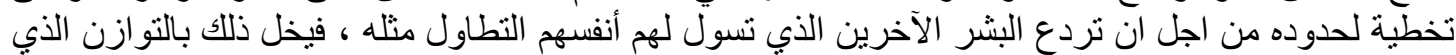

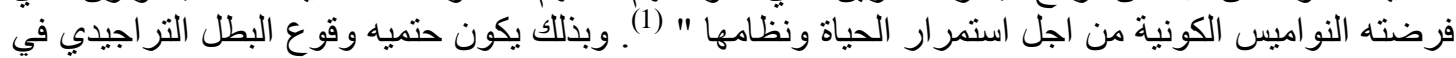

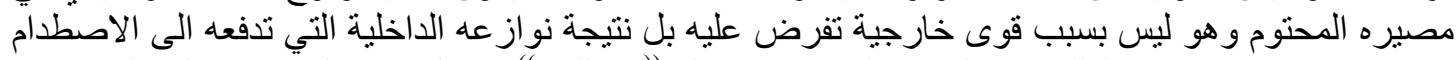

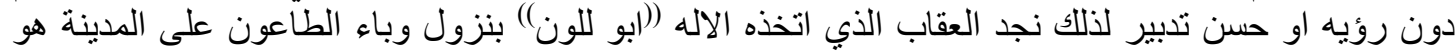

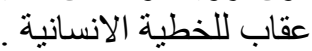

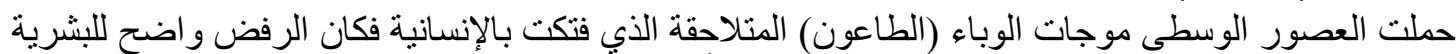

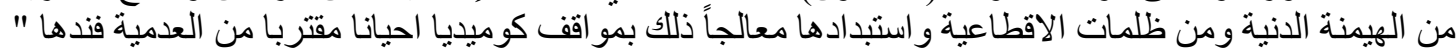

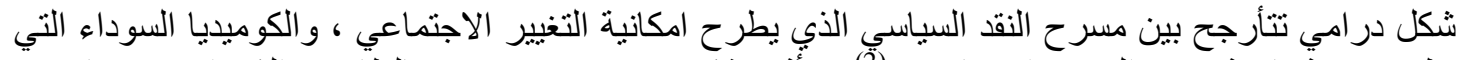

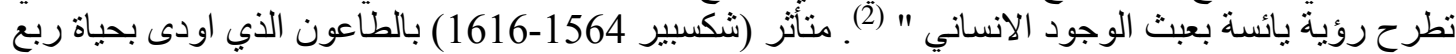

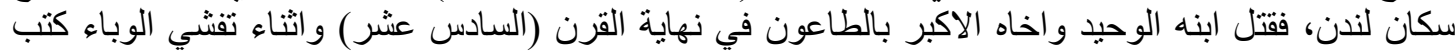

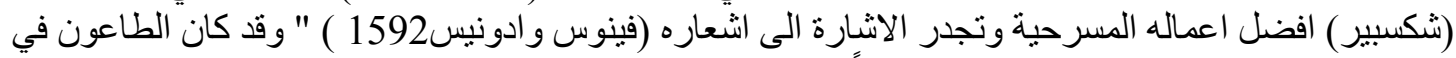

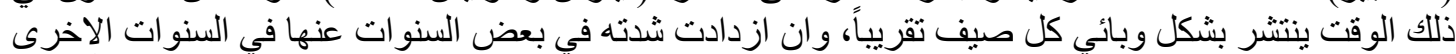

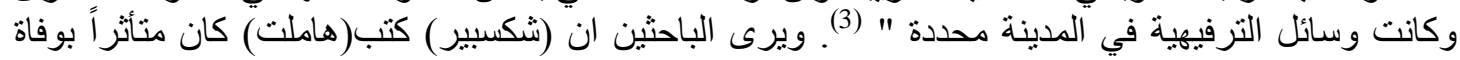

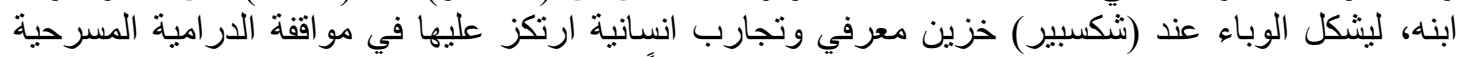

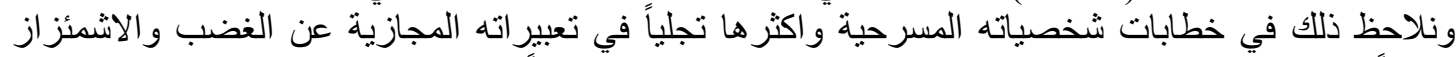

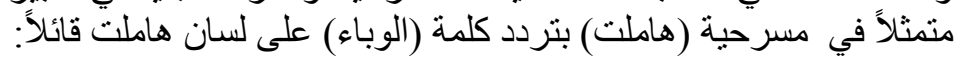

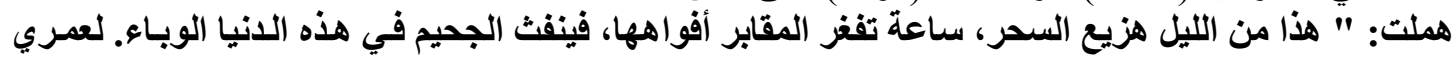

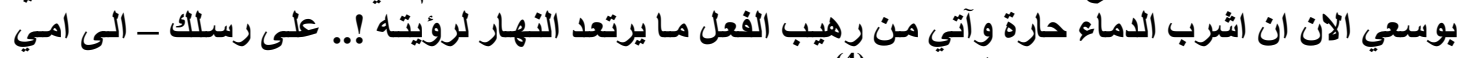

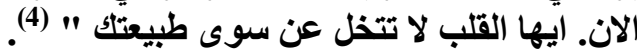

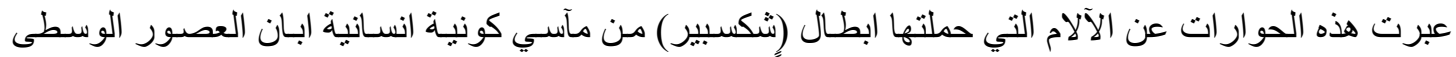

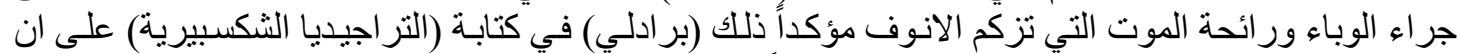

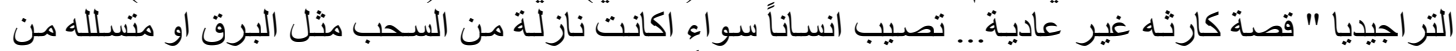

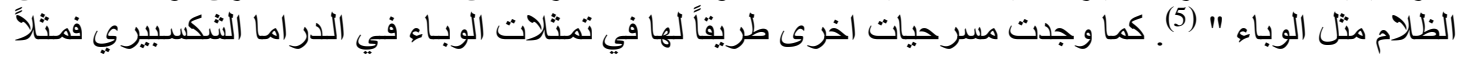

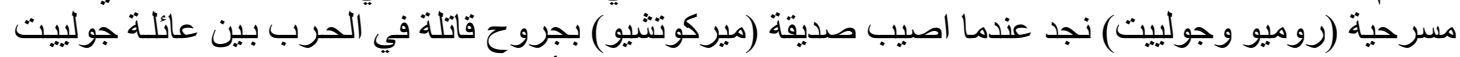

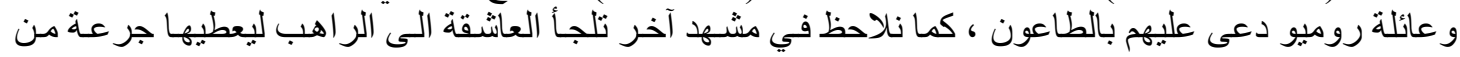

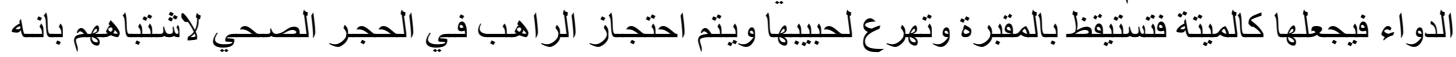

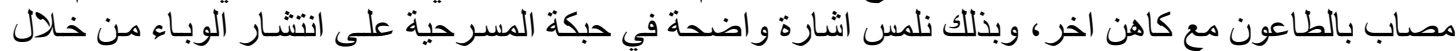
اصابه شخصية (الرسول) الذي ارسله الر اهب (لور انس) الذي يحمل الاخبار ان (جولييت) قد زورت التئ وفاتها

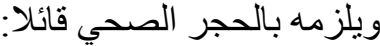
القس جون :" لم اذهب ايها الاخ بعد ـ لقد خطر لي قبل السفر ان اصطحب زميلا في رحلتي

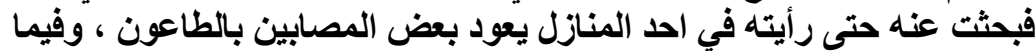

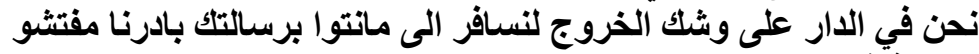

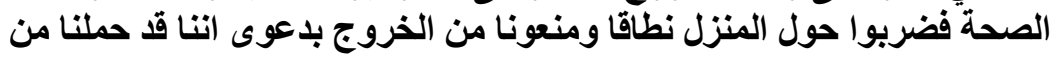

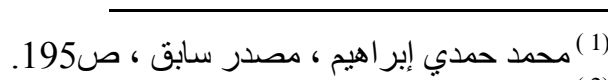

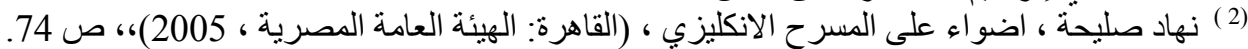

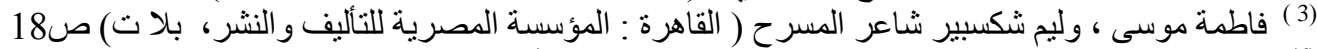

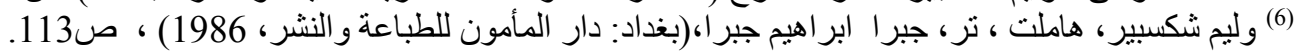

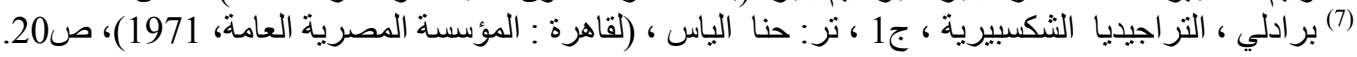




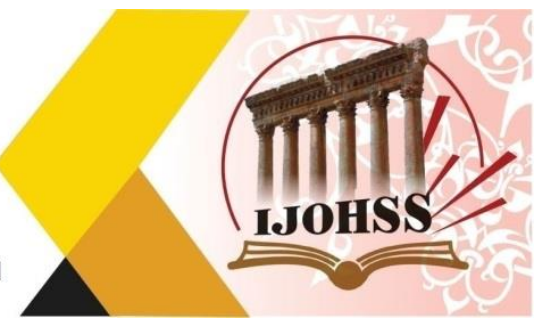

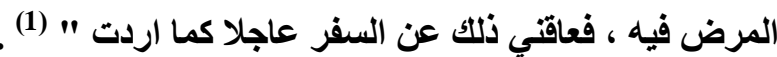

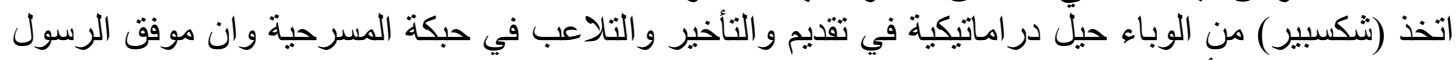

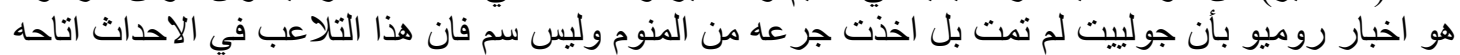

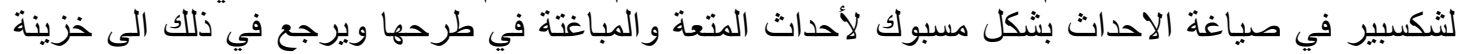

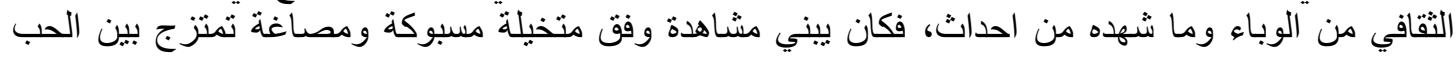

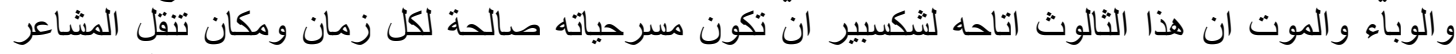

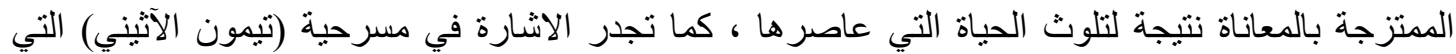

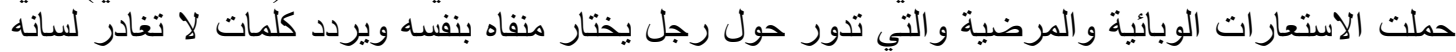

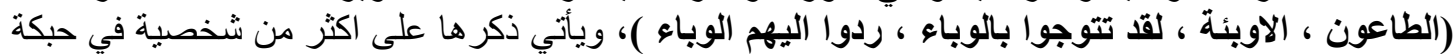

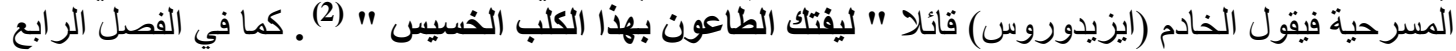

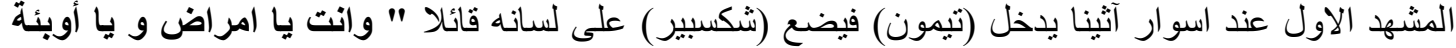

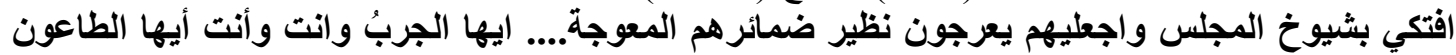

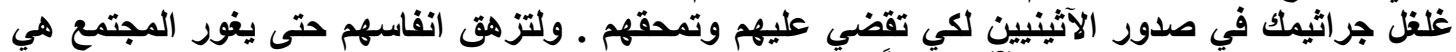

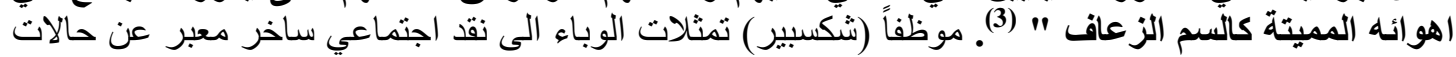

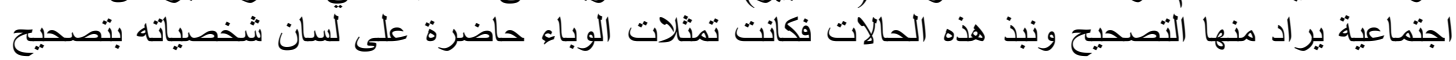

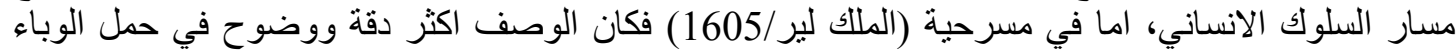

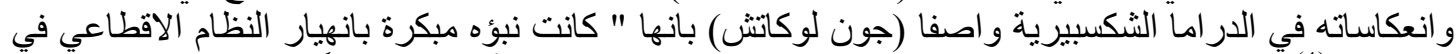

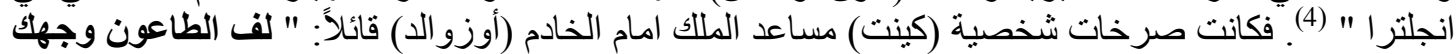

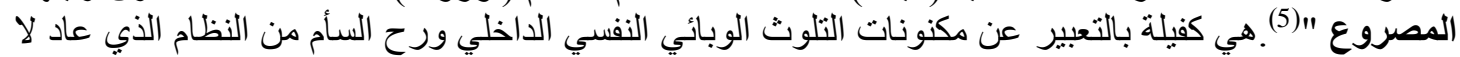

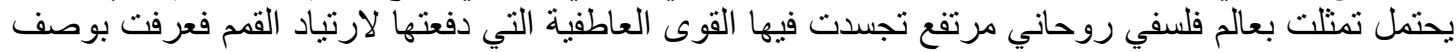

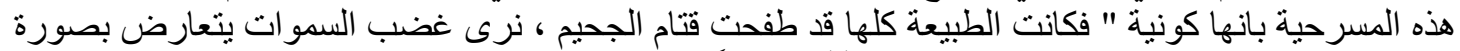

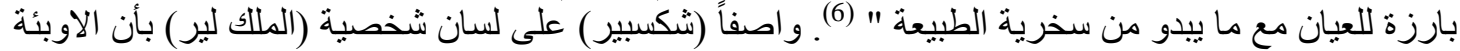

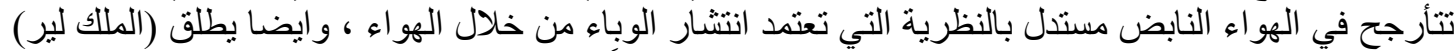

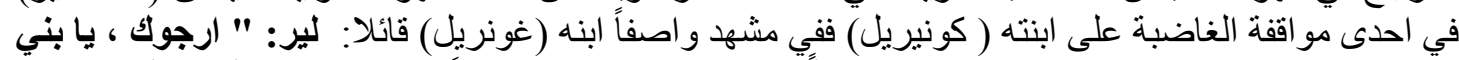

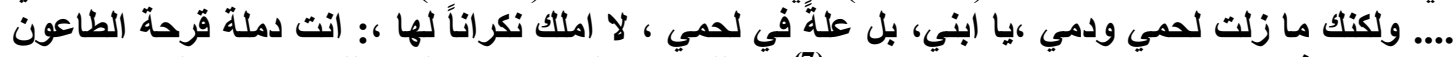

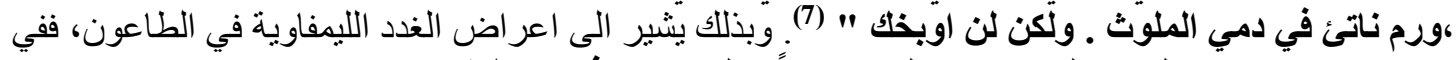

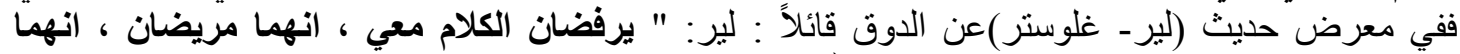

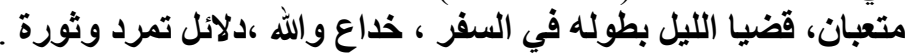

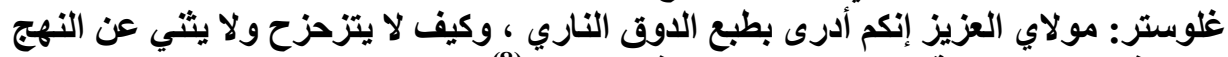

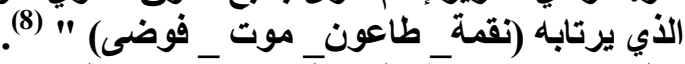

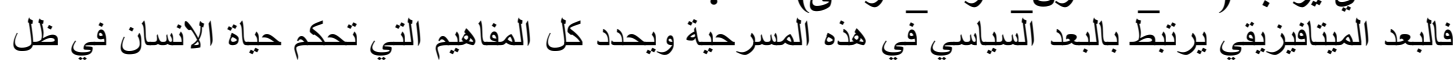

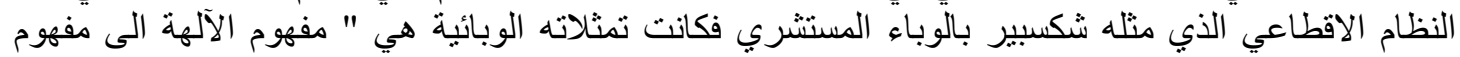

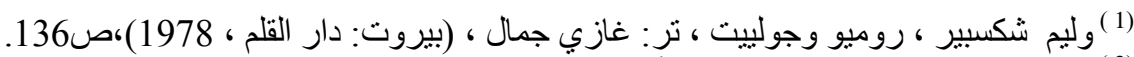

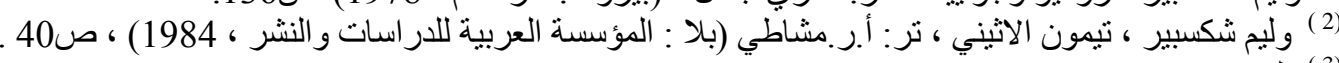

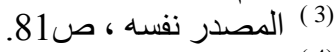

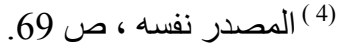

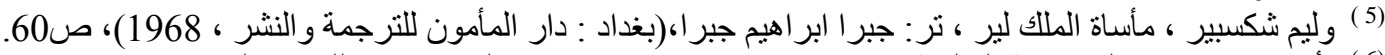

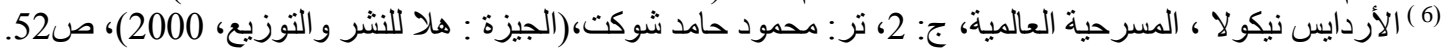

(7) وليم شكسبير ، مأساة الملك لير ، مصدر سابق ، ص75.

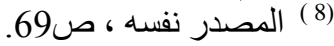




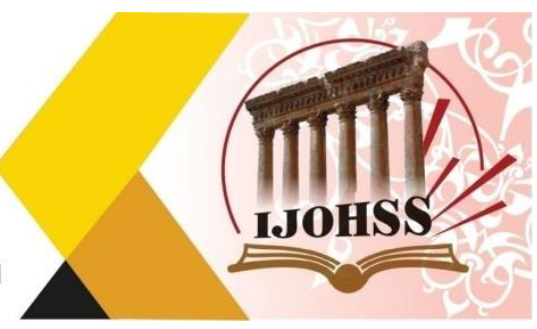

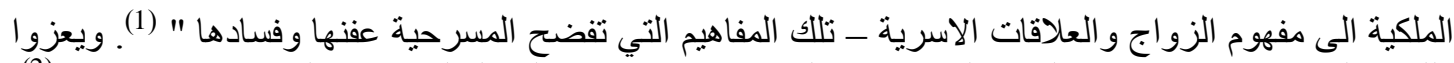

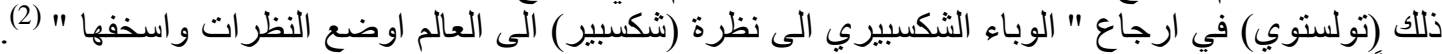

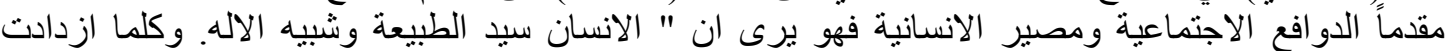

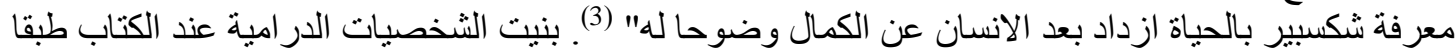

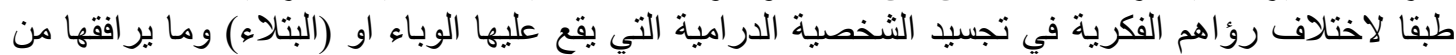

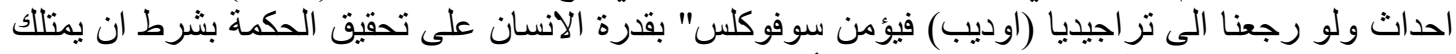

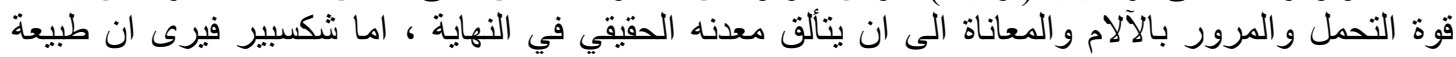

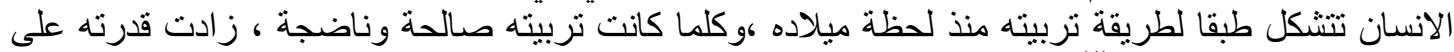

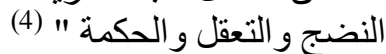

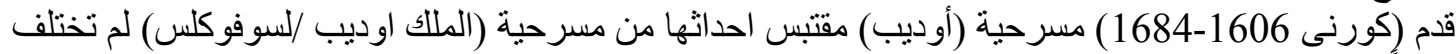

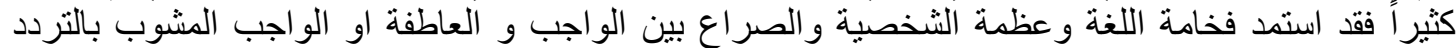

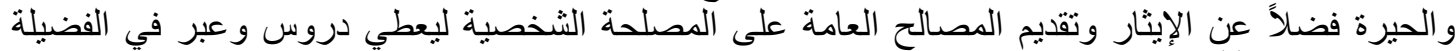

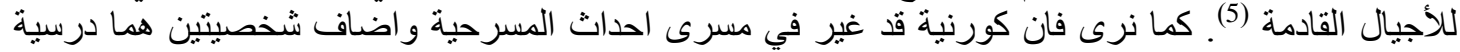

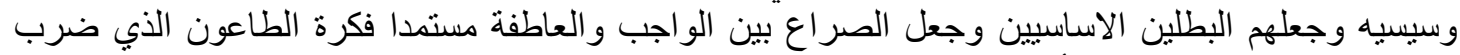

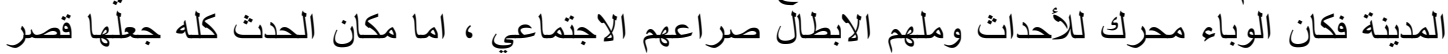

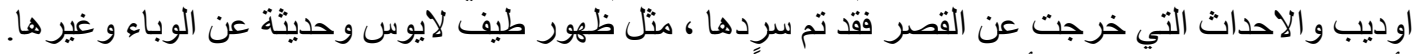

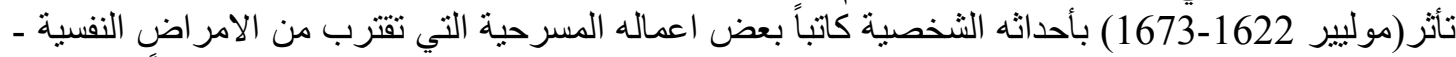
وبائية الفكر و التحليل الطبي- فهي حالات نفسية مرضية رافئ افتت شخصيات (موليير) المسرحية مثلاً (البخيل ،

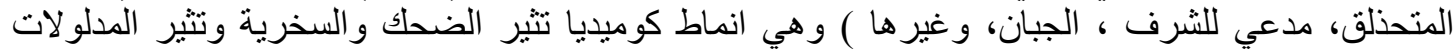

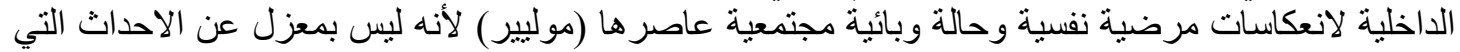

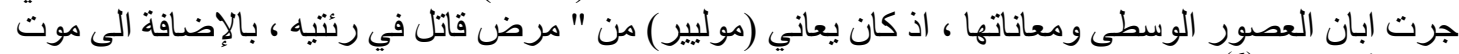

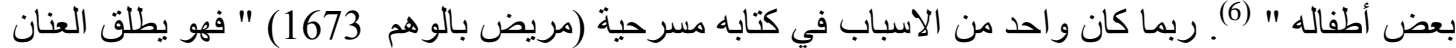

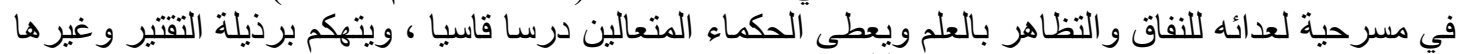

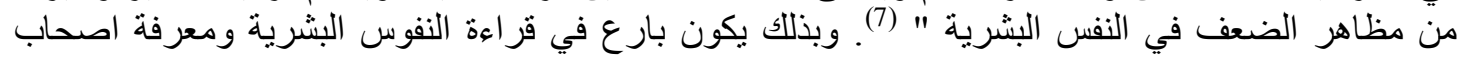

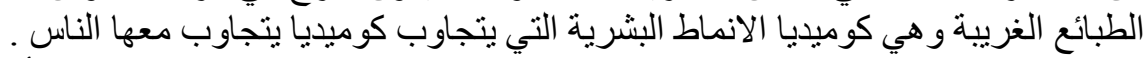

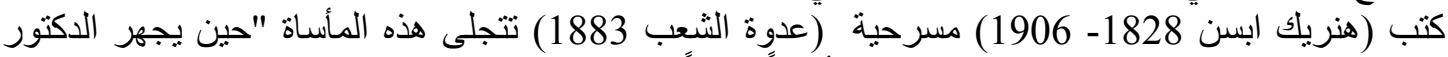

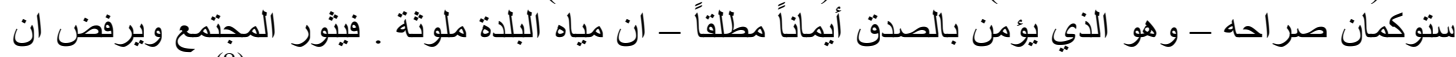

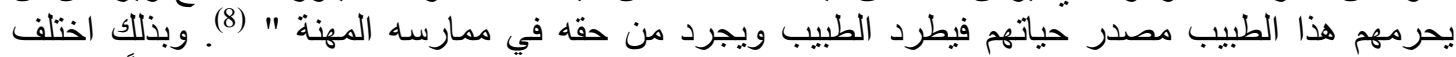

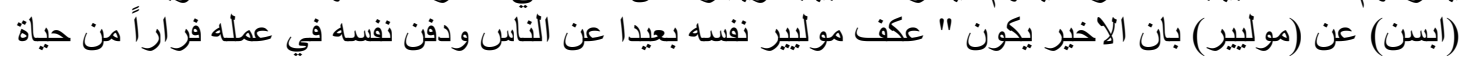

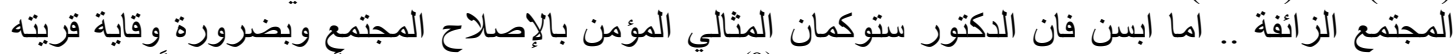

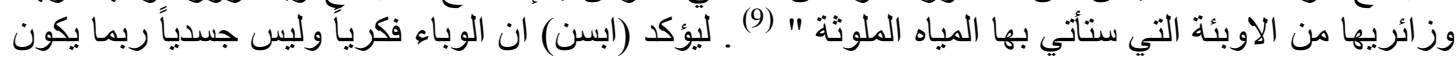

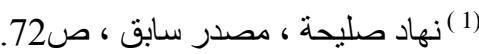

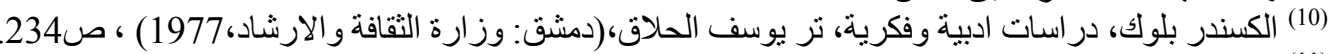

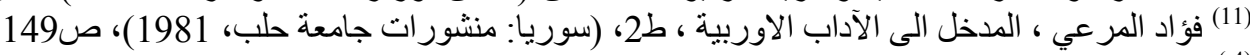

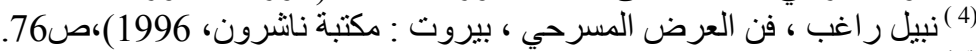

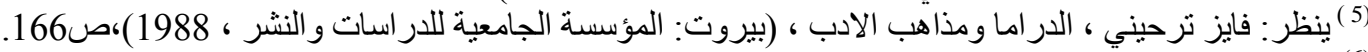

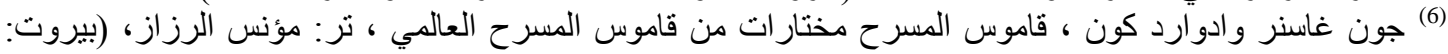

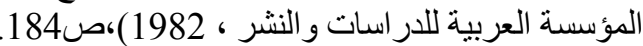
دار فر انك م هو ايتتج ، المدخل الى الفنون المسرحية ،تر: كامل يوسف وآخرون ، مر : حسن محمود وآخرون، (القاهرة :

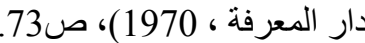
(8) (9) لويس عوض ، البحث عن شكسبير، (القاهرة : مطبعة المعارف ، 1968) ، ص 161 


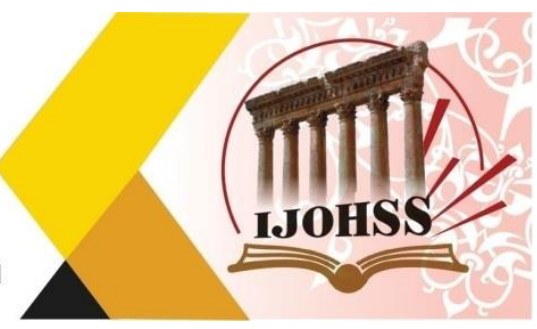

احيانا، كما برع (اندريه جيد 1869-1951) بتصوير مسرحية (أوديب) والتي عرضت عام عام (1949) التي

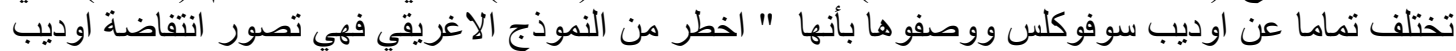

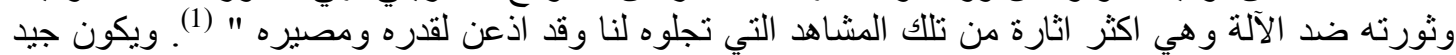

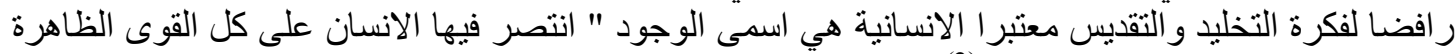

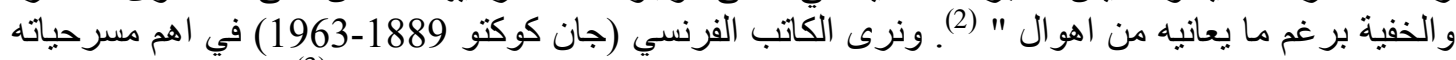

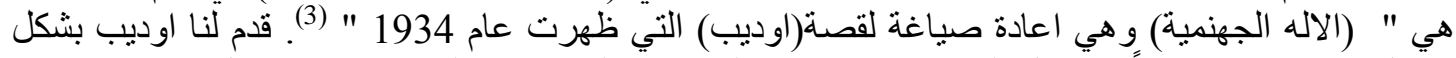

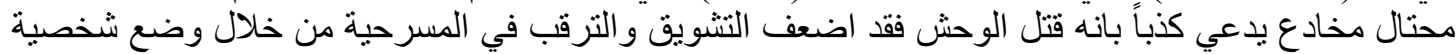

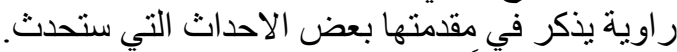

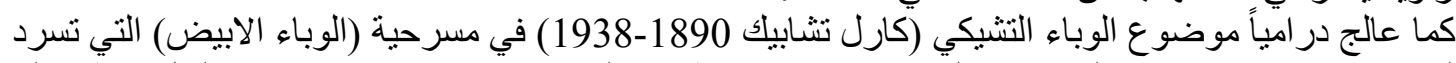

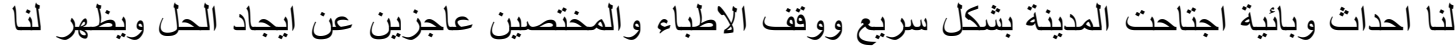

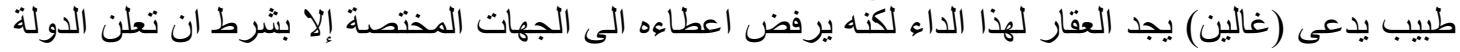

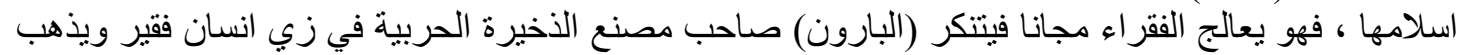

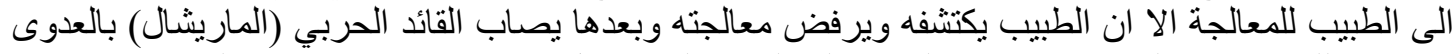

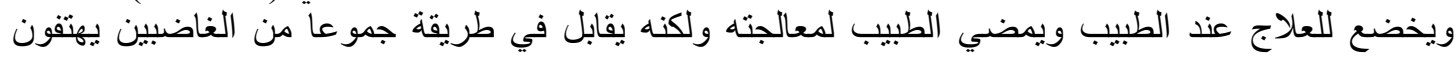

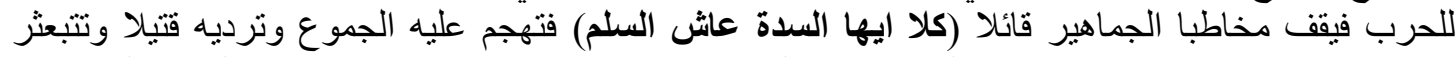

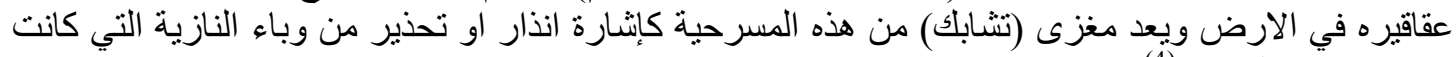

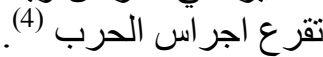

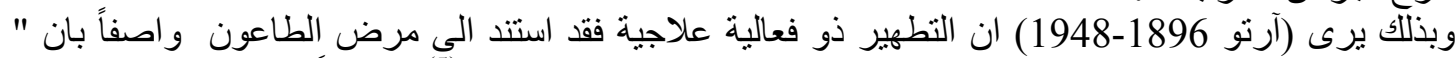

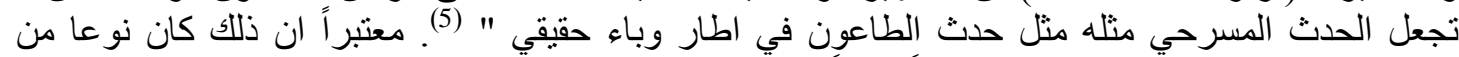

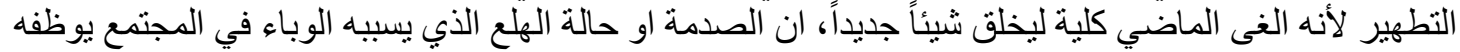

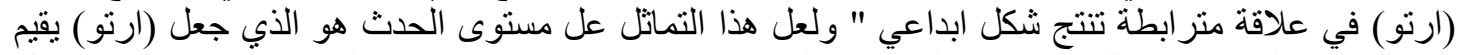

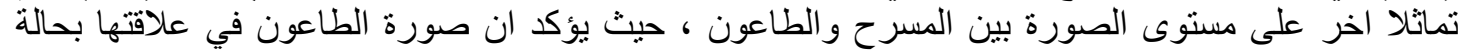

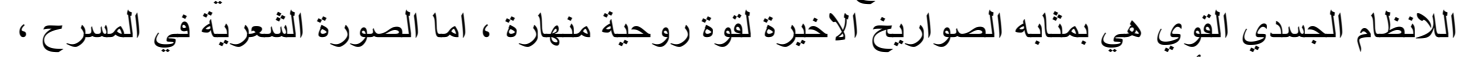

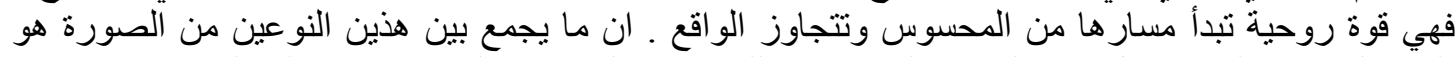

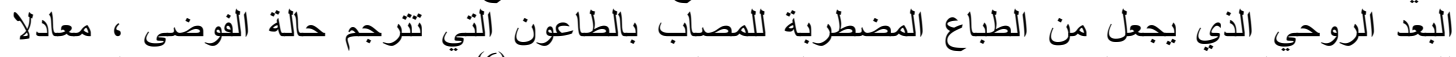

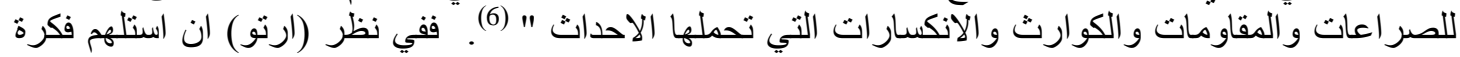

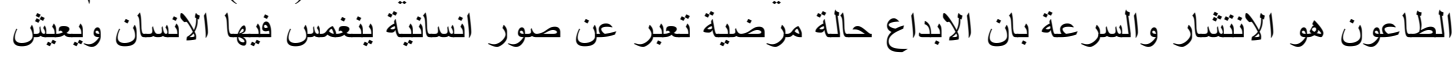

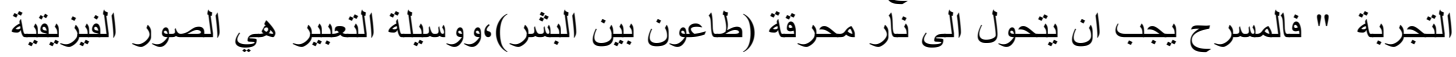

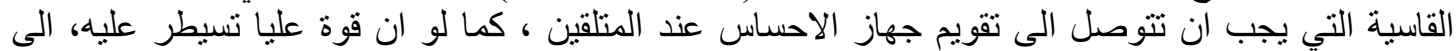

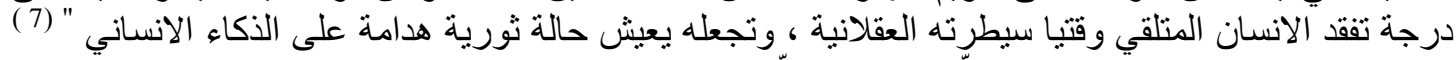

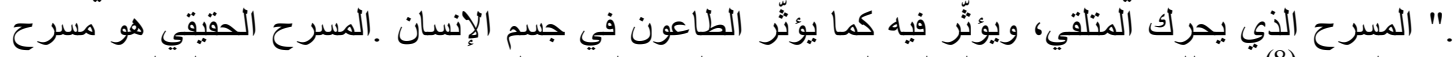

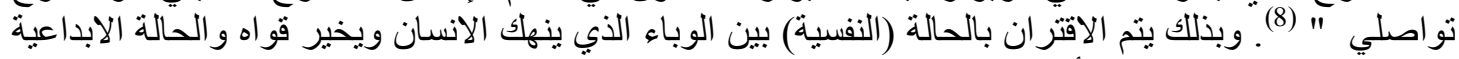

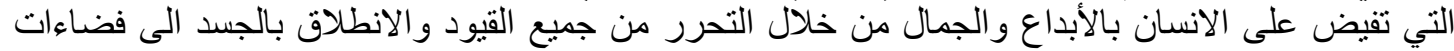

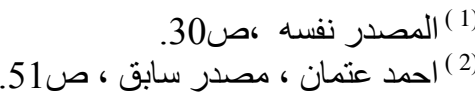

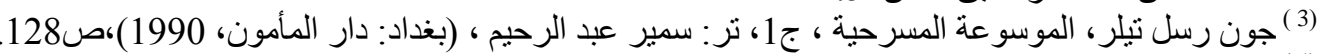

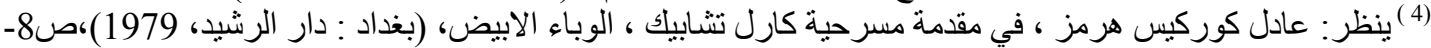

$$
\begin{aligned}
& \text { (5) (5) حسن يوسفي ، مصدر سابق، ص57. }
\end{aligned}
$$

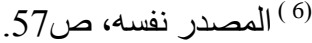

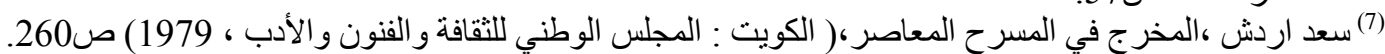

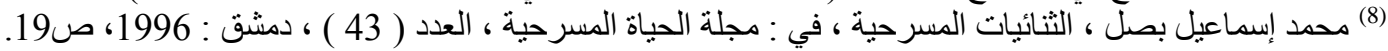




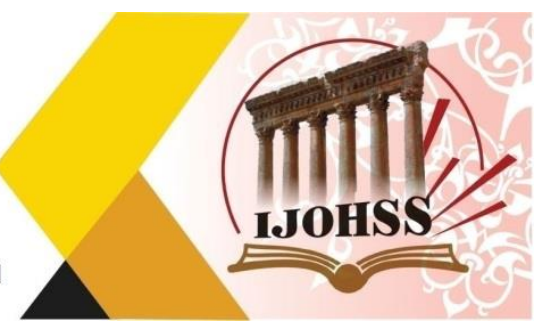

اكبر واوسع خالقه مبدعة مصورة الاحالة الانسانية وما تعانيه او ربما تللك الفلسفة القائمة على تمثلات الوبات الوباء

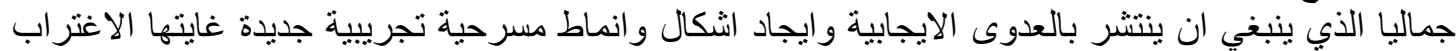

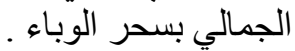

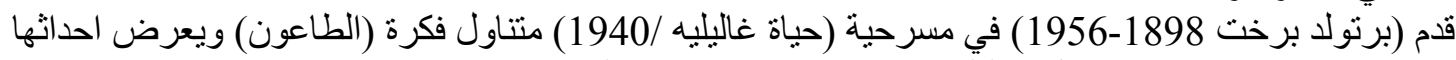

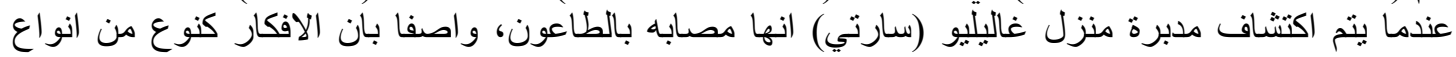

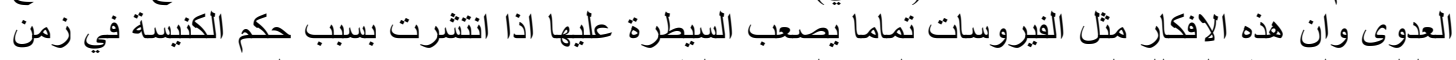

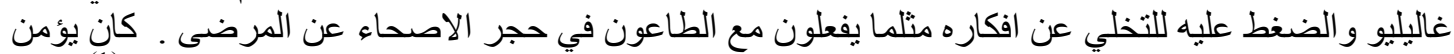

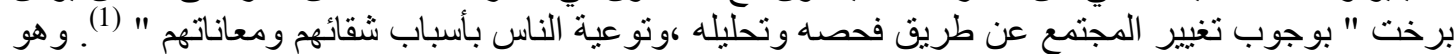

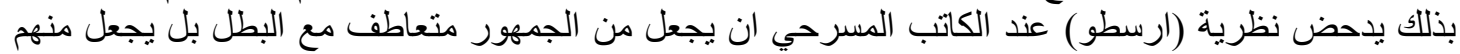

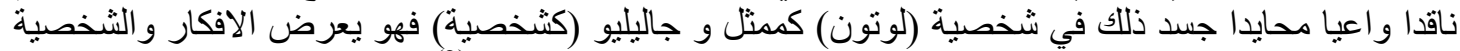

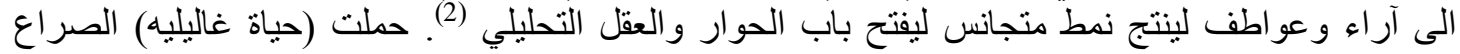

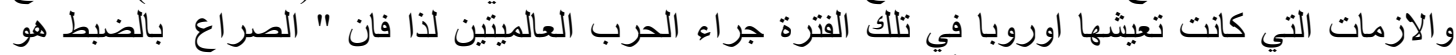

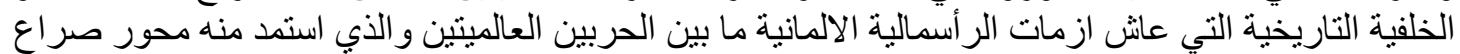

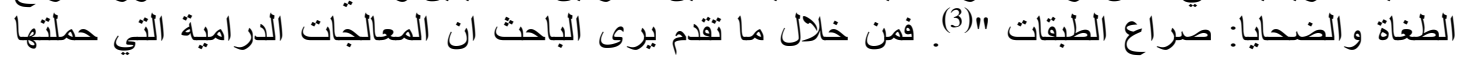

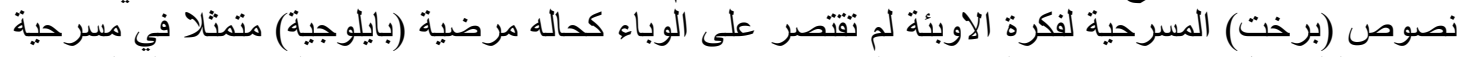

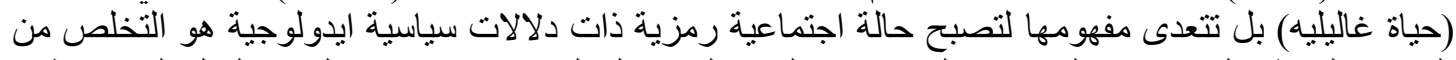

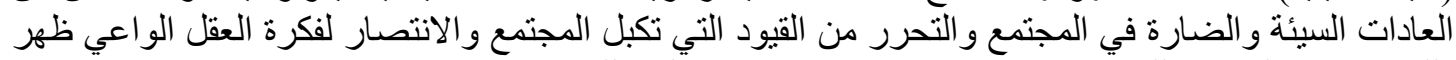

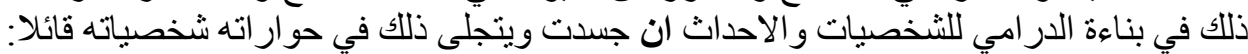
المرأة العجوز: انهم لا يكافحون النار حيث يشكون في وجود الطاعون ـ لم يعد احد يفكر الان الأن

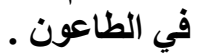
جاليلو: كم يشّبهون الطاعون هم الاخرون هذا هو نظام حكومتهم .انهم يقصوننا يقصون

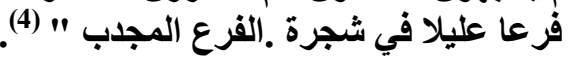

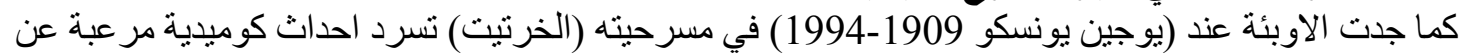

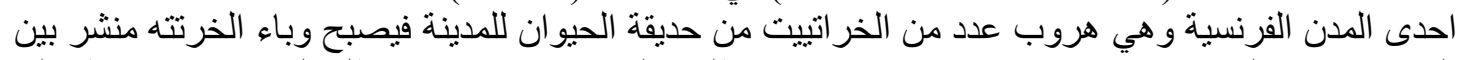

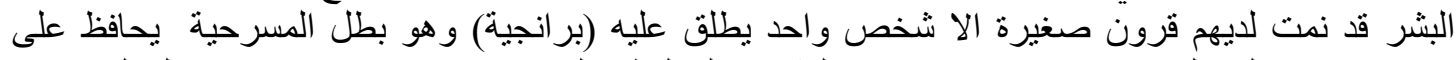

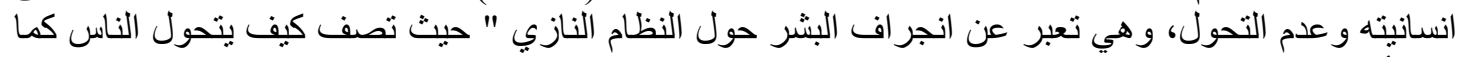

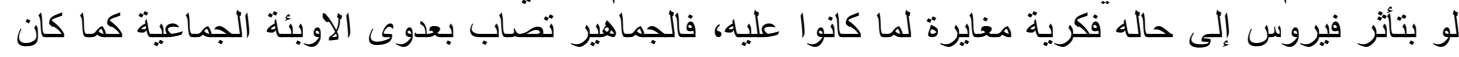

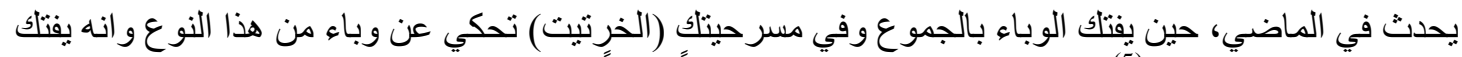

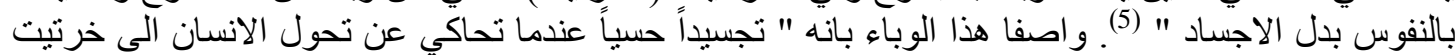

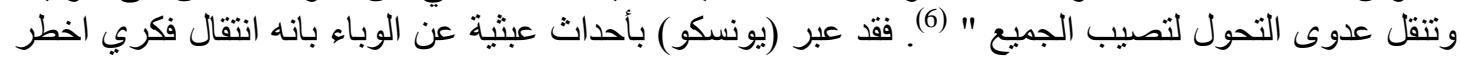

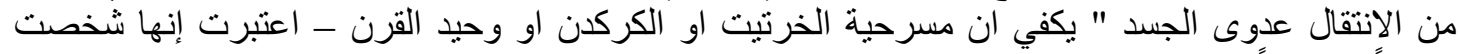

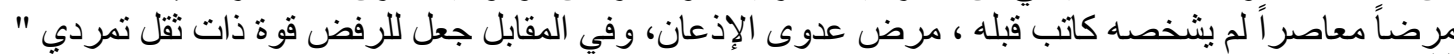

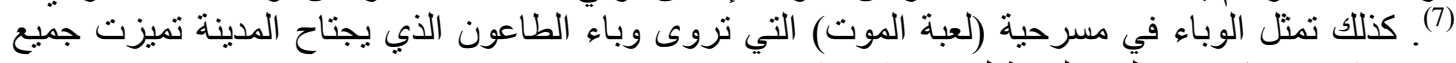
مسرحيات(يونسكو) بمعالجه فلسفية لمصير الانسان.

$$
\begin{aligned}
& \text { (1) برنولا برخت ، الاروجون الصغير ، تر : فاروق عبد الوهاب ، (الجيزة: دار هلا للطباعة و النشر، 2000)،ص6. }
\end{aligned}
$$

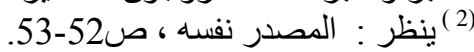

$$
\begin{aligned}
& \text { (3) برنولد برشت، حياة غاليليه ، تر : بكر الشرقاوي ، (بيروت : دار الفار ابي ، 1979)، ص4. }
\end{aligned}
$$

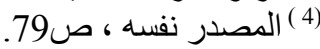

$$
\begin{aligned}
& \text { (6 ) (5 ) عصام محفوظ ، مسرح القرن العشرين (المؤلفون) ، ج1، (بيروت : دار الفار ابي ، 2002)، ص70. }
\end{aligned}
$$

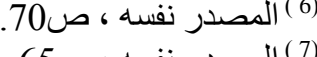




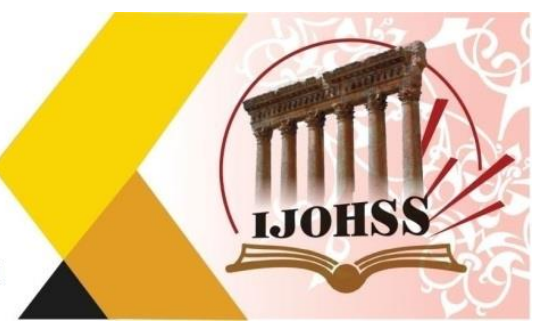

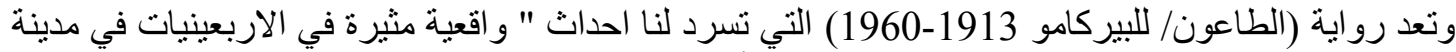

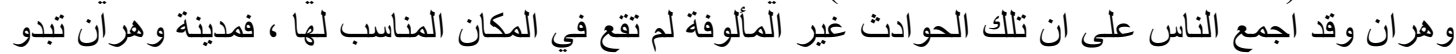

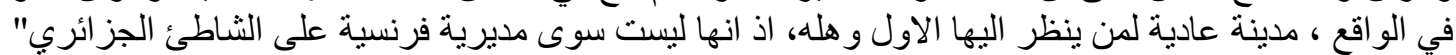

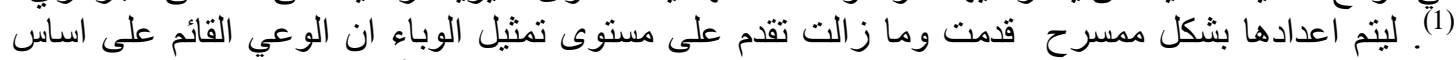

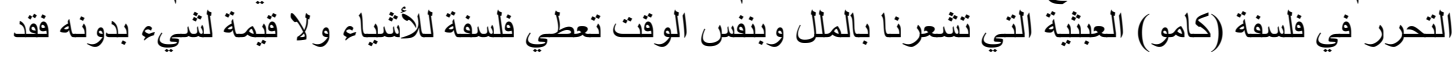

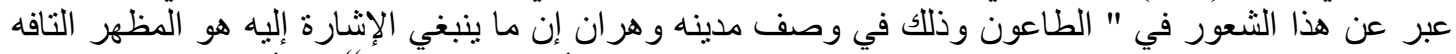

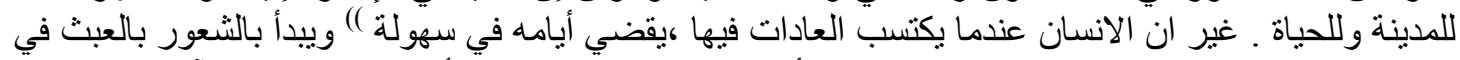

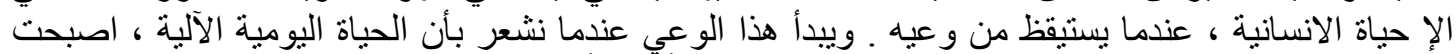

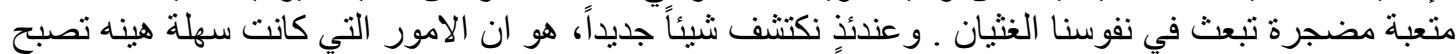

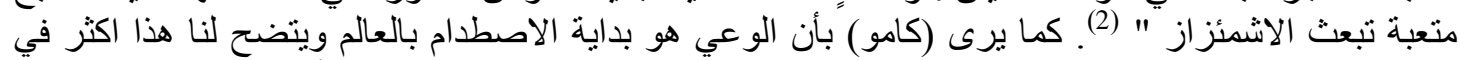

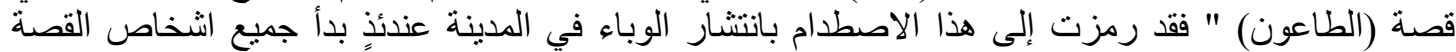

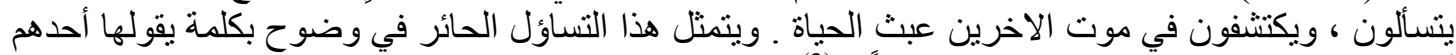

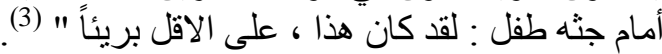

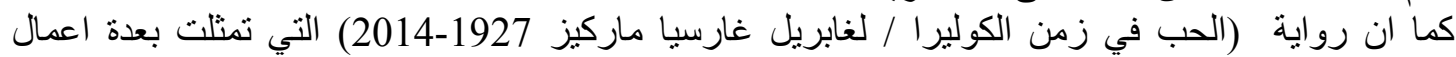

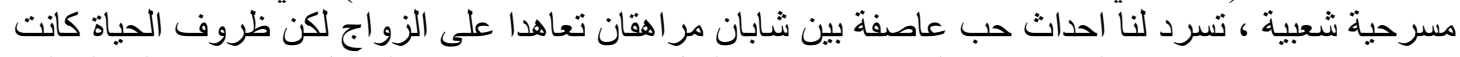

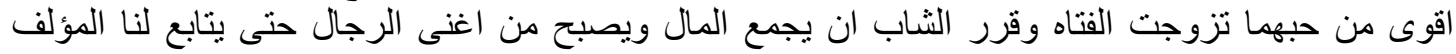

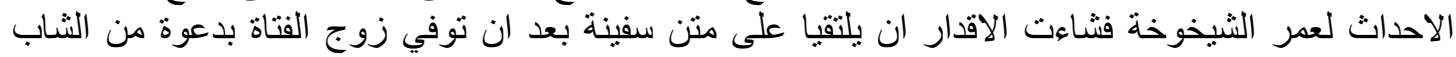

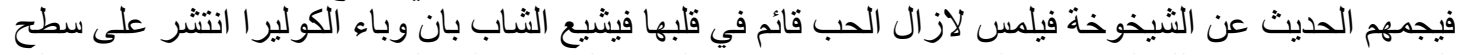

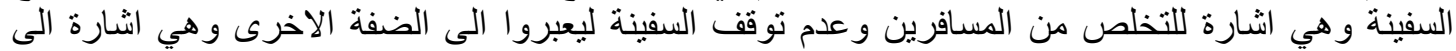

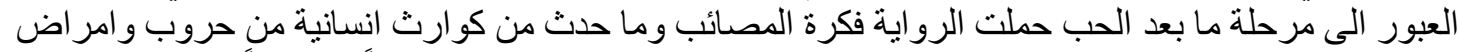

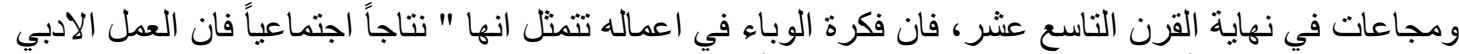

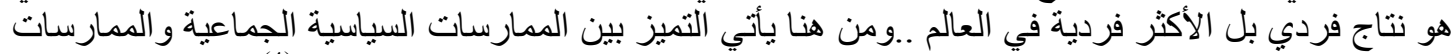
الادبية الفرديةٌ البحتة ...ر افضا جميع الاشكال و والممارسات القمعية الدكتاتورية في التيات العالم " (4).

المحور الثاني : (الأوبئة وتمثلاتها في النص المسرحي العربي )

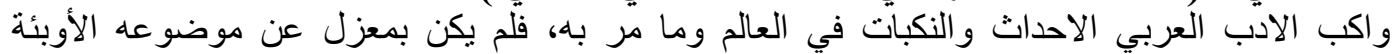

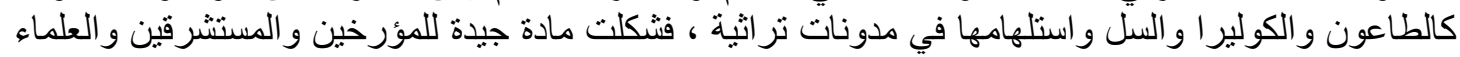

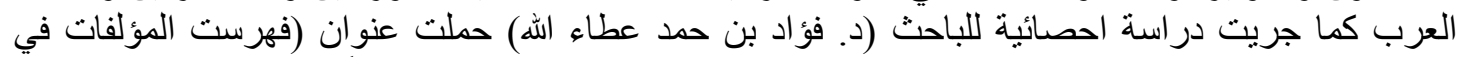

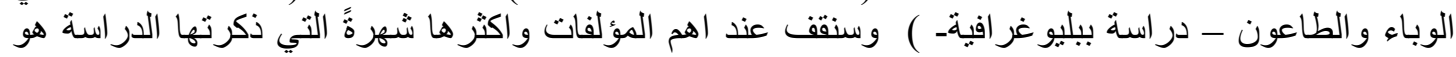

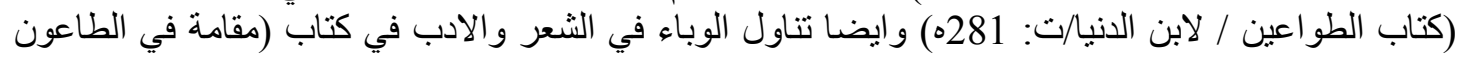

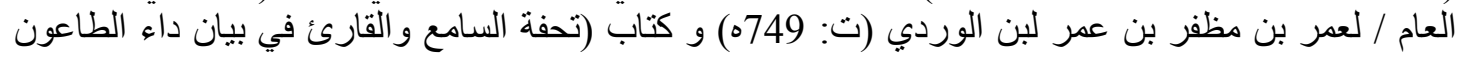

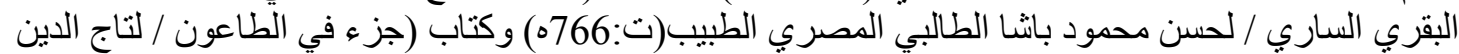

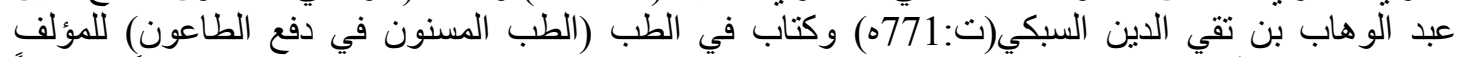

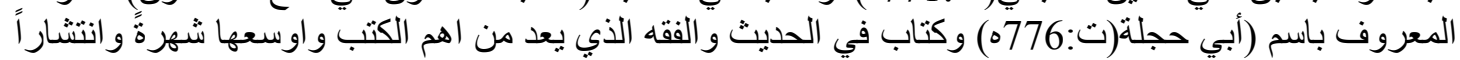
هو (بذل الماعون في فوائد الطاعون / لابن حجر العسقلاني (ت:852ه) و ايضا من مؤلفات العرب كتاب (تسلية

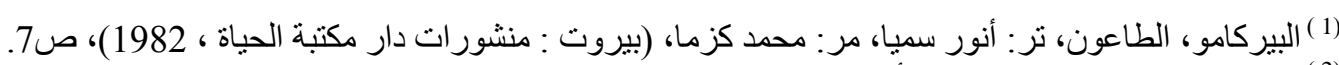

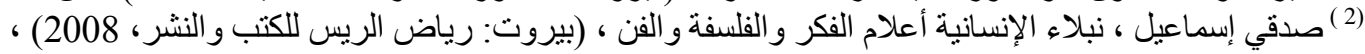

(4) غابريل غارسيا ماركيز ، الحب في في زمن الكولير ا ، تر : صالح علماني عن مقدمة بقلم المترجم ، (دمشق: دانه للطباعة

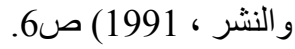




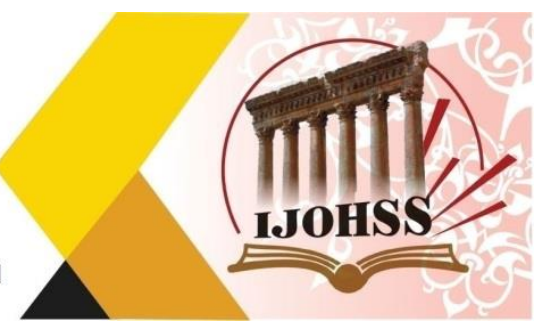

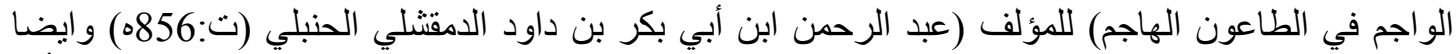

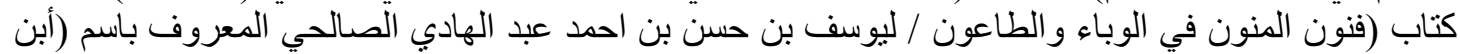

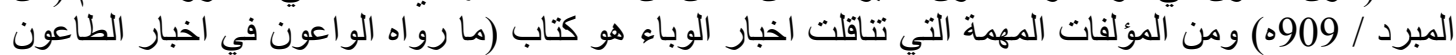

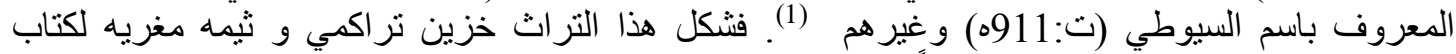

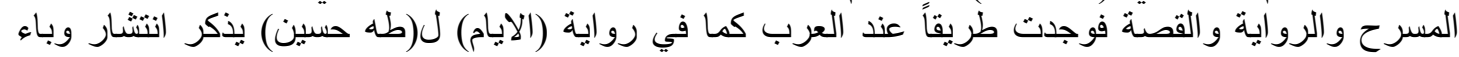

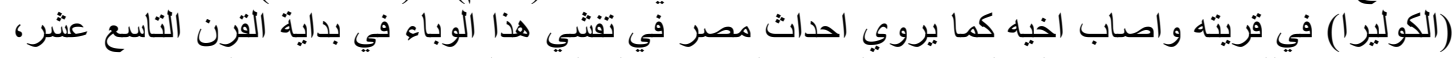

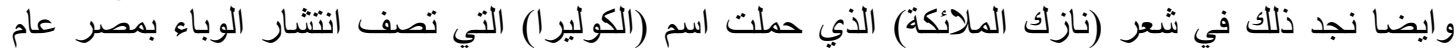

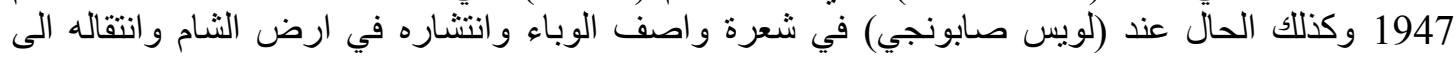

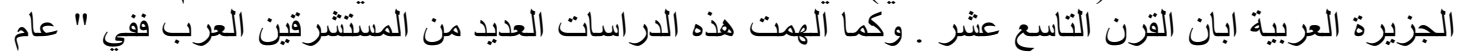

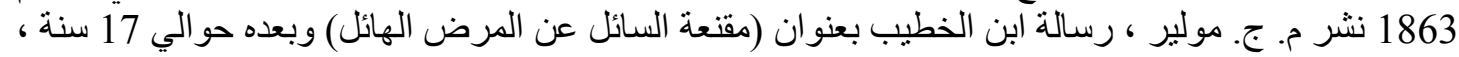

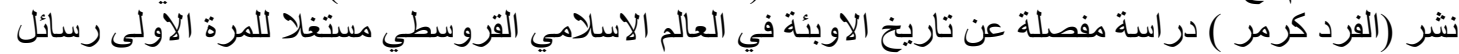

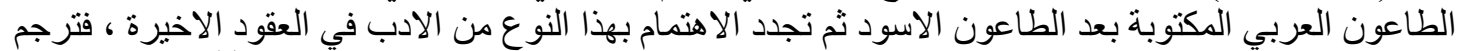

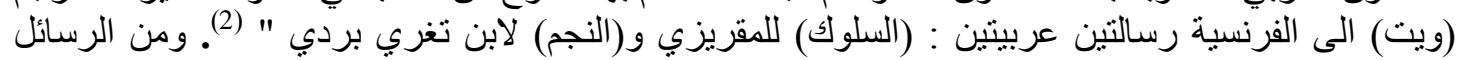

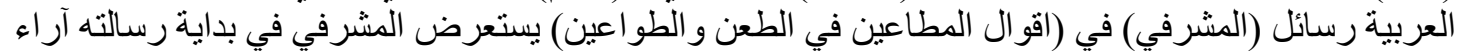

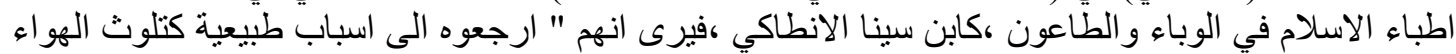

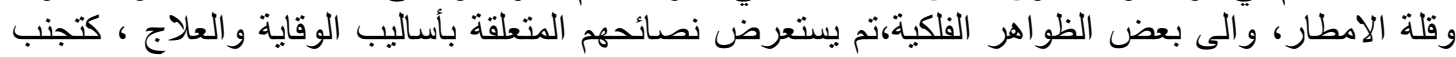

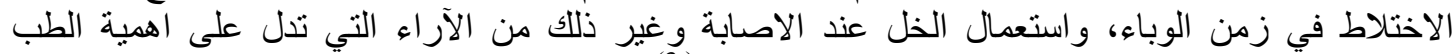

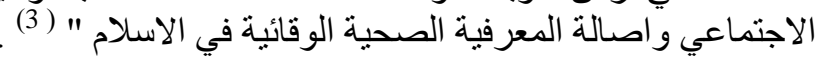

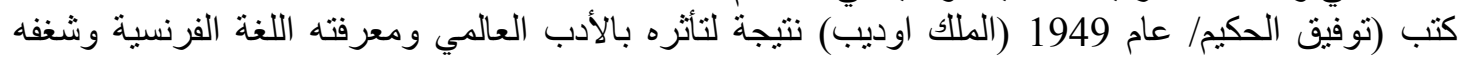

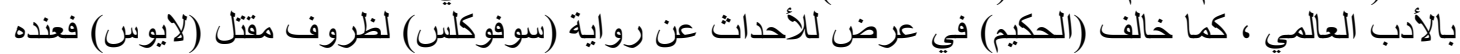

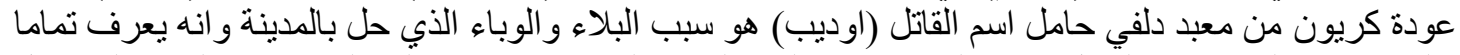

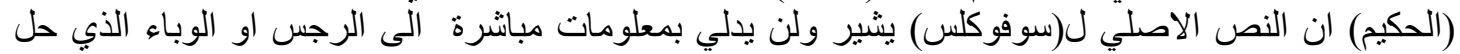

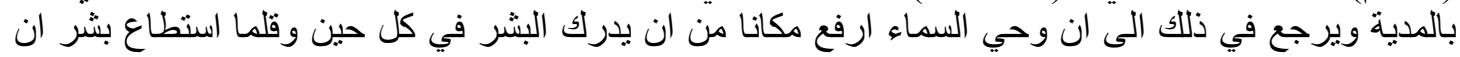

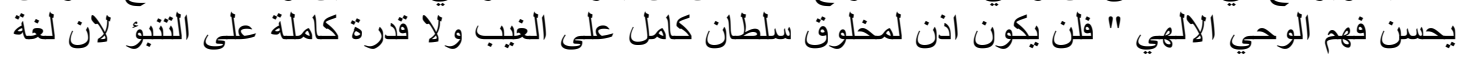

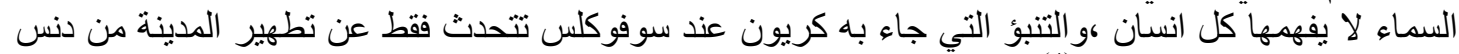

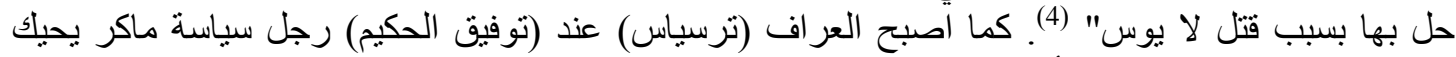

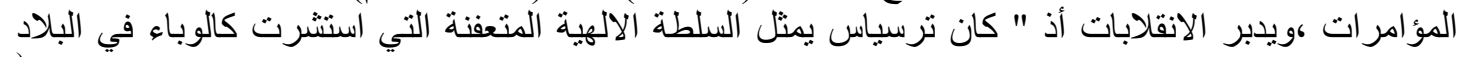

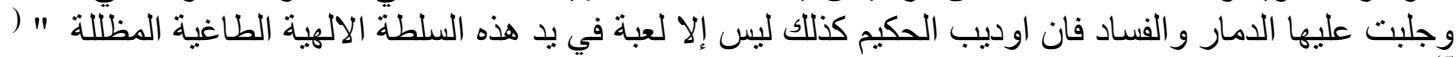

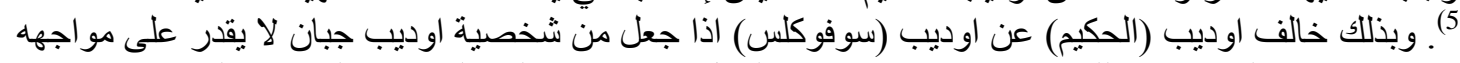

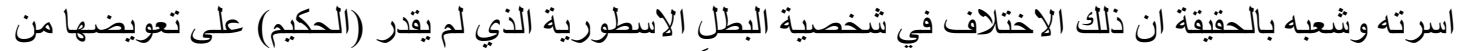

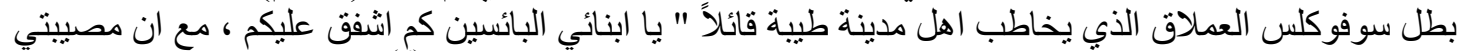

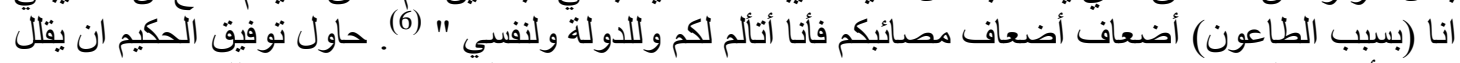

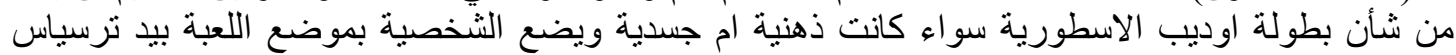
الضرير الجبار ويتضح ذللك جليا في خطاب يوكاستى عندما تخاطب اوديب " انت لا تملك لدفعه (اي الطاعون)

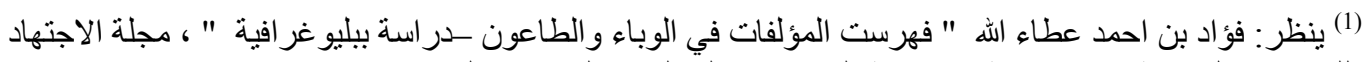

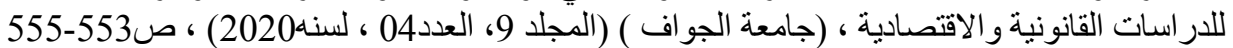

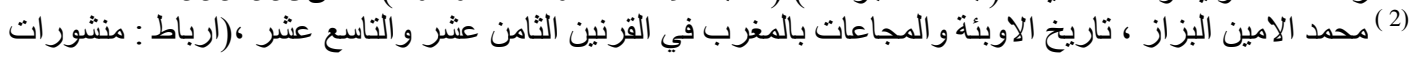

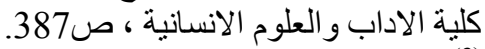

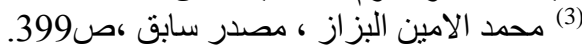

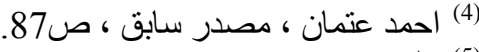

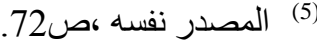

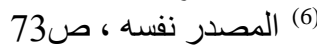




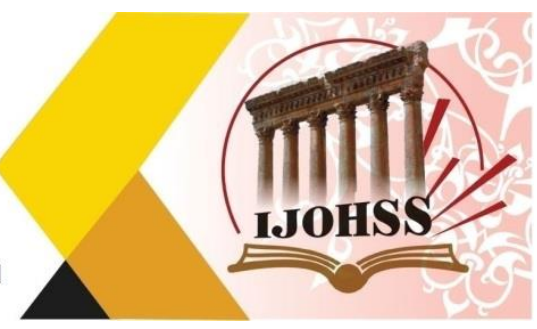

شيئًا " (1). ان (اوديب) الحكيم خانع خاضع لا يستطيع مو اجهه مصبره ومو اجهاه شعبة وكأن الحكيم برد ان ان يقول

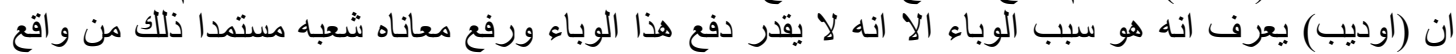

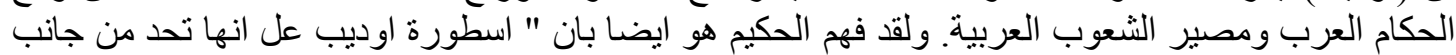

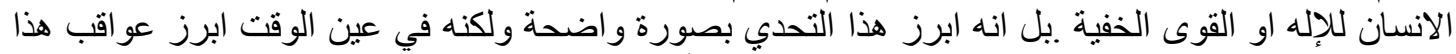

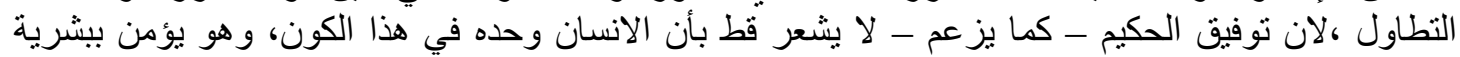

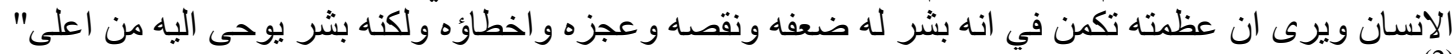

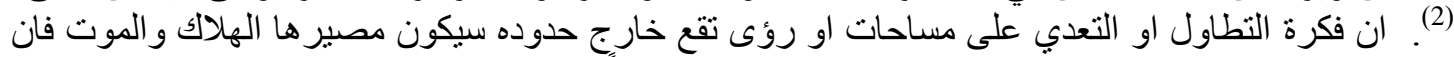

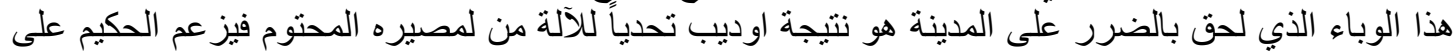

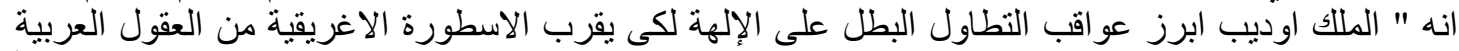

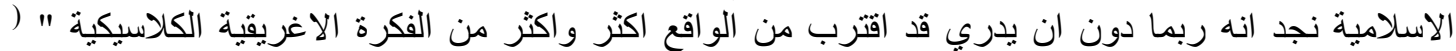

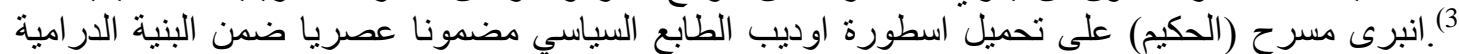

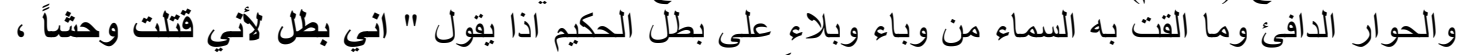

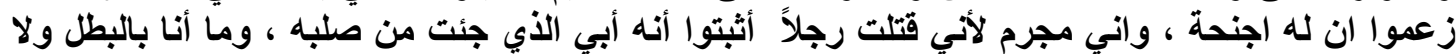

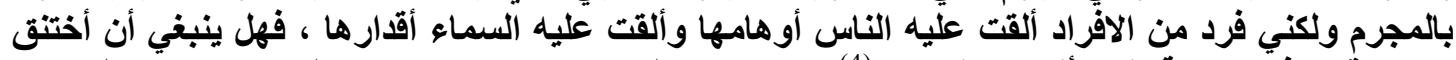

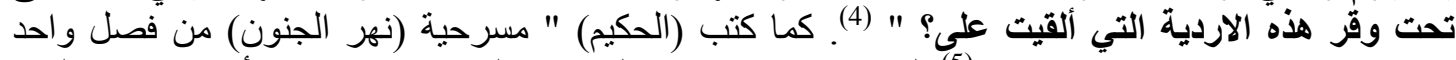

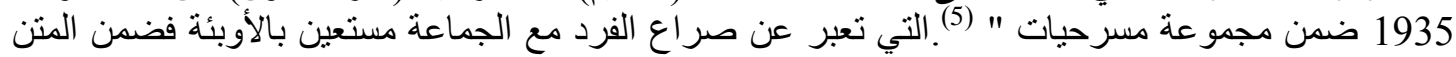

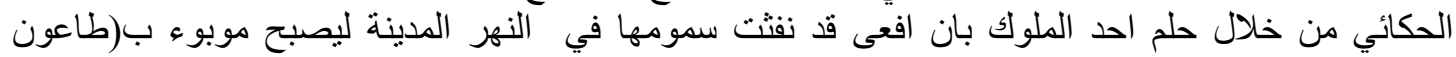

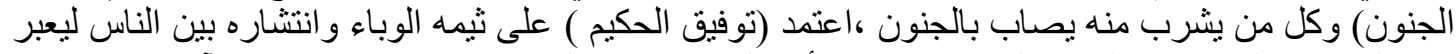

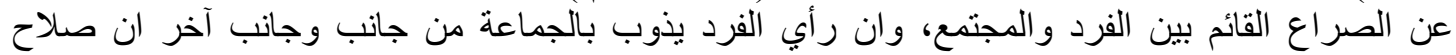

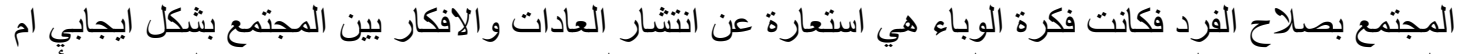

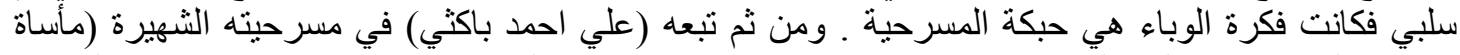

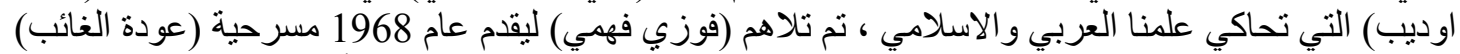

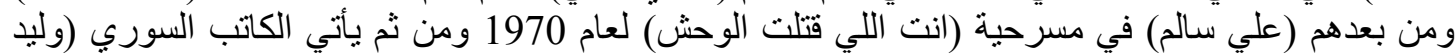

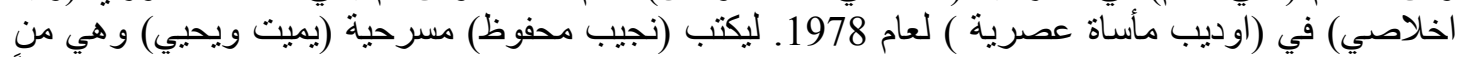

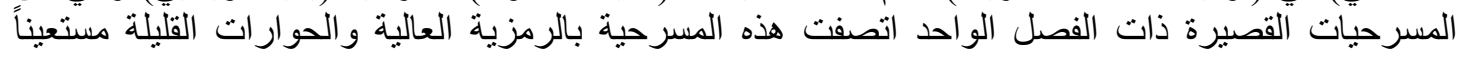

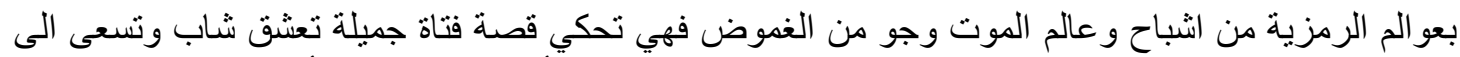

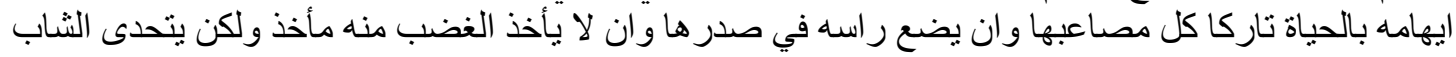

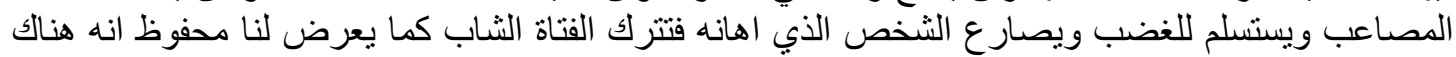

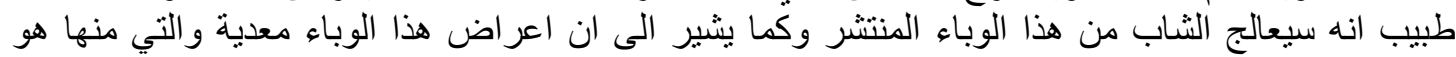

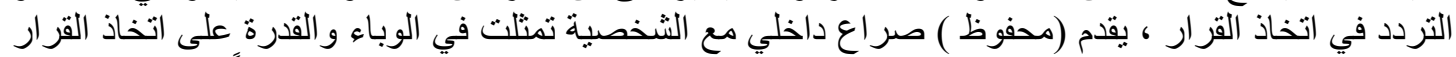

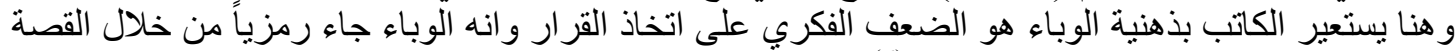

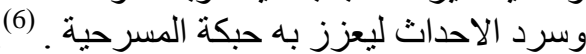

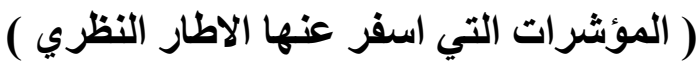

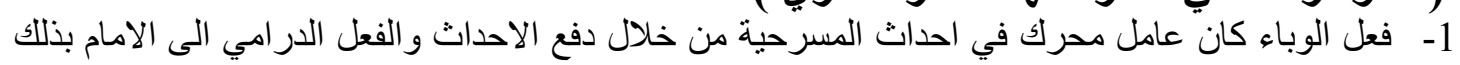
ربما يكون حافز للفعل في المنن الحكائي وبناءه الدرامي المير في من

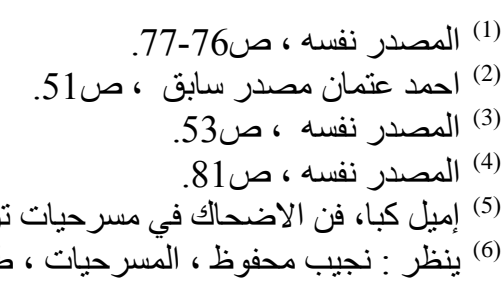




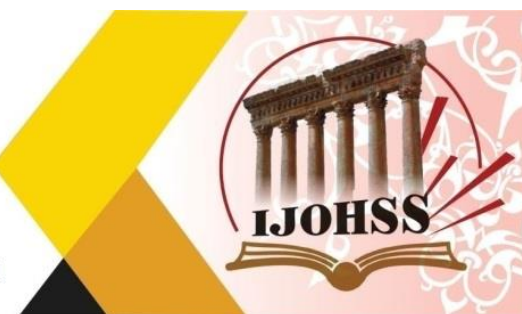

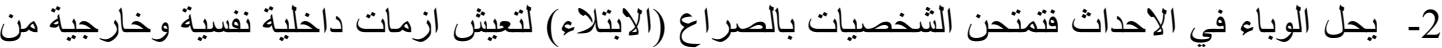

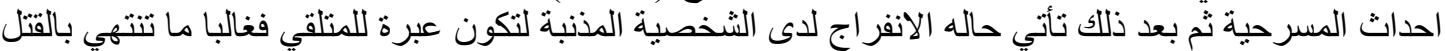
او الضياع

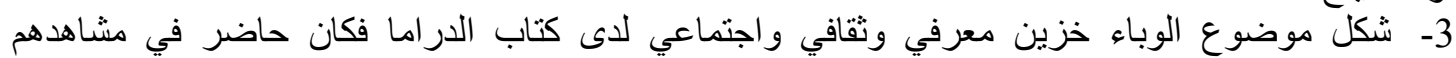

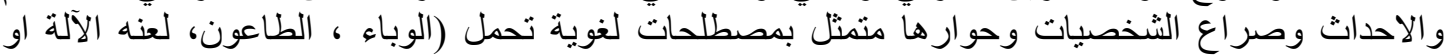

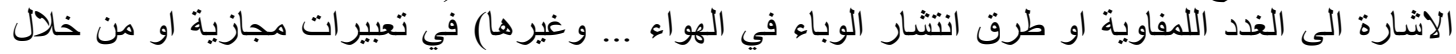

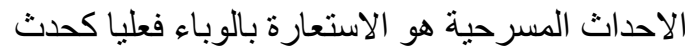

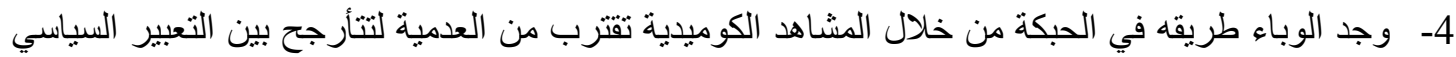

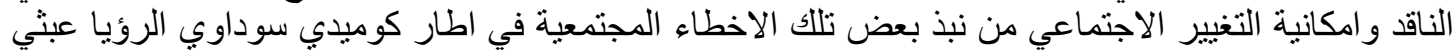
الوجود مذكر ا باليأس الانساني الاحتياعي

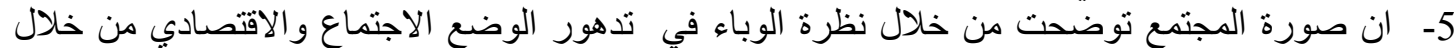

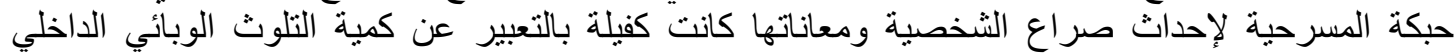
والخارجي وتحطيم الروح السائمة اعة الإعة

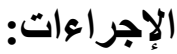

\begin{tabular}{|c|c|c|c|}
\hline سنة التأليف & اسم المؤلف & اسم المسر حـة & ث \\
\hline 1965 & نور الدين فارس & اشجار الطاعون & 1 \\
\hline 2007 & يحيى صاحب & الله الطاعون & 2 \\
\hline 2011 & عبد الخالق كريم & الحب في زمن الطاعون & 3 \\
\hline 2014 & حسن الغبيني & الرقص على انغام زحل & 4 \\
\hline 2015 & ستعد اهدابي & كوليرا & 5 \\
\hline 2018 & عبد الكريم العامري & وباء & 6 \\
\hline 2019 & عبد الكريم العامري & كوفيا & 7 \\
\hline 2020 & هشام شبر & انتفا يروس & 8 \\
\hline 2020 & هشام شبر & ذات وباء & 9 \\
\hline 2020 & سرحان احمد سرحان & الوباء القاتل & 10 \\
\hline 2020 & سعد اهدابي & شرفات & 11 \\
\hline 2020 & عمار سيف & 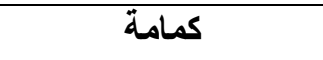 & 12 \\
\hline 2020 & شاكر عبد العظيم & هيكابا & 13 \\
\hline 2021 & سعد اهدابي & ارواح جائحة & 14 \\
\hline
\end{tabular}

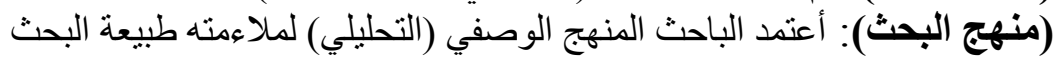

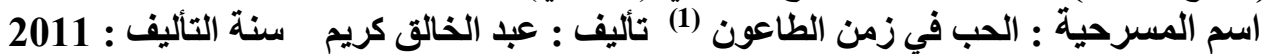

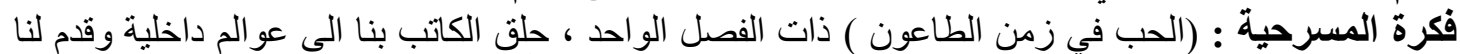

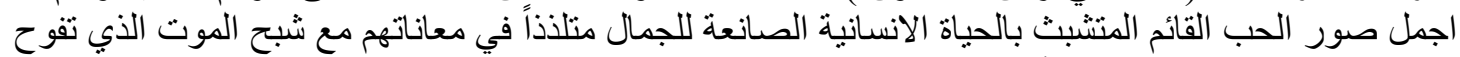

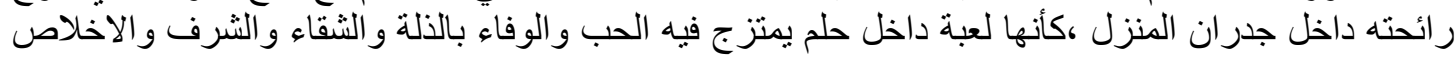

www.dailymoton.com. ${ }^{(1)}$ 


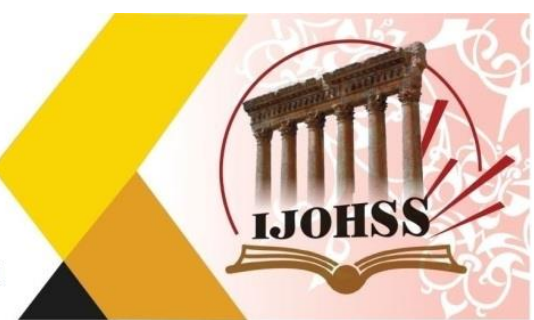

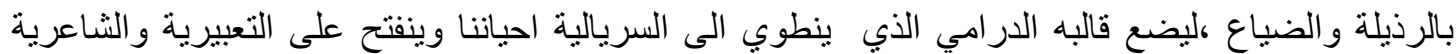

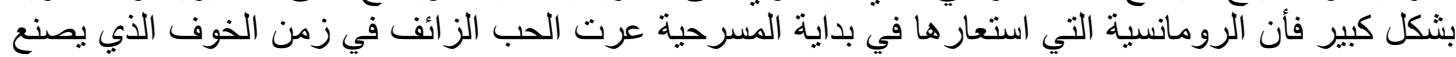

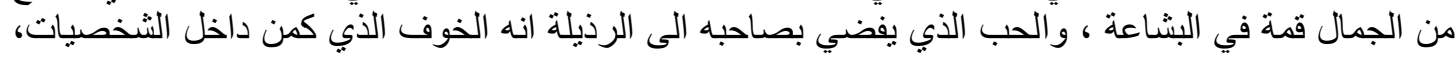

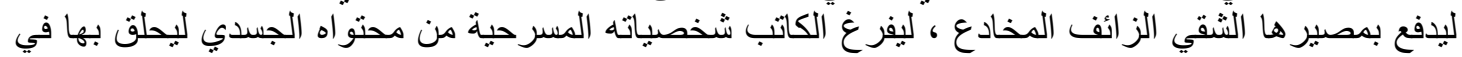

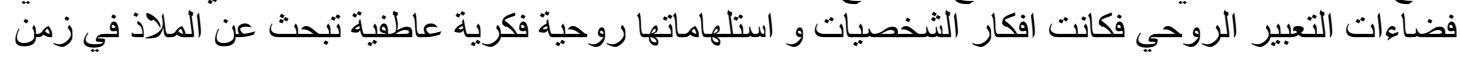

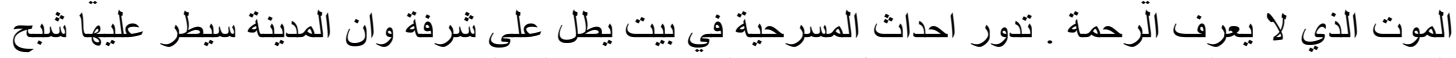

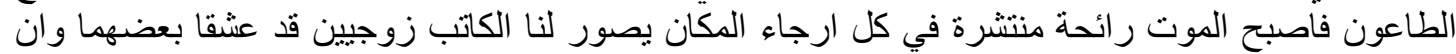

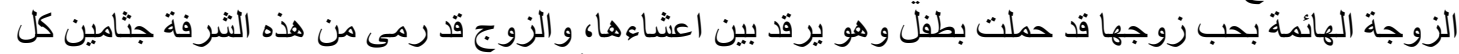

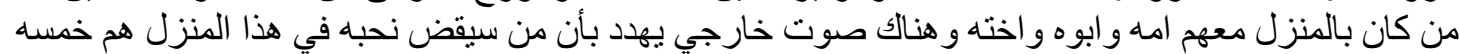

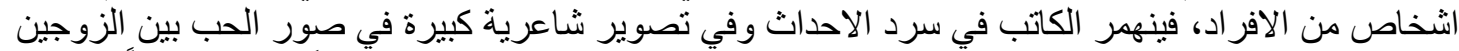

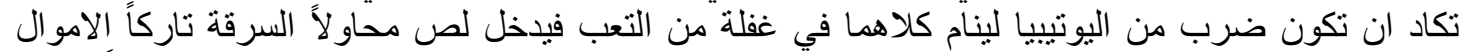

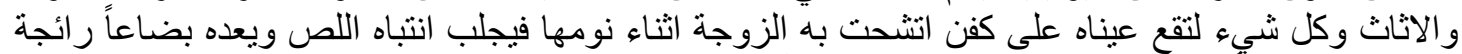

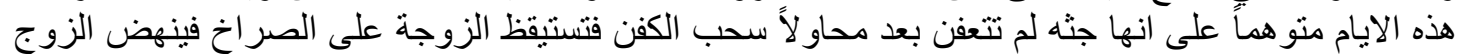

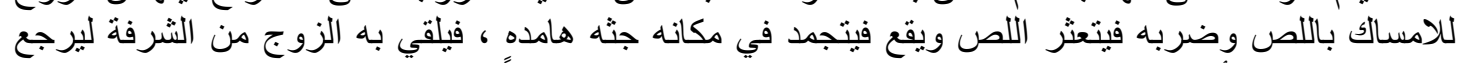

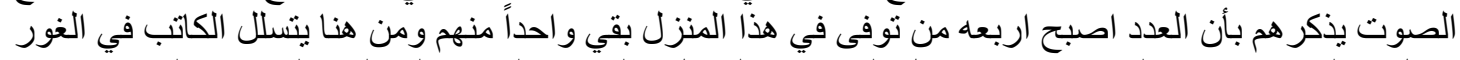

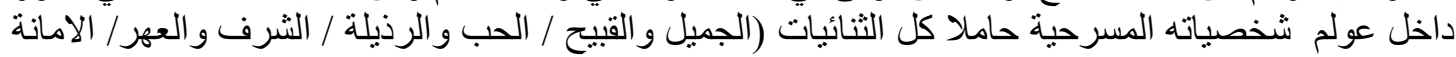

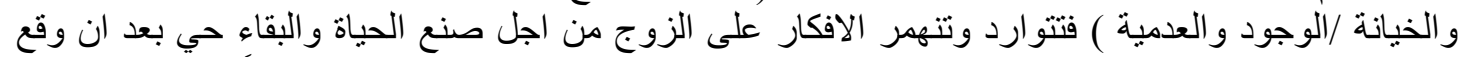

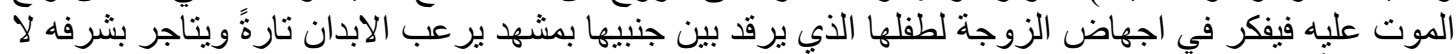

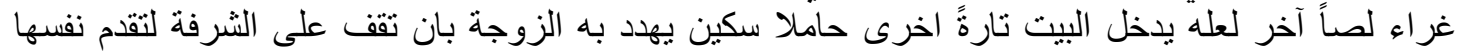

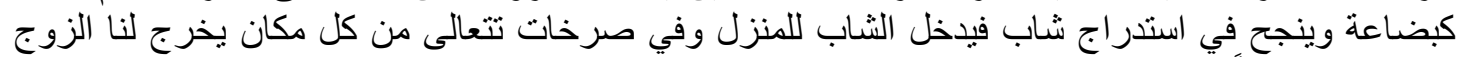

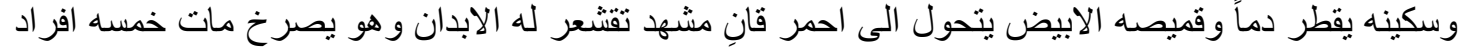

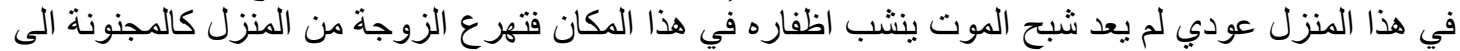

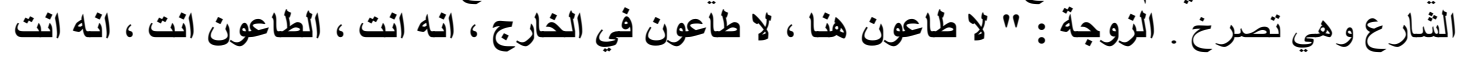

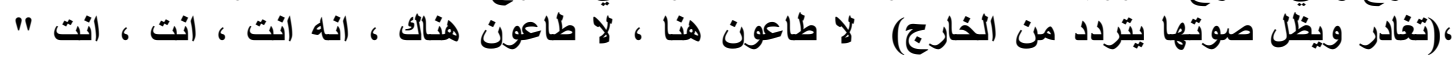

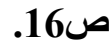

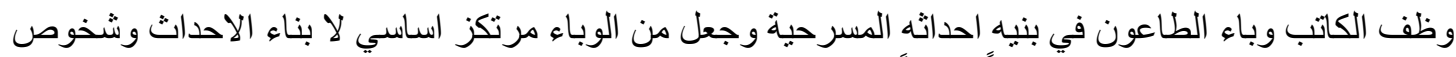

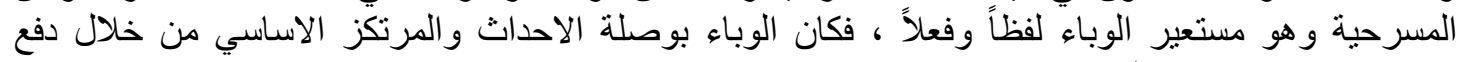

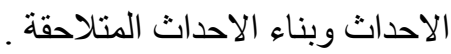
الزوج : " الزره نفسي ، سأمت الحياة وهي محرقة الألة القي بها اهلي واحداً تلو الآخر . الزوجة : الزوجة : انا جبانها الزوج : أضع تباعاً امي ، ابي ، واختي في محرقة هي طبق الموت الذي يلتهنا بفٍٍ من

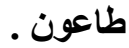

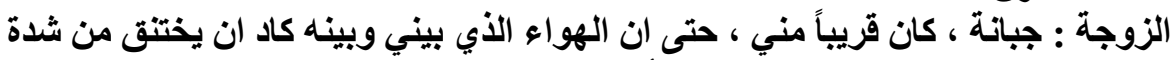

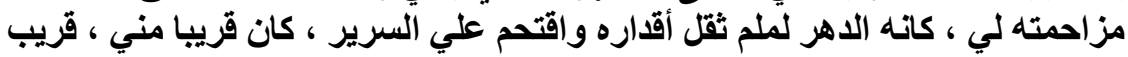

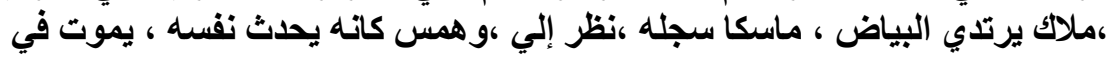

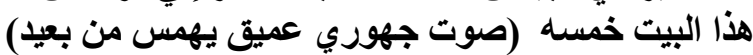

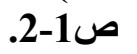

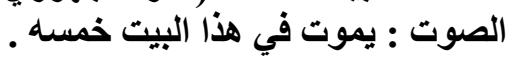

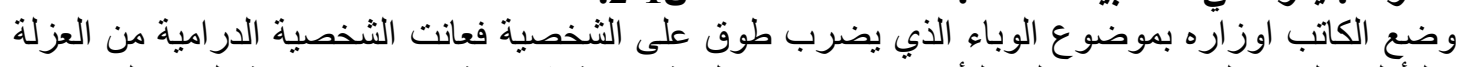

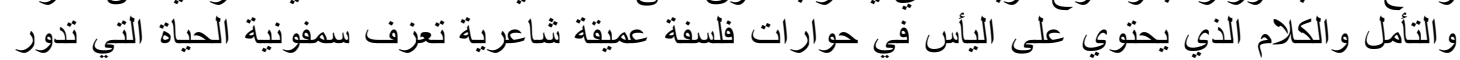

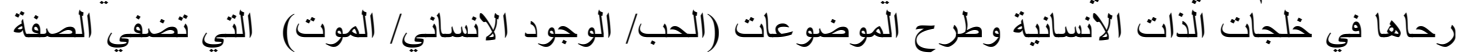

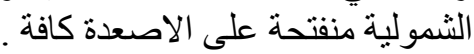




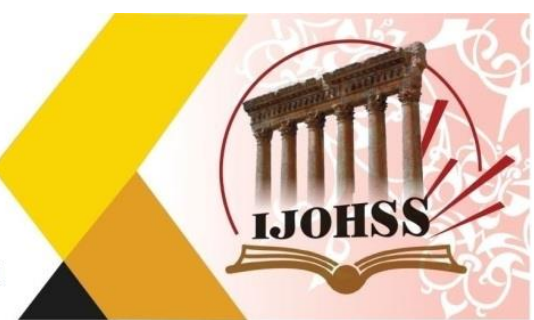

الزوجة : " ( تقلت من بين يديه وتجري ) لا لا يجب ان لا يعود (تصرخ بالجدران) تعال ،

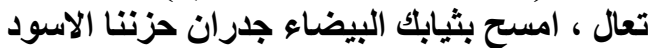

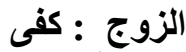

الزوجة :(تجري بالاتجاه الاخر ) تعال اعتق روحي من أسر مدادك ، أسار لم اقترف ذنبا لا حياه

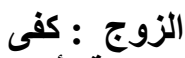

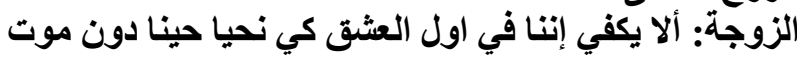

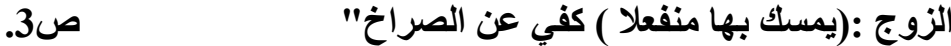

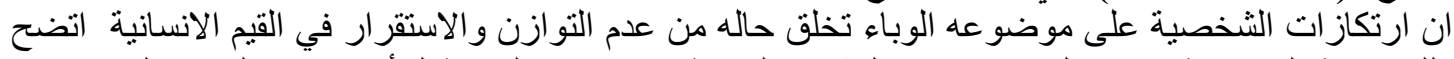

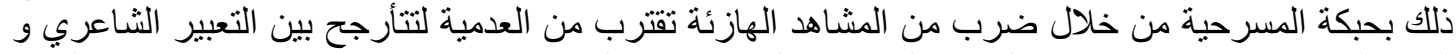

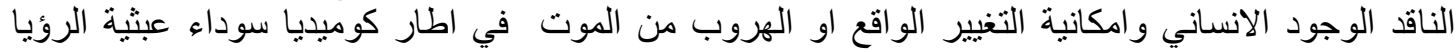

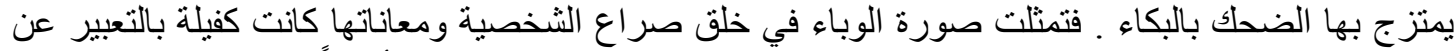

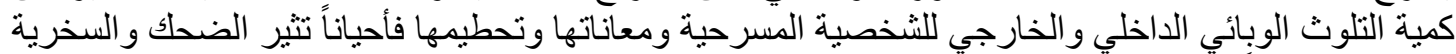

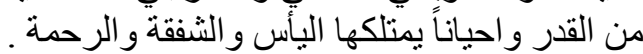

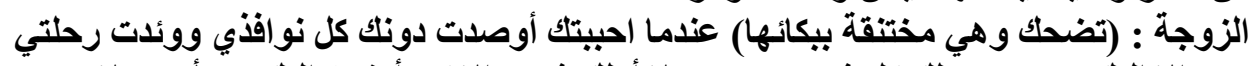

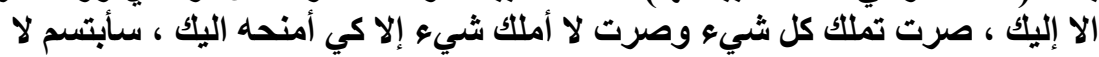

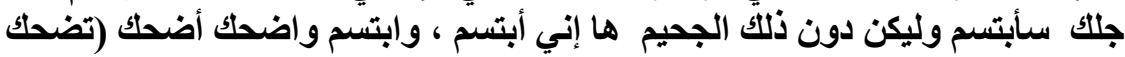

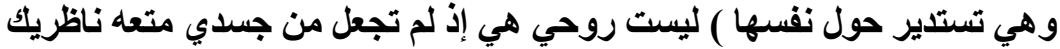

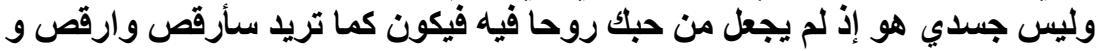

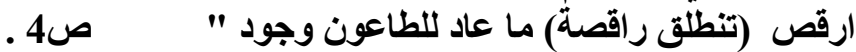

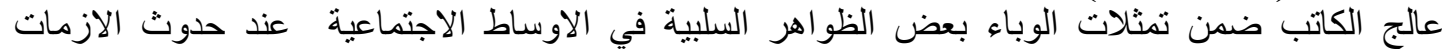

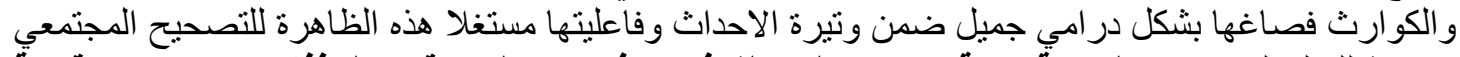

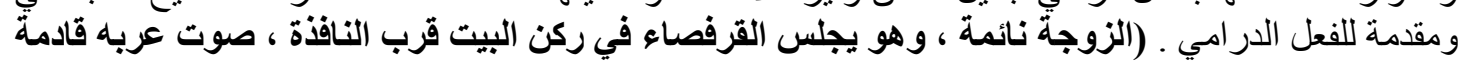

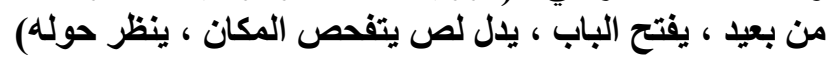

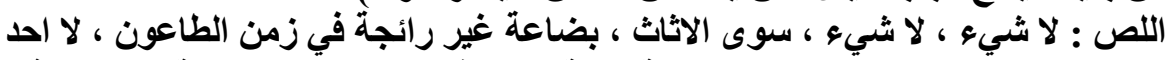

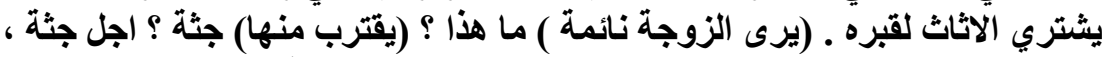

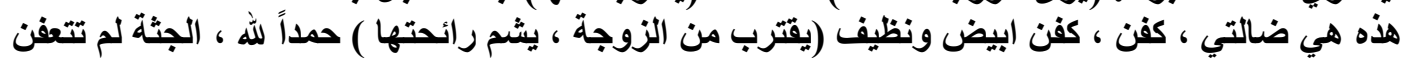

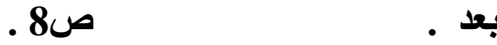

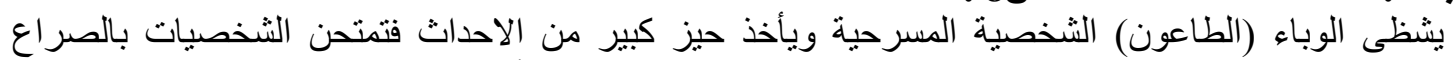

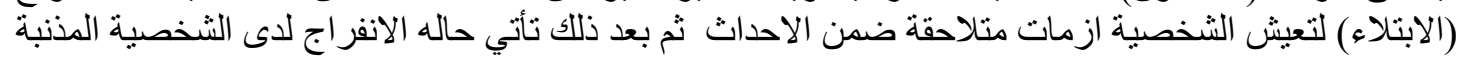

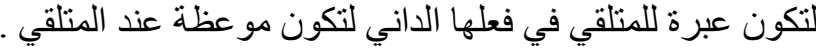

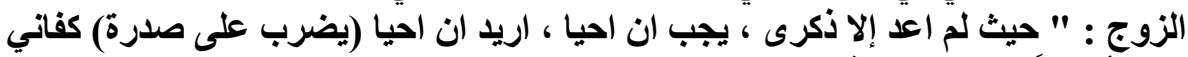

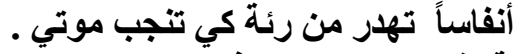

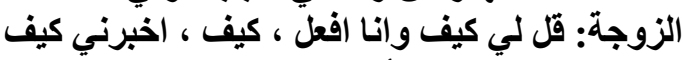

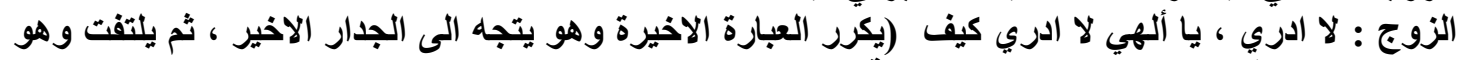

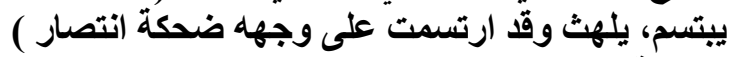

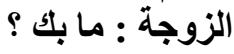
الزوج : الزوجة : وجدتها

ص11

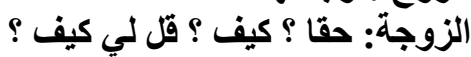

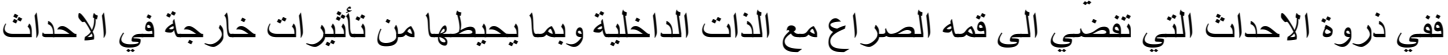

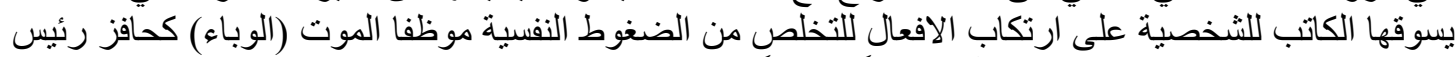
لارتكاب ابشع المو اقف و اكثر ها اثارةً و غر ابةً ودهثةً في المسرحية لتحقيق الثفاء الجسدي والرئة الروحي من الالام 


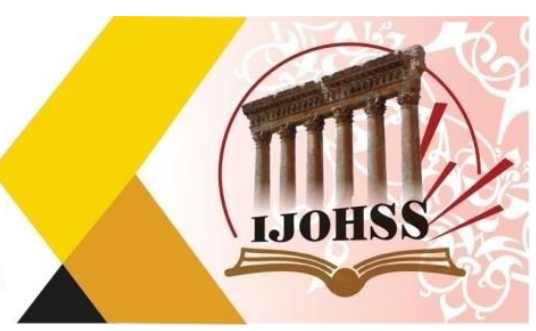

بوساطة التعبير الفني من خلال احداث حالة التطهير .ان تللك الفكرة الثمولية العالمية الانسانية التي يشترك بها الانسان.

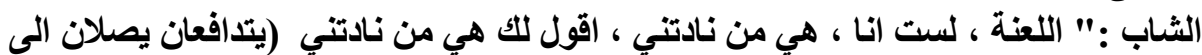

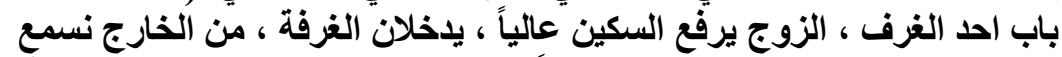

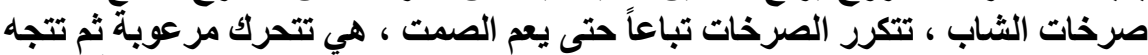

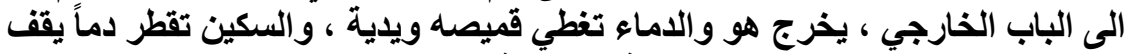

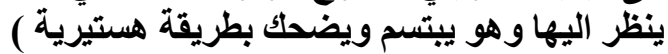

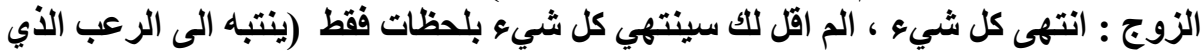
.15

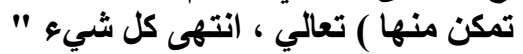

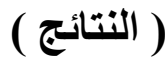

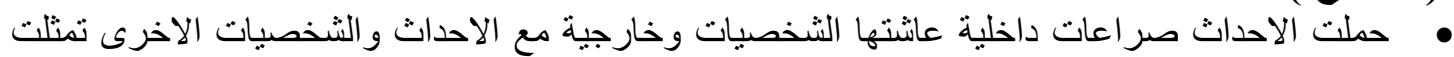

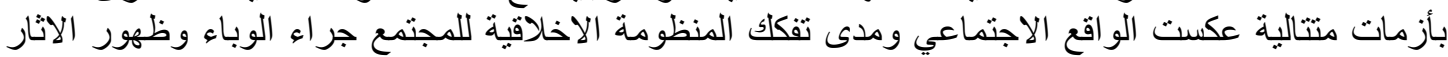

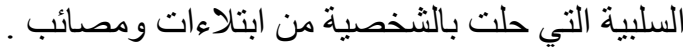

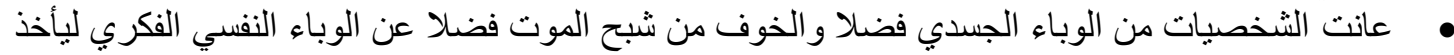

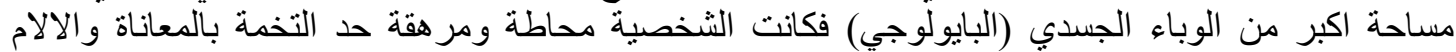

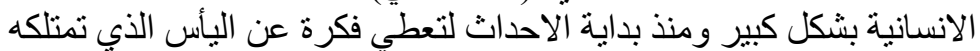

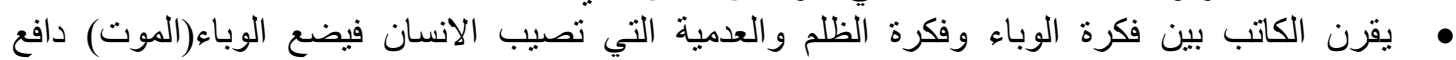

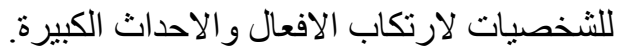

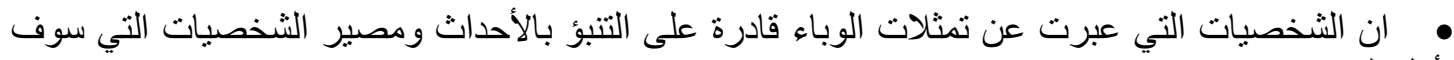
تأول اليها الاحداث فيما بعد الني

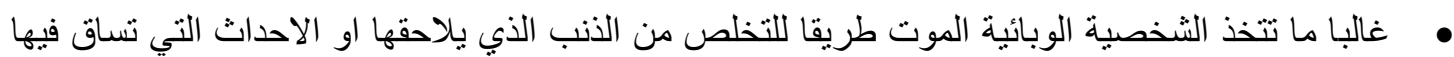
فتكون مستسلمة متخذة الموقف البطولي راضية بالية البان الاقدار حتمية

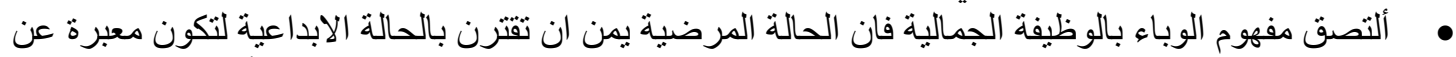

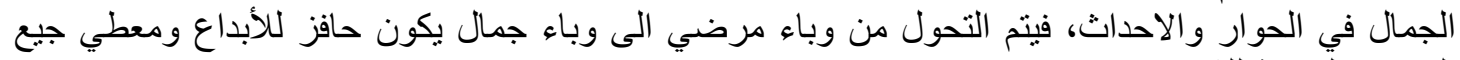

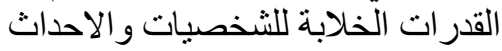

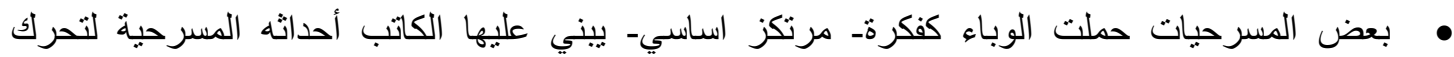

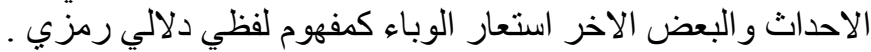

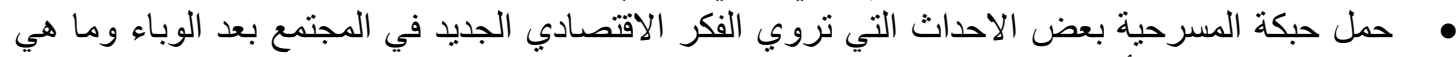

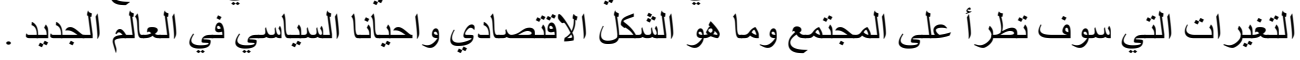

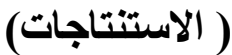

• • ان الوباء كان مؤثر بشكل فعال في بنية الاحداث وان الكاتب المسرحي اتخذ منه محور اً الاحداثة

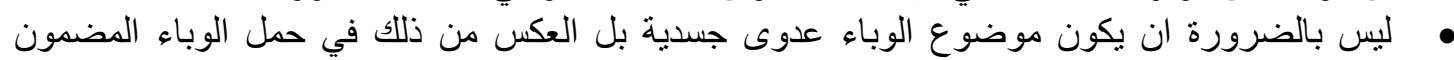
الفكري النفسي بالضرو

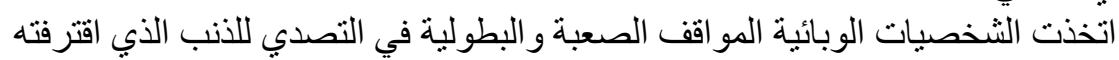
تمثلت الاوبئة في الحبكة بشكل رئيس او منها احداث ثانوية او منها استعار ات لفضية لفئ. 


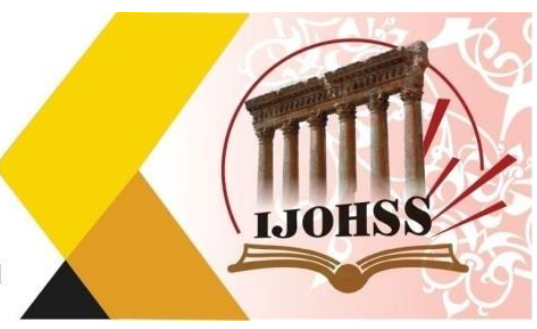

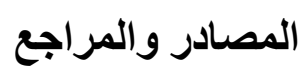

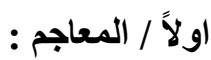

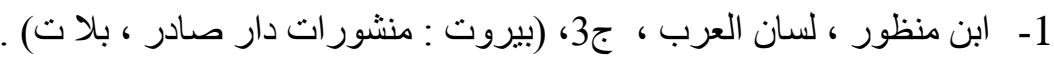

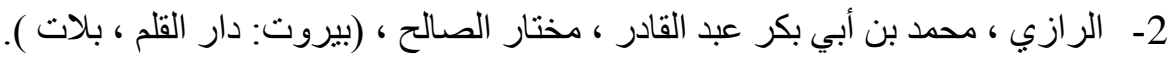

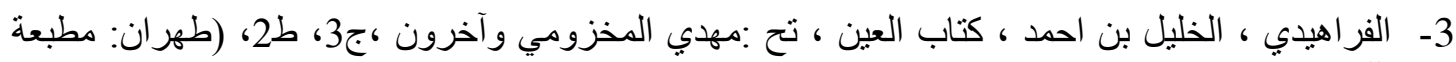

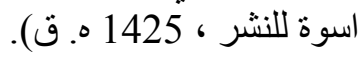

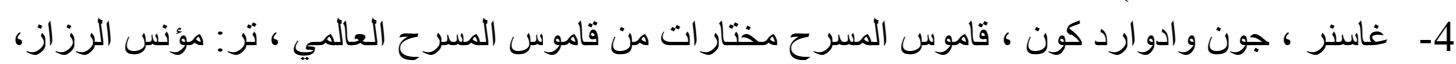

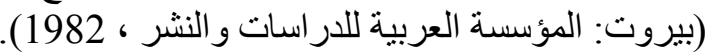

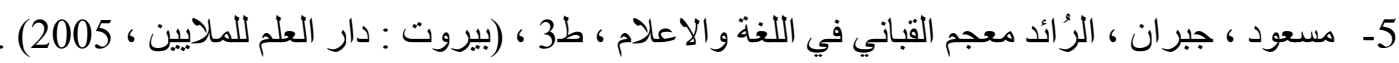

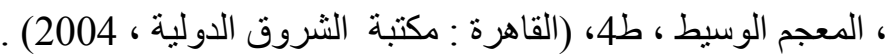
$-6$

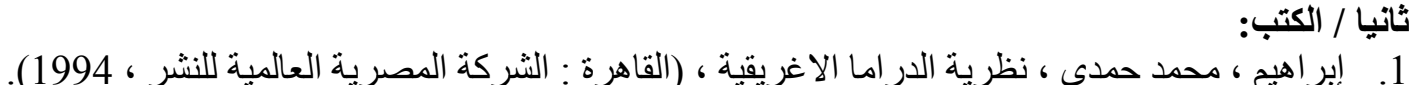

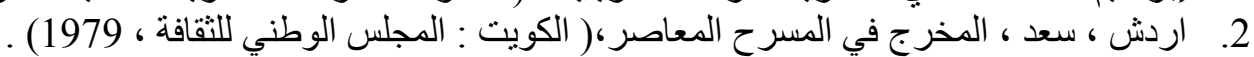

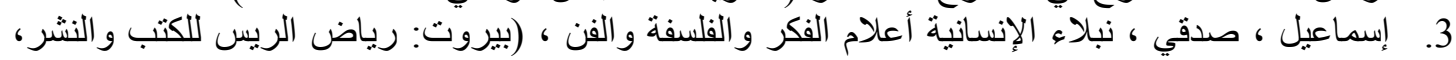

4. الازهري ، محمد ويروس سيمبو البوغيسي ، عواصف الاوبئة القاتلة من الطاعون الى فايروس كورونا

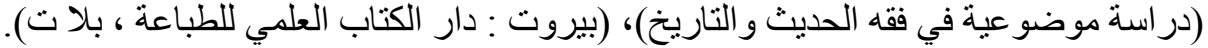

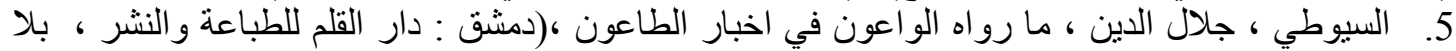

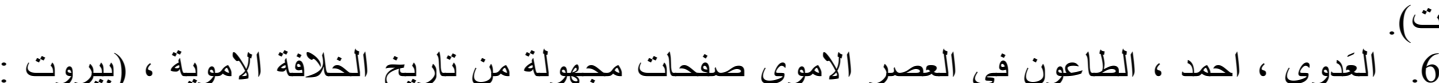

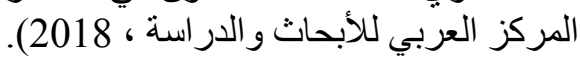

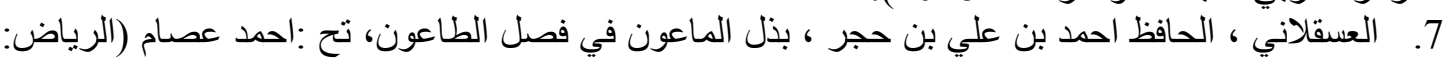

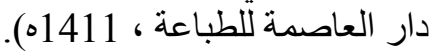
8. الريان ، جميل ابو العباس ، فلسفة علم الاوبئة جائحة كورونا (كوفيد-19) ، (الاسكندرية : المثقف للنشر

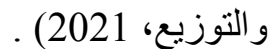
9. الغريري ، ياسر محمود مجبل راشد ، الزلازل والامر اض والاوبئة واثر ها على بلاد الثام ، (بغداد :

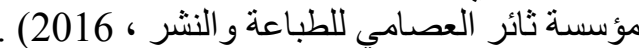

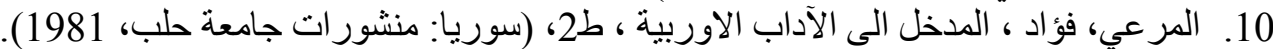

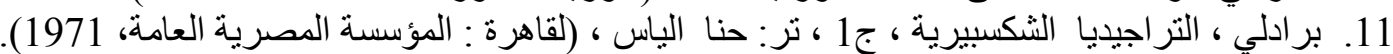

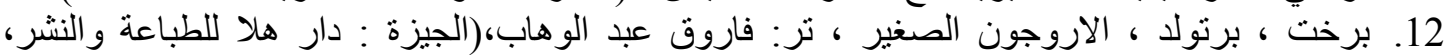

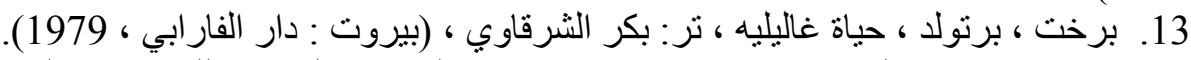

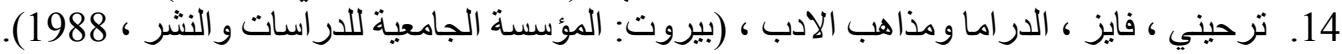

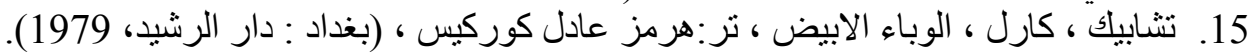

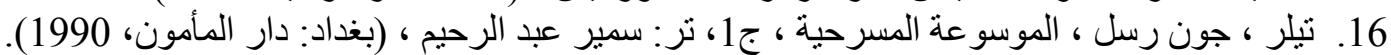

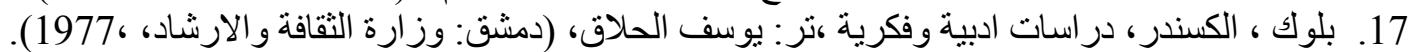

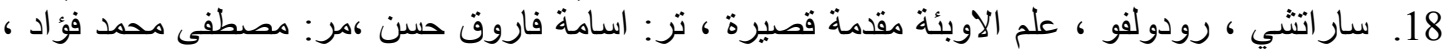

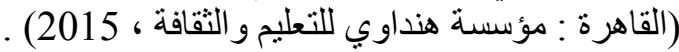




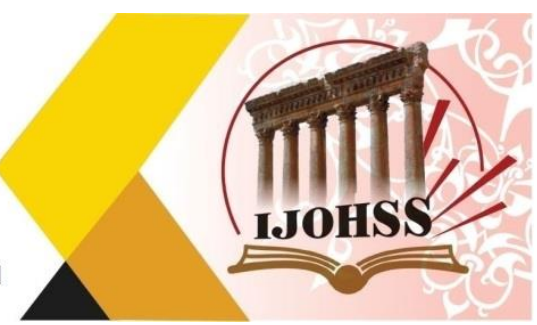

19. جوتفريد ، روبرت س ، الموت الاسود جائحة طبيعية وبشرية في عالم العصور الوسطى ، تر: عبادة كحيلة ، (القاهرة : المركز القومي للترجمة ، 2017) 2019) .

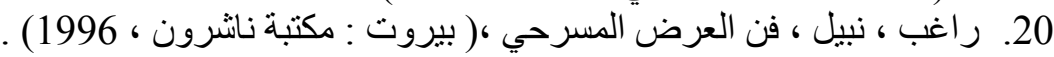

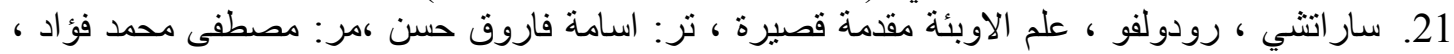

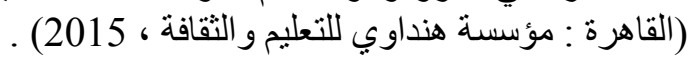

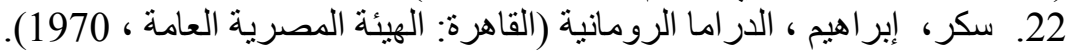

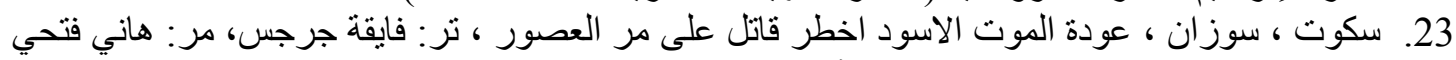

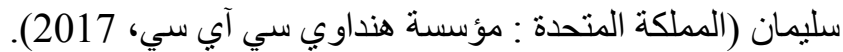

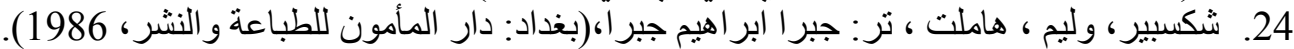

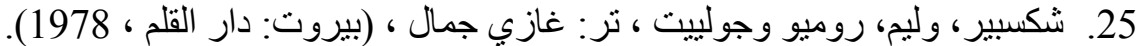

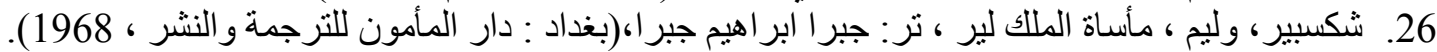

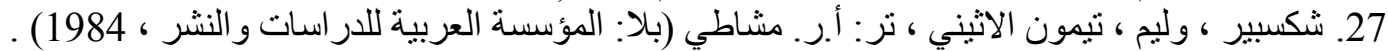

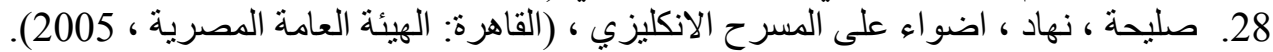

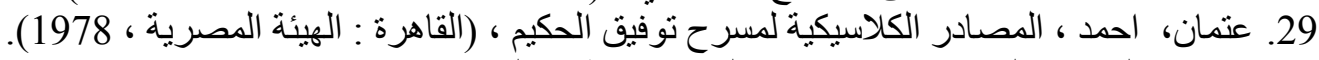

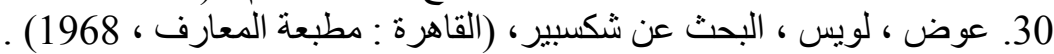

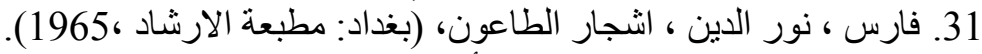

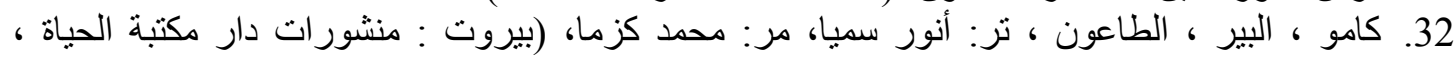

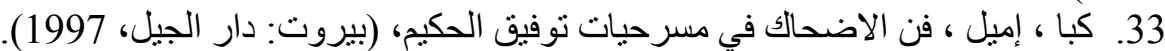

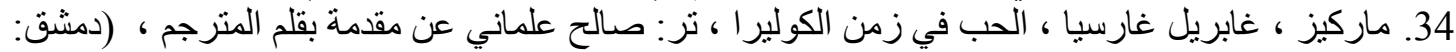

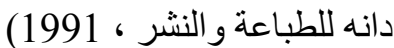

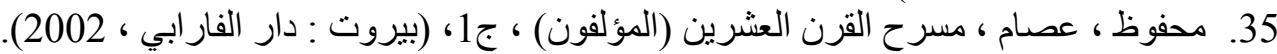

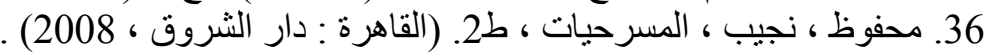

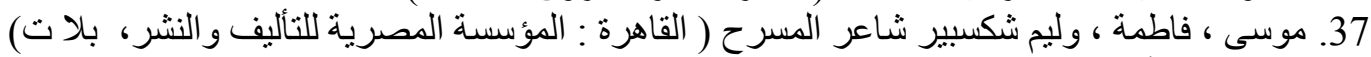

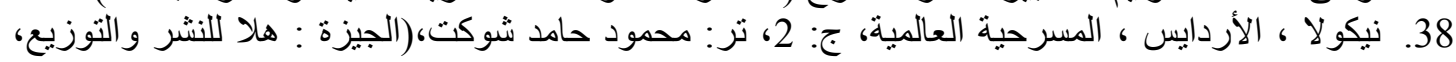
. (2000 39. هوايتتج ، فرانك م ، المدخل الى الفنون المسرحية ،تر: كامل يوسف وآخرون ، مر: حسن محمود وآخرون، (القاهرة : دار المعرفة ، 1970 1970).

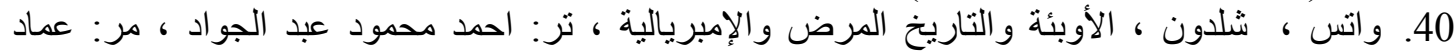

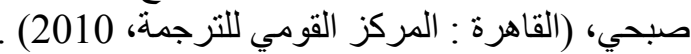
41. يوسفي ، حسن ، المسرح ومفارقاته ، (ميتشيغان : مطبعة سندي للطباعة والنشر ، 1996).

$$
\text { ت تالثا / المجلات والدوريات }
$$

1-إسماعيل ، بصل محمد ، الثنائيات المسرحية ، في : مجلة الحياة المسرحية ، العدد ( 43 ) ، ، دمثق : 1996).

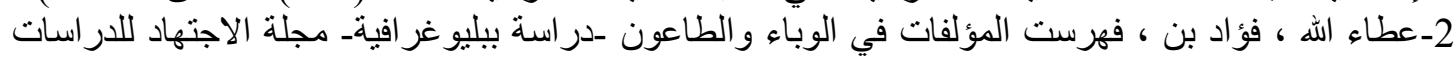

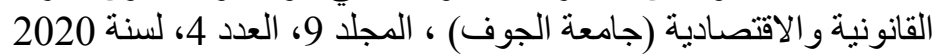

1- www.dailymoton.com . 


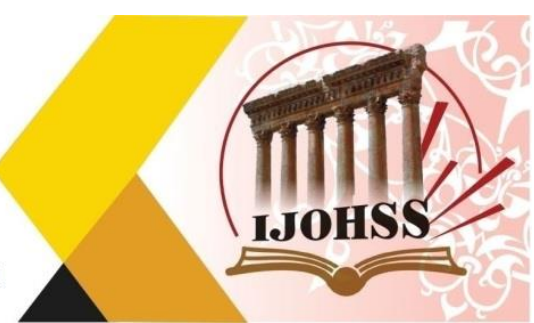

\section{References}

\section{First/ Dictionaries}

1- Ibn Manzur, Lisan Al-Arab, j3, (Beirut: dar sadir, bila t).

2- Al-Razi, Muhammad bin Abi Bakr Abdul Qadir, Mukhtar Al-Saleh, (Beirut: Dar Al-Qalam, Platt).

3- Al-Farahidi, Al-Khalil bin Ahmed, Al-Ain book, edited by: Mahdi Al-Makhzoumi and others, vol. 3, 2nd edition, (Tehran: Aswa Publishing Press, 1425 AH).

4- Gasner, John and Edward Conn, Theatrical Dictionary, Selections from the Dictionary of World Theater, tr: Munis Al-Razzaz, (Beirut: The Arab Foundation for Studies and Publishing, 1982).

5- Masoud, Gibran, The Pioneer Lexicon Al-Qabbani in Language and Media, 3rd Edition, (Beirut: Dar Al-Ilm for Millions, 2005).

6- _ _ _ , Al-Mu'jam Al-Wasat, 4th floor, (Cairo: Al-Shorouk International Library, 2004).

\section{Second / books:}

1. Ibrahim, Mohamed Hamdy, Theory of Greek Drama, (Cairo: The Egyptian International Publishing Company, 1994).

2. Ardash, Saad, The Director in Contemporary Theatre, (Kuwait: The National Council for Culture, 1979).

3. Ismail, Sidqi, Nobles of Humanity, Flags of Thought, Philosophy and Art, (Beirut: Riyad Al Rayes for Books and Publishing, 2008).

4. Al-Azhari, Muhammad Weros Simbo Al-Boughisi, the storms of the deadly epidemics from the plague to the Corona virus (objective study in the jurisprudence of hadith and history), (Beirut: Dar Al-Kitab Al-Alami for printing, Blat T).

5. Al-Suyuti, Jalal Al-Din, What the Conscious Narrated in the Plague News, (Damascus: Dar Al-Qalam for Printing and Publishing, no t)

6. Al-Adawi, Ahmed, The Plague in the Umayyad Era, Unknown Pages from the History of the Umayyad Caliphate, (Beirut: Arab Center for Research and Study, 2018).

7. Al-Asqalani, Al-Hafiz Ahmed Bin Ali Bin Hajar, Making Al-Ma'oon in the Plague Chapter, edited by: Ahmed Essam (Riyadh: Dar Al-Asima for printing, $1411 \mathrm{AH}$ ).

8. Al-Rayyan, Jamil Abu Al-Abbas, The Philosophy of Epidemiology, the Corona Pandemic (Covid-19), (Alexandria: Al-Muthaqaf for Publishing and Distribution, 2021).

9. Al-Ghurairi, Yasser Mahmoud Mijbal Rashid, Earthquakes, diseases and epidemics and their impact on the Levant, (Baghdad: Thaer Al-Asami Foundation for Printing and Publishing, 2016).

10. Al-Marei, Fouad, Introduction to European Literatures, 2nd Edition, (Syria: Aleppo University Publications, 1981).

11. Bradley, Shakespearean Tragedy, part 1, tr: Hanna Elias, (Cairo: Egyptian General Organization, 1971). 


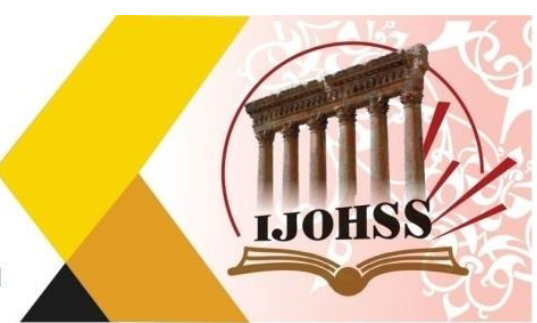

12. Brecht, Berthold, Little Argon, see: Farouk Abdel Wahab, (Giza: Hala House for Printing and Publishing, 2000).

13. Brecht, Berthold, The Life of Galilee, tr: Bakr Al-Sharqawi, (Beirut: Dar AlFarabi, 1979).

14. Tarhini, Fayez, Drama and Doctrines of Literature, (Beirut: University Foundation for Studies and Publishing, 1988).

15. Chabek, Carl, The White Plague, tr: Hormuz Adel Korkis, (Baghdad: Dar AlRashid, 1979).

16. Teller, John Russell, Theatrical Encyclopedia, part 1, see: Samir Abdel Rahim, (Baghdad: Dar Al-Mamoun, 1990).

17. Block, Alexander, Literary and Intellectual Studies, t.: Youssef Hallaq, (Damascus: Ministry of Culture and Guidance, 1977).

18. Sarachi, Rodolfo, Epidemiology, a short introduction, see: Osama Farouk Hassan, Murr: Mustafa Mohamed Fouad, (Cairo: Hendawy Foundation for Education and Culture, 2015).

19. Gottfried, Robert S., The Black Death, a Natural and Human Pandemic in the Medieval World, TR: Kahil Worship, (Cairo: The National Center for Translation, 2017).

20. Ragheb, Nabil, The Art of Theatrical Performance, (Beirut: Publishers Library, 1996).

21. Sarachi, Rodolfo, Epidemiology, a short introduction, see: Osama Farouk Hassan, Murr: Mustafa Mohamed Fouad, (Cairo: Hendawi Foundation for Education and Culture, 2015).

22. Sugar, Ibrahim, Roman Drama (Cairo: Egyptian General Authority, 1970).

23. Scott, Suzanne, The Return of the Black Death, the Most Dangerous Killer of All Time, TR: Fayqa Gerges, Murr: Hani Fathi Suleiman (UK: Hendawi CIC Foundation, 2017).

24. Shakespeare, William, Hamlet, tr: Jabra Ibrahim Jabra, (Baghdad: Dar AlMamoun for printing and publishing, 1986).

25. Shakespeare, William, Romeo and Juliet, tr: Ghazi Jamal, (Beirut: Dar Al-Qalam, 1978).

26- Shakespeare, William, The Tragedy of King Lear, tr: Jabra Ibrahim Jabra, (Baghdad: Dar Al-Mamoun for Translation and Publishing, 1968).

27. Shakespeare, William, Timon of Athens, TR: A.R. Mashati (No: The Arab Foundation for Studies and Publishing, 1984).

28. Saliha, Nohad, Lights on the English Stage, (Cairo: Egyptian General Authority, 2005).

29. Atman, Ahmed, The Classical Sources of Tawfiq Al-Hakim Theatre, (Cairo: The Egyptian Authority, 1978).

30. Awad, Lewis, Searching for Shakespeare, (Cairo: Al-Maaref Press, 1968).

32. Fares, Nour Al-Din, Plague Trees, (Baghdad: Al-Irshad Press, 1965). 


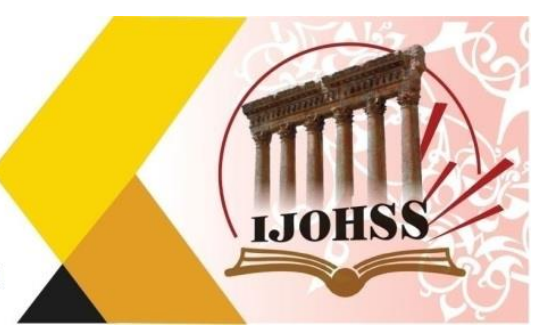

33. Kamo, Albert, The Plague, see: Anwar Sumaya, Murr: Muhammad Kazma, (Beirut: Al-Hayat Library Publications, 1982).

34. Kaba, Emile, The Art of Laughing in the Plays of Tawfiq Al-Hakim, (Beirut: Dar Al-Jeel, 1997).

35. Marquez, Gabriel García, Love in the Time of Cholera, tr: Salih Lamani for an Introduction by the Translator, (Damascus: Danah Printing and Publishing, 1991)

36. Mahfouz, Issam, The Twentieth Century Theater (Authors), Part 1, (Beirut: Dar Al-Farabi, 2002).

37. Mahfouz, Naguib, The Plays, 2nd Edition. (Cairo: Dar Al-Shorouk, 2008).

38. Musa, Fatima, and William Shakespeare, poet of the theater (Cairo: The Egyptian Institution for Writing and Publishing, Bla T)

39. Nicolas, Al-Ardays, The International Theatrical, C: 2, see: Mahmoud Hamed Shawkat, (Giza: Hala Publishing and Distribution, 2000).

40. Whiting, Frank M., Introduction to theatrical arts, seer: Kamel Youssef and others, passed by: Hassan Mahmoud and others, (Cairo: Dar Al Marefa, 1970).

41. Watts, Sheldon, Epidemics, History of Disease and Imperialism, see: Ahmed Mahmoud Abdel-Gawad, Murr: Imad Sobhi, (Cairo: The National Center for Translation, 2010).

42. Yousefi, Hassan, theater and its paradoxes, (Michigan: Sindi Press for Printing and Publishing, 1996).

\section{Third / magazines and periodicals}

1- Ismail, Basal Muhammad, Theatrical Duos, in: Theatrical Life Journal, Issue (43), Damascus: 1996).

2-Ata Allah, Fuad bin, Index of Works on Epidemic and Plague - Bibliographical Study - Journal of Ijtihad for Legal and Economic Studies (Jouf University), Volume 9, Issue 4, for the year 2020 .

\section{Fourthly, the Internet}

.1www.dailymoton.com 